\title{
Geochemical Environments and Cardiovascular Mortality Rates in Georgia
}

GEOLOGICAL SURVEY PROFESSIONAL PAPER 574-C

Prepared in cooperation with the U.S. Public Health Service

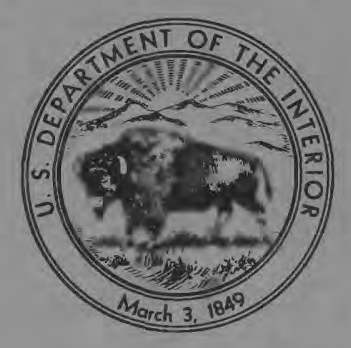




\section{Geochemical Environments and Cardiovascular Mortality Rates}

in Georgia

By HANSFORD T. SHACKLETTE, HERBERT I. SAUER, and A. T. MIESCH STATISTICAL STUDIES IN FIELD GEOCHEMISTRY

GEOLOGICAL SURVEY PROFESSIONAL PAPER 574-C

Prepared in cooperation with the

U.S. Public Health Service

A study of the chemical elements

in soils and plants from counties that have

contrasting rates for diseases of the heart

and blood vessels

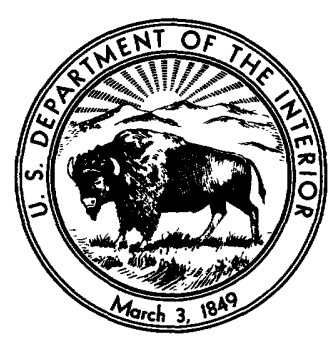

UNITED STATES GOVERNMENT PRINTING OFFICE, WASHINGTON : 1970 


\section{UNITED STATES DEPARTMENT OF THE INTERIOR \\ WALTER J. HIGKEL, Secretary \\ GEOLOGICAL SURVEY \\ William T. Pecora, Director}

For sale by the Superintendent of Documents, U.S. Government Printing Office Washington, D.C. 20402 - Price 50 cents (paper cover) 


\section{CONTENTS}

\begin{abstract}
.
Introduction

Cardiovascular mortality rates in Georgia ............

Physiography, geology, and soils of Georgia

Collection and analysis of geochemical data . . . . . . .

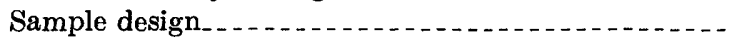

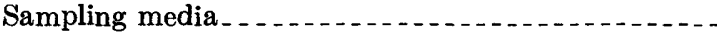

Plants

Soils _. . . . .

Procedures used in chemical analysis. . . . . .

Methods of statistical analysis ...

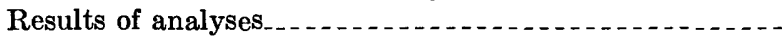

Compositions of vegetables and garden soils......
\end{abstract}

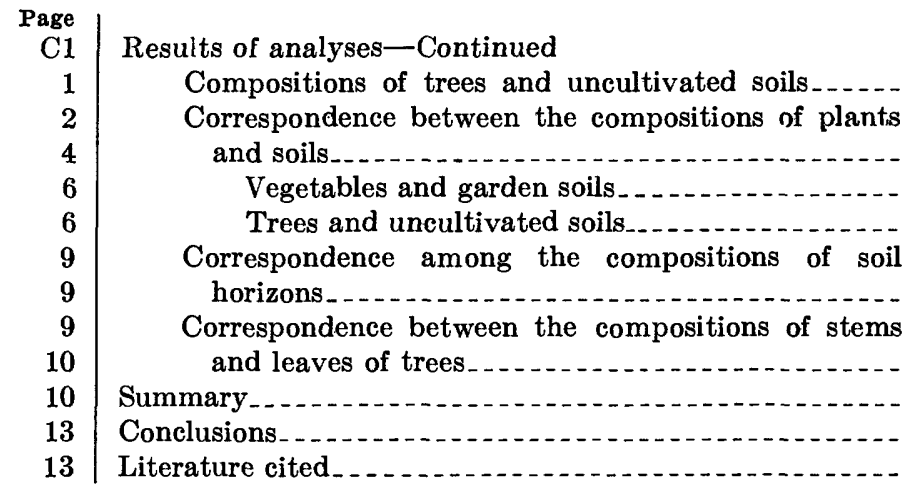

Page

$\mathrm{C} 13$

13

19

25

31

34

34

38

39

\section{ILLUSTRATIONS}

Figure 1. Map showing physiographic regions and provinces in Georgia, and locations of counties with high and low death rates per 100,000 population for cardiovascular diseases.

2. Map showing Great Soil Groups of Georgia, and the locations of counties that have high and low cardiovascular mortality rates

3-7. Diagrams showing:

3. Correlations between the amounts of elements in garden soils and the amounts in vegetables.

4. Correlations between the amounts of elements in the $\mathrm{C}$ horizon of uncultivated soils and the amounts

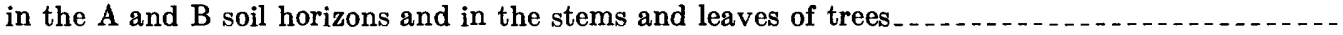

5. Correlations between the amounts of elements in the B horizon of uncultivated soils and the amounts in the $A$ horizon of soils and in the stems and leaves of trees

6. Correlations between the amounts of elements in the A horizon of uncultivated soils and the amounts

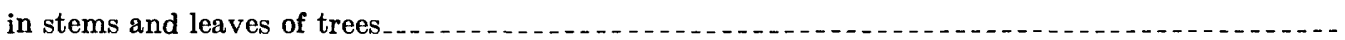

7. Correlations between the amounts of elements in stems and in leaves of trees.

\section{TABLES}

TABLE 1. Death rates for selected causes, white males age 35-74, selected counties of Georgia, during the period 1950-59.

2. Localities, kinds, and numbers of samples that were collected in Georgia

3. Analytical limits of detection.

4. Components of logarithmic variance between samples, sites, and areas.

5. Ash contents of vegetables and element contents of vegetable ashes and garden soils

6. Ash contents of trees and element contents of tree ashes.

7. Element contents of uncultivated soils .

8. Correlations between the amounts of elements in vegetables and garden soils

9. Correlations between the amounts of elements in trees and in the $\mathrm{C}$ horizon of uncultivated soils

10. Correlations between the amounts of elements in trees and in the B horizon of uncultivated soils

11. Correlations between the amounts of elements in trees and in the $A$ horizon of uncultivated soils

12. Correlations between the amounts of elements in horizons of uncultivated soils.

13. Correlations between the amounts of elements in stems and leaves of trees 



\title{
STATISTICAL STUDIES IN FIELD GEOCHEMISTRY
}

\section{GEOCHEMICAL ENVIRONMENTS AND GARDIOVASGULAR MORTALITY RATES IN GEORGIA}

\author{
By Hansford T. Shacklette, Herbert I. Sauer, and A. T. Miesch
}

\begin{abstract}
Nine contiguous counties of northern Georgia that have a low cardiovascular mortality rate lie in an area where the rocks, by weathering, continuously contribute a supply of minor elements to the soil that is formed. Nine counties of central and southcentral Georgia, in contrast, have a high cardiovascular mortality rate, and the soil is largely composed of materials that generally are deficient in weatherable minerals. The concentrations of the elements that were studied in both garden soils and uncultivated soils from the two areas tend to be significantly different and are generally higher in the low-death-rate area. The difference in element composition of soils from the two areas is not apparent in analyses of most regetables; only cabbage and green beans tend to refiect, on a broad scale, the compositional differences in amounts of certain elements in soils. The concentrations of most elements in tree samples tend to be higher in the low-rate area; therefore, trees appear to be more sensitive than vegetables to the variation in element content of soils. The difference between the two areas in the levels of various chemical elements present in vegetables appears to be so slight as to be unlikely to contribute appreciably to the observed differences in death rates in middleaged humans. The chemicals in soils, however, may enter the human food chain in water, in food plants that were not sampled in this study, and in meat and milk from animals that have fed on cultivated forage plants and native vegetation. If geochemical differences between the two areas do, in fact, have a causal relationship to death from cardiovascular diseases, the cause would appear to be a dietary deficiency, rather than an excess, of the elements that were studied.
\end{abstract}

\section{INTRODUCTION}

The counties of Georgia that have low rates of cardiovascular mortality are in the northern part of the State, whereas those that have high rates are in the southern and central parts. Northern and southern counties are very different in their characteristic geological formations and soil types. The fact that the two areas of contrasting mortality rates coincide with two areas of contrasting physiography gave rise to the hypothesis that cardiovascular mortality might be causally related to physical factors of the environment. Of these factors, the chemical composition of the surficial deposits and the vegetation appeared likely to have the greatest effect on the human inhabitants of a region. At the beginning of this study, the patterns of heart-disease mortality rates in this State were well known; the chemical element contents of soils and plants, on the other hand, were but poorly known. Therefore, the Heart Disease and Stroke Control Program of the U.S. Public Health Service and the U.S. Geological Survey undertook a cooperative study of the geochemical properties of soils and plants as they relate to the occurrence of cardiovascular mortality in Georgia.

A preliminary survey was made in the summer of 1963 in which rocks, uncultivated soils, and native plants were sampled in counties that have low, intermediate, and high rates of heart-disease mortality. These samples were analyzed chemically, and the results of the analyses indicated that the areas of high and low mortality rates could be identified by the amounts of certain elements that were in samples from the areas (Shacklette and Sauer, 1964). Following this study, a more rigorous design for sampling, which included sampling of garden soils and vegetables as well as uncultivated soils and native plants, was devised for the areas under study, and fieldwork was completed in the summer of 1965 . The results obtained from chemical analyses of the samples, and the abundance of the elements in the areas of high and low mortality rates, are presented in this report.

Interest in the relation of the environments in Georgia to human health began early in the history of the State and continued up to the time of the Civil War. Cramer (1967) gave an account of the papers that reflect this interest. Most early reports were prepared by physicians who were careful to note the effects of physiography on the prevalence of diseases and the occurrence of epidemics. Yellow fever and malaria were the two diseases most commonly reported to have been associated with topographic features because they were more prevalent in areas of low-lying, swampy ground than in welldrained upland areas. Methods of clearing the land of 
trees and cultivating the soil that resulted in impeding the flow of streams and increasing the amount of standing water caused an accompanying increase in incidence of these diseases. Putrefaction of vegetation in wet locations was thought to produce a noxious effluent that caused the diseases; the fact that mosquitoes, which breed in standing water, are the vectors in the transmission of these diseases was not known at the time.

Speculation on the association of health problems with geological features, however, was not limited to specific diseases. Cramer $(1967$, p. 216$)$ quoted a report that was read to the Georgia Medical Society in 1806 by Dr. Joshua E. White, who said,

To obtain a correct knowledge of medical topography, we should possess some information respecting the face of the country; its elevations and depressions, the quality and proportion of low and high grounds; the number and magnitude of the streams; and various other local circumstances. In relating facts, and detailing alterations which have been produced by the art and industry of man or by fortuitous causes, on the surface of the country, we should not confine our views solely to the present moment. To those who succeed us, it may be satisfactory to be informed what was, and thus they may be enabled to calculate what may be.

Cramer (1967, p. 217-218) reported further that as early as 1837 physicians had recognized the difference in disease rates between the Coastal Plain and the Piedmont regions and that the healthful environment of northern Georgia counties had been noted in 1853 by Dr. Robert C. Ward, who related the effects of lithology and topography on the properties of soil that was formed.

Geochemical characteristics of regions are, in the final analysis, expressions of bedrock geology and the concomitant changes produced by pedological and biological processes that relate to climate and the passing of time. An understanding of these characteristics is necessary in assessing the factors that control the chemical environment of a region. The data included in this report illustrate some chemical relationships of soils to their geologic parent materials and of plants to the soils that support them. The distribution and chemical behavior of elements in the system "rock-soils-plants" is a subject of increasing concern in several other types of geological investigations. For these reasons, these data are of geochemical and biogeochemical interest, independent of their possible usefulness in interpreting patterns of human disease mortality.

Shacklette, a botanist of the U.S. Geological Survey, directed this project and made the field studies; Miesch, a geologist of the same organization, devised and conducted statistical studies of the data; and Sauer, a statistician of the U.S. Public Health Service, provided all data on disease mortality rates and assisted in con- structing the sampling plan and in interpreting the data.

We express our appreciation to Messrs. David F. Davidson and James A. Banta for their assistance in initiating and planning the study, to Messrs. Todd Church and John R. Keith for their help in collecting and preparing samples, to Messrs. Gary L. Selner, Robert Terrazas, and George Van Trump for assistance in computer programming, and to Mmes. Josephine G. Boerngen, Jessie M. Bowles, and Dorothy Moore and Mr. Darrel Parke for their contributions to data processing and analysis. The following chemists of the Geological Survey analyzed the samples: J. C. Hamilton, Thelma F. Harms, J. B. McHugh, Harriet G. Neiman, Clara S. E. Papp, A. L. Sutton, Jr., Barbara Tobin, and J. H. Turner.

We also acknowledge the cooperation of the many property owners in Georgia who freely gave us permission to obtain samples on their land; without their generosity this study could not have been made.

\section{CARDIOVASCULAR MORTALITY RATES IN GEORGIA}

Death rates for the cardiovascular (CV) diseases include those for coronary heart disease (which accounts for more than half of all CV deaths), stroke, hypertensive diseases, and other diseases of the heart and blood ressels. Rates have been computed for the State of Georgia by usual county of residence, utilizing all deaths for the period 1950-59, inclusive (Sauer and others, 1966). Standard vital statistics techniques have been used in computing rates, which are expressed as average annual death rates per 100,000 population at risk, along with several refinements to meet the specific needs of this type of ecological study. The age-sex group of greatest epidemiological concern is middle-aged white males, which may be defined broadly as white males age 35-74. Rates have been computed for this age group, using the average of the 1950 and 1960 censuses as the population at risk, and have been adjusted by the direct method by 10-year age groups to the total United States population of that age in 1950 (Linder and Grove, 1943, p. 66-68). Differences in rates are, therefore, not due to differences in the age, sex, or race composition of the population of the various counties.

The high-rate counties have mortality rates for the cardiovascular diseases roughly double, and in some instances more than double, the rates for the low-rate counties. In this one State, contrasts are found that are almost as great as those for the entire United States (Sauer, 1962). Rates for 1949-51 by economic subregions show northern Georgia in a very low death-rate area and south-central Georgia in a very high rate area (Enterline and other, 1960, p. 762). 
The nine contiguous low-rate counties chosen for this study are listed in table 1 . The cardiovascular diseases death rate for white males age 35-74 ranged from 560 to 682 . Only three other counties of the 159 counties in Georgia had rates equally low-Irwin, Liberty, and Miller; each of these three has very small populations of middle-aged white males, and these counties are isolated from other low-rate counties, therefore the possibility is strongly suggested that the low rates for these three counties are phenomena of chance fluctuation or random error.

Eighteen counties are listed as "high-rate," with death rates from 1,151 to 1,446 ; the first nine counties in this list were chosen for the study because they are rural counties in the section of the Sate which consistently had high rates. Two metropolitan counties, Chatham (including the city of Savannah) and Richmond (including Augusta), were not included because soils and locally grown plants are presumed to have a lesser effect upon the risk of dying in urban areas than in rural areas. Five scattered counties were not included because they are surrounded by counties that have more moderate rates, which again suggests the possibility of chance fluctuation of rates.

The determination of the underlying cause of death frequently may be difficult, and the available diagnostic information may not always be adequate. For a broad group of diseases, such as the CV diseases, the available evidence suggests that this potential shortcoming does not invalidate the comparison of the counties that we selected (Sauer and Enterline, 1959). The rates for "all non-CV" causes follow a pattern similar to that for $\mathrm{CV}$ diseases (table 1). Of the nine counties with low CV rates, all but one had "all non-CV causes" rates below the State average, and of the nine counties selected with high CV rates, all but two had rates for all non-CV causes above the State rate. The factors which are causing these differences in cardiovascular disease rates are presently unknown, but whatever they are, they (or factors associated with them) tend to produce a somewhat similar pattern of rates for nonCV causes. Similar findings are presented in greater detail for the nation as a whole by Sauer and Enterline (1959) and Sauer and Brand (unpub. paper by H. I. Sauer and F. R. Brand, "Geographic differences in cause-specifie death rates," presented to the Society for Epidemiologic Research, Washington, D.C., May 10, 1968).

The all-causes death rates, therefore, show almost as much contrast as do the rates for the cardiovascular diseases. Several counties, in fact, in the high-deathrate area have all-causes rates approximately double those for several counties in the low-death-rate area (table 1). In general, the all-causes death rates for the
TABLE 1.-Death rates for selected causes, white males age 35-74, selected counties of Georgia, during the period 1950-59

[A verage annual death rates per 100,000 population, age adjusted by 10-year age groups by the direct method to the entire United States population age 35-74 in 1950 Deaths tabulated by Georgia State Department of Health, by county of usual residence]

\begin{tabular}{|c|c|c|c|c|c|}
\hline \multirow[b]{2}{*}{ County } & \multicolumn{3}{|c|}{$\begin{array}{l}\text { Cardiovascular diseases } \\
\quad(330-334,400-4681)\end{array}$} & \multirow[b]{2}{*}{$\begin{array}{l}\text { All non- } \\
\text { cardio- } \\
\text { vascular } \\
\text { causes } \\
\text { of death }\end{array}$} & \multirow[b]{2}{*}{$\begin{array}{c}\text { All } \\
\text { causes } \\
\text { of death }\end{array}$} \\
\hline & Total & $\begin{array}{l}\text { Coronary } \\
\text { heart } \\
\text { disease } \\
(4201)\end{array}$ & $\begin{array}{l}\text { Other } \\
\text { cardio- } \\
\text { vascular } \\
\text { diseases }\end{array}$ & & \\
\hline \multicolumn{6}{|l|}{ Low-rate counties: } \\
\hline $\begin{array}{l}\text { Cherokee....... } \\
\text { Fannin }\end{array}$ & 671.0 & 344.1 & 326.9 & 525.4 & $1,196.4$ \\
\hline Forsyth... & 635.7 & 275.1 & $\begin{array}{l}339.0 \\
360.6\end{array}$ & $\begin{array}{l}607.9 \\
529.6\end{array}$ & $\begin{array}{l}1,165.1 \\
1,165.3\end{array}$ \\
\hline Gilmer.... & 647.5 & 296.9 & 350.6 & 485.4 & $1,132.9$ \\
\hline Hall ....... & 667.7 & 328.6 & 339.1 & 573.3 & $1,241.0$ \\
\hline Murray-.. & 680.8 & 274.8 & 406.0 & 593.6 & $1,274,4$ \\
\hline Pickens.-. & 681.7 & 332.2 & 349.5 & 735.5 & $1,417.2$ \\
\hline Towns..- & 587.6 & 201.2 & 386.4 & 480.0 & $1,067.6$ \\
\hline \multirow{2}{*}{\multicolumn{6}{|c|}{$\begin{array}{l}\text { High-rate counties that } \\
\text { were studied: }\end{array}$}} \\
\hline & & & & & \\
\hline Bacon & $1,302.2$ & 743.1 & 559.1 & 789.9 & $2,092.1$ \\
\hline Bleckley.... & $1,205.5$ & 650.6 & 554.9 & 546.0 & $1,751.5$ \\
\hline Burke...... & $1,167.0$ & 603.7 & 563.3 & 834.3 & $2,001.3$ \\
\hline Dodge_... & $1,206.3$ & 569.4 & 636.9 & 736.1 & $1,942.4$ \\
\hline Emanuel-- & $1,167.8$ & 467.4 & 700.4 & 731.5 & $1,899.3$ \\
\hline Jeff Davis _ - & $1,446.4$ & 701.1 & 745.3 & 568.6 & $2,015.0$ \\
\hline $\begin{array}{l}\text { Jefferson............... } \\
\text { Jenkins }\end{array}$ & $1,151.2$ & $\begin{array}{l}679.3 \\
530.1\end{array}$ & 471.9 & $\begin{array}{l}677.9 \\
8025\end{array}$ & $1,829.1$ \\
\hline $\begin{array}{l}\text { Jenkins............ } \\
\text { Warren }\end{array}$ & $1,330.8$ & 530.1 & 800.7 & 802.5 & $2,133.3$ \\
\hline \multicolumn{6}{|l|}{$\begin{array}{l}\text { Warren.-- } \\
\text { Other high-rate } \\
\text { enntios. }\end{array}$} \\
\hline counties: & & & & & \\
\hline Baldwin ${ }^{2}$ & $1,218.8$ & 781.5 & 437.3 & 744.7 & $1,963.5$ \\
\hline Chatham... & $1,177.2$ & 753.7 & 423.5 & 757.2 & $1,934.4$ \\
\hline Johnson & $1,170.3$ & 644.1 & 526. 2 & 700.1 & $1,870.4$ \\
\hline Lee_-_t_- & $1,170.6$ & 754.5 & 416.1 & 927.8 & $2,098.4$ \\
\hline Long & $1,162.3$ & 614.6 & 547.7 & 638.1 & $1,800.4$ \\
\hline Marion & $1,155.8$ & 667.2 & 488.6 & 686. 6 & $1,842.4$ \\
\hline $\begin{array}{l}\text { Kandolph } \\
\text { Richmond } 2\end{array}$ & $\begin{array}{l}1,252.1 \\
1,203.0\end{array}$ & $\begin{array}{l}572.2 \\
773.5\end{array}$ & 679.9. & $\begin{array}{l}618.1 \\
771.3\end{array}$ & $\begin{array}{l}1,870.2 \\
1,074.3\end{array}$ \\
\hline Treutlen. & $1,171.7$ & 533.2 & 638.5 & 766.2 & $1,937.9$ \\
\hline $\begin{array}{c}\text { All counties of } \\
\text { Georgia }\end{array}$ & 095 & 520.4 & 404.8 & 649.0 & 1.574 .2 \\
\hline
\end{tabular}

1 Code number of International Statistical Classification of Diseases, 7th Revision (World Health Organization, 1957).

2 With adjustments for resident institution populations.

low-rate counties are similar to or lower than the CV diseases rates alone for the high-rate counties.

Calculation of death rates for the $\mathrm{CV}$ diseases for 1959-61 indicates that all nine high-rate counties have rates which are above the United States rate and which are roughly 70 percent higher than the rates for the lowrate counties.

For $1950-59$, the pattern of rates for white females age 35-74 tended to be similar to that for males. Since there are fewer deaths among white females, however, chance fluctuation will tend to be higher (Lilienfeld and others, 1967, p. 121-126). Of the nine counties selected because of their low male death rates, seven had rates for white females below the State average, several of the rates being among the lowest in the State. Of the nine counties selected because of their high male death rates, seven also had white female rates higher than the State average. Although nonwhite rates tend to a considerable extent to present patterns parallel to those for whites, the number of nonwhites in the northern Georgia counties is generally too small to provide a basis for calculating meaningful rates. 
These contrasts in rates are in general not due to random error, and thus far show no evidence of being due to methods of data collection or classification - and we have made extensive search for such evidence. There is an incentive, therefore, to search for and test hypotheses regarding factors which may be responsible for these differences.

The death rates tell us that the risk of dying of CV diseases in middle age is twice as great in the high-rate area as in the low-rate area. The rates do not, however, tell us whether the attack rate is higher in the high-rate area, or whether these diseases are more lethal in this area, or both. It is possible that the attack rate or incidence rate in the high-death-rate area is higher than in the low-death-rate area, or it may be that the time period between onset of clinical disease and death is shorter-that is, that the lethality or fatality rate is higher; it is also possible that both the attack rate and the fatality rate are somewhat higher in the high-rate areas than in the low.

The nine counties in the northern part of the State that have very low death rates due to $\mathrm{CV}$ causes are identified in figure 1 . They are part of a group of closely associated or contiguous low-rate counties in the Blue Ridge, the Valley and Ridge, and the upper part of the Piedmont provinces. The nine counties with very high death rates are likewise part of a group of contiguous or closely associated high-rate counties in the east-central part of the State; all counties but one lie entirely within the Atlantic Coastal Plain region. The counties that were chosen for this study give substantial evidence that they are properly classified. As a further illustration: Of the 159 counties in Georgia the low-rate counties are all among the 20 lowest for all causes of death as well as among the very lowest for the cardiovascular diseases generally, and coronary heart disease specifically. Similarly, the high-rate counties are all among the 20 highest for all causes of death.

\section{PHYSIOGRAPHY, GEOLOGY, AND SOILS OF GEORGIA}

The northern part of the State lies within four provinces of the Appalachian Highlands region, and the southern part is in the Atlantic Coastal Plain region (U.S. Geological Survey, 1968), as is shown in figure 1. These regions are characterized by features of relief and geologic formations (Georgia Division of Mines, Mining and Geology, 1939) that have been largely responsible for the differences in soils within the State. The Southern Appalachian region, according to Laurence (1968, p. 156), comprises four major geologic provinces whose boundaries are almost identical with those of the four physiographic provinces, therefore the same names may be used for both kinds of provinces. The Appala- chian Plateaus province barely extends into the extreme northwestern part of the State, where high, narrow ridges of sandstone occur interbedded with layers of shale. This province was not sampled in this study.

The Valley and Ridge province is characterized by long, narrow ridges that parallel broad valleys, which have a northeast-southwest trend. The folded and faulted sedimentary rocks range in age from Early Cambrian to Pennsylvanian. The Cambrian, Ordovician, and Mississippian Systems include thick and extensive deposits of carbonate rocks. Clastic rocks predominate in the Lower Cambrian, Middle Ordovician, Silurian, Devonian, Lower Mississippian, and Pennsylvanian (Laurence, 1968, p. 158). Soils derived from limestones in the valleys generally are rich loams that are suitable for agriculture. The noncalcareous shales produce a soil that is less fertile than that derived from limestone, and the soils that have sandstone parent materials are relatively infertile (Carter and Giddens, 1954).

The Blue Ridge province in the northeastern part of the State is characterized by high mountains, narrow valleys, and rapid streams. The rocks range from crystalline gneisses and schists to unmetamorphosed clastic sedimentary rocks of late Precambrian and Early Cambrian age. Igneous rocks of Paleozoic age, from peridotite to granite, are widespread in this province (Laurence, 1968, p. 156-157). The cool climate of the high elevations has favored the retention of organic matter in the generally acid soils, but the great relief of the region does not promote large-scale agriculture, therefore subsistence farms are prevalent.

The Piedmont province extends from the foot of the Appalachian Mountains to the fall line at the coastal plain and constitutes about one-third of the State. This province includes a wide variety of Precambrian and Paleozoic metamorphic rocks, and intrusive rocks of several different ages. Much of the area has been deeply weathered, and saprolite conceals the unweathered bedrock at places (Laurence, 1968, p. 156). The soils of the part of the province that was sampled in this study commonly are sandy loams, but at places erosion has exposed clay subsoils.

Southern Georgia and parts of central Georgia lie within the Atlantic Coastal Plain region. The landscape has but little relief, and swamps and sluggish streams are common. The typically sandy soils overlie marine rocks of Cretaceous and Tertiary age. These rocks, especially where exposed, have been subjected to intensive weathering. The counties that were studied, if low lying, were largely covered with swamp forests; those with greater relief and better drainage were devoted to small-scale diversified agriculture. 
GEOCHEMICAL ENVIRONMENTS, CARDIOVASCULAR MORTALITY RATES, GEORGIA

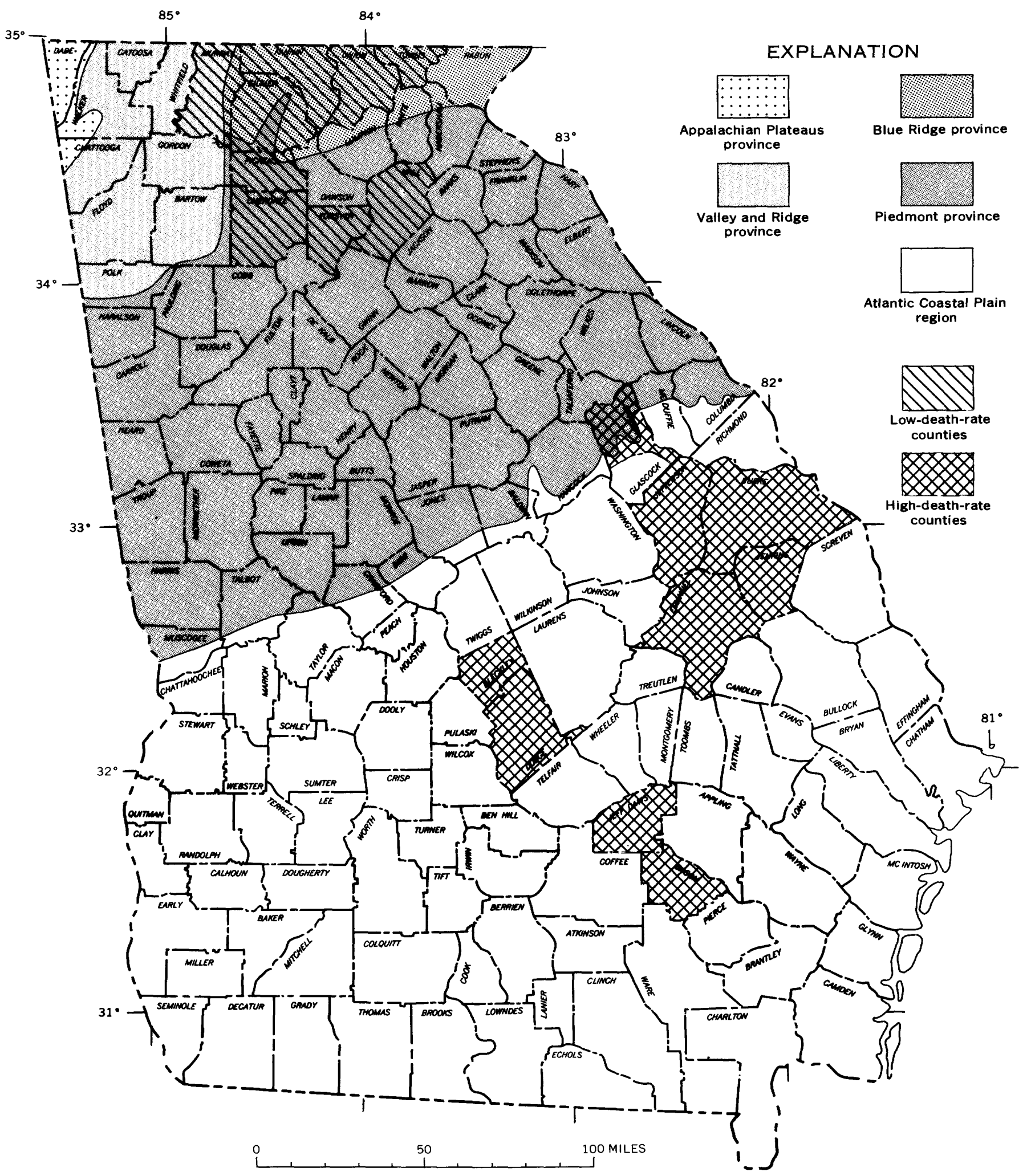

Frgure 1.-Physiographic regions and provinces in Georgia, and locations of counties with high and low death rates per 100,000 population for cardiovascular diseases among white males of ages 35-74 during the period 1950-59. 
The kinds of soils that occur in Georgia were shown on a map prepared by the U.S. Soil Conservation Service (1969), which utilized the new soil classification system that was established by the Soil Survey Staff $(1960,1967)$. This map classified soils into the four highest categories (Order, Suborder, Great Group, and Subgroup) of the hierarchical system. The lowest of these categories, Subgroup, is distinguished principally by degree of slope and combinations of other Great Groups that are given for the map unit. For simplicity of presentation in this report, Subgroups have been ignored in preparing the classification outline and the soils map (fig. 2) that follow.

ORDER Entisols-Soils that have no pedogenic horizons.

Suborder Psamments-Entisols that have textures of loamy fine sand or coarser.

Great Group Quartzipsamments-Psamments that consist almost entirely of minerals highly resistant to weathering, mainly quartz.

ORDER Histosols-Wet organic (peat and muck) soils.

Suborder (not named)-Histosols of warm regions.

Great Group (not named) - Plant residue highly decomposed.

ORDER Inceptisols-Soils with weakly differentiated horizons showing alteration of parent materials.

Suborder Aquepts-Seasonally wet Inceptisols that have an organic surface horizon and a sodium saturation, mottles, or gray colors.

Great Group Humaquepts-Aquepts that have an acid dark surface horizon (in Georgia, tidal marshes).

Suborder Ochrepts-Inceptisols that have formed in materials with crystalline clay minerals, have light-colored surface horizons, and have altered subsurface horizons that have lost mineral matter.

Great Group Dystrochrepts-Ochrepts that are usually moist and low in bases and have no free carbonates in the subsurface horizons.

ORDER Spodosols-Soils with low base supply that have in subsurface horizons an accumulation of amorphous materials consisting of organic matter plus compounds of aluminum and usually iron.

Suborder Aquods-Seasonally wet Spodosols.

Great Group Haplaquods-Aquods that have a subsurface horizon that contains dispersed aluminum and organic matter, but only small amounts of free iron oxides.

ORDER Ultisols-Soils with horizons of clay accumulation and low base supply.

Suborder Aquults-Seasonally wet Ultisols that have mottles, iron-manganese concretions, or gray colors.

Great Group Ochraquults-Aquults that have a lightcolored or thin black surface horizon.

Suborder Udults-Ultisols that are usually moist, relatively low in organic matter in the subsurface horizons; formed in humid climates that have short or no annual dry period.

Great Group Hapludults-Udults that have a thin subsurface horizon of clay or appreciable weatherable minerals, or both.

Great Group Paleudults-Udults that have a thick horizon of clay accumulation without appreciable weatherable minerals.
The counties that have a low cardiovascular mortality rate are in an area where Hapludults predominate (fig. 2). The principal characteristic, from the geochemical standpoint, of soils in this Great Group is their content of weatherable minerals which serve as a constant source of element enrichment in the process of soil development. The counties that have a high mortality rate for these diseases are located in areas where one of the three soils, Paleudults, Quartzipsamments, and Ochraquults, predominates. Paleudults are characterized by the absence of appreciable amounts of weatherable minerals, Quartzipsamments consists mostly of minerals that are highly resistant to weathering, and Ochraquults are deficient in available elements because of their high seasonal water content which causes excessive leaching. Soils in the low-death-rate counties, therefore, were expected to contain certain elements in greater abundance than is found in soils from the highdeath-rate counties. The analyses given in this report support this hypothesis.

Most soils of Georgia are not very fertile as judged by agricultural standards in their natural condition. This infertility was attributed by Carter and Giddens (1954) to climatic conditions and soil development processes. The soils generally are deficient in the major elements for plant nutrition, as well as in magnesium, boron, and zinc; therefore, trace elements commonly are added to the fertilizers used on certain crops.

The relation of the two areas of contrasting rates of heart disease mortality to the occurrence of soil types can be summarized by stating that the high-mortality counties have soils that are derived from the highly weathered marine sediments of the coastal plains, whereas the low-mortality counties have soils that originated from a great variety of rock types from which weathering is continuously providing a fresh supply of chemical elements to the soils.

\section{COLLECTION AND ANALYSIS OF GEOCHEMICAL DATA SAMPLE DESIGN}

The counties of Georgia to be sampled were divided into two groups of nine counties each, according to their classification by rates of death due to heart disease. The counties that have high death rates are Bacon, Bleckley, Burke, Dodge, Emanuel, Jeff Davis, Jefferson, Jenkins, and Warren; those with a low death rate are Cherokee, Fannin, Forsyth, Gilmer, Hall, Murray, Pickens, Towns, and Union. Within each of the two groups, 30 sites were selected for sampling native plants (trees) and uncultivated soils, and 30 sites were chosen for sampling vegetables and garden soils. This made a total of 120 sample sites in the two areas.

A sample site for trees and uncultivated soils was defined as an area in which the required species of trees 


\section{EXPLANATION}

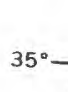

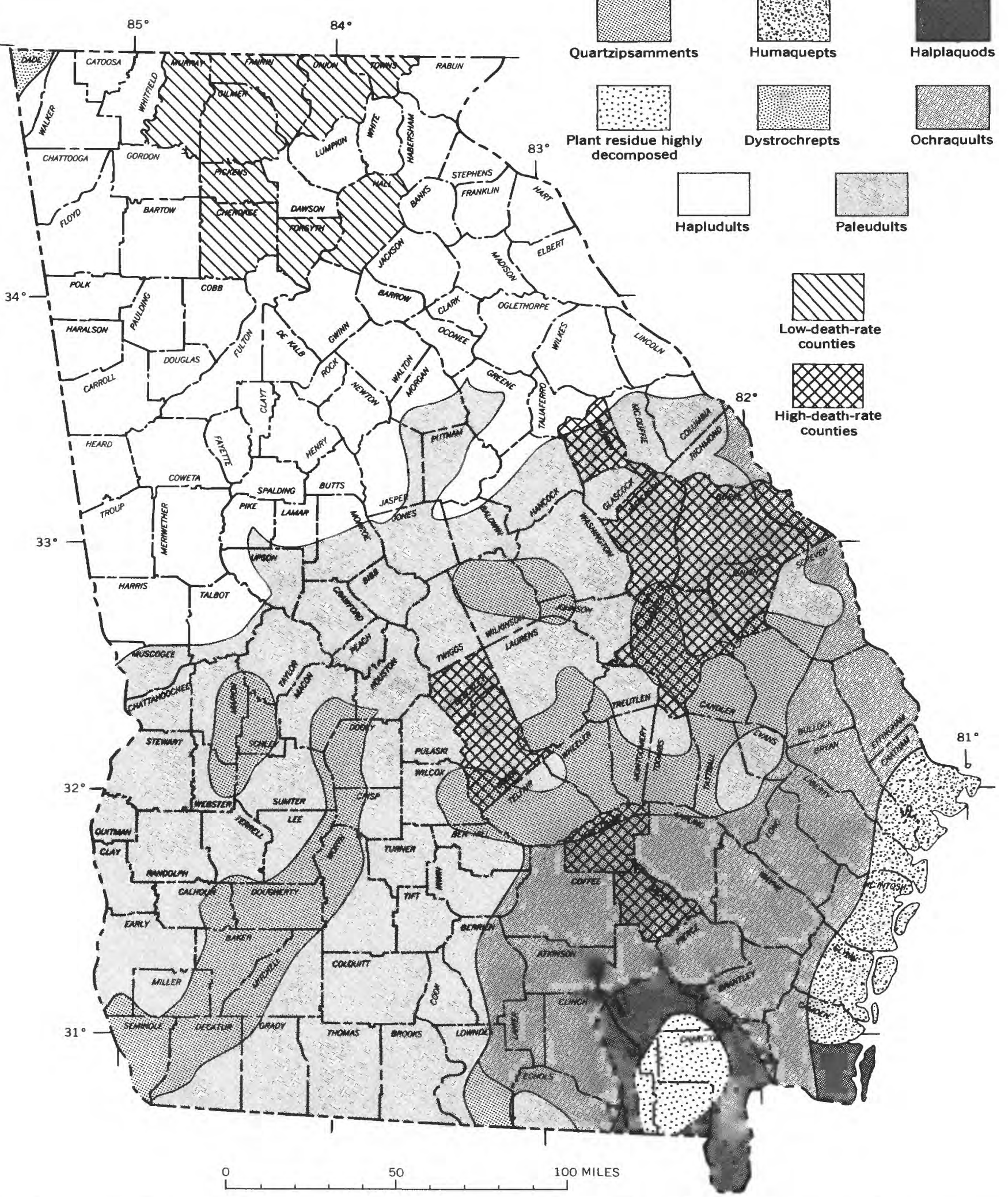

Frgure 2.-Great Soil Groups of Georgia, and the locations of counties that have high and low cardiovascular mortality rates. 
could be found rooted in a soil unit which was judged to be relatively homogeneous. Ordinarily, the sample site was considered to be within a radius of 20-60 feet of the point that was selected for the soil-sample hole; however, this radius was extended at places in order to include a required species of tree, if the same soil unit continued into this enlarged area. A sample site for vegetables and garden soils was defined as a single home garden (not a commercial truck farm). The size of these gardens ranged from about 400 square feet to a quarter acre $(10,890$ sq. ft.).

The distribution of sample sites by counties within each area (the high and low-death-rate areas) was arbitrarily set at three native plant and soil sites and three garden sites for each of six counties of an area, and four native plant and soil sites and four garden sites for each of three counties (table 2). Within a county the exact location of sample sites was dictated, to a large extent, by the restrictions of the sampling plan - that is, the locations of the sites often were determined by the limited occurrence of the required sampling media. The selection of sites for sampling native plants and uncultivated soils first required that relatively undisturbed forests be found in which the selected species of trees and a reasonably homogeneous soil unit occurred. The selection of garden sites was controlled largely by the requirements that the kinds of vegetables that were wanted occurred in each garden and that permission of the owner to sample the garden was obtained. The former requirement was at places difficult or impossible to meet, therefore complete suites of samples were not obtained at all sites. Permission to sample gardens was almost invariably given by the owners, many of whom assisted us in gathering the vegetable samples.

Within the limitations imposed on selection of sites as described above, we attempted to obtain samples that were representative of a county. In effect, the unpredictable occurrence of suitable sites contributed a degree of randomness to the sampling plan.

The two sampling areas are disposed in a northsouth orientation and, therefore, encompass a wide range of climates, soils, forest types, plant species, and cultural preferences. In the most southern counties, where the fieldwork began, we collected samples of persimmon, blackgum, black cherry, red maple, blackjack oak, smooth sumac, sassafras, and sweetgum. Of these eight species, only five (blackgum, persimmon, red maple, smooth sumac, and black cherry) could be found at all sites throughout the State (table 2). Blackjack oak was found at all sites in the high-death-rate area, but did not occur at all sites in the low-death-rate area; therefore, two other species of oak (black oak and post oak) that are closely related morphologically were substituted in the latter area. Sassafras was more abundant

TABLE 2.-Localities, kinds, and numbers of samples that were collected in Georgia

[...., no samples collected]

\begin{tabular}{|c|c|c|c|c|c|c|c|c|c|c|c|c|c|c|c|c|c|c|c|}
\hline \multirow{3}{*}{ Counties } & \multicolumn{19}{|c|}{ Kinds and numbers of samples } \\
\hline & \multicolumn{8}{|c|}{ Native trces 1} & \multicolumn{6}{|c|}{ Vegetables } & \multicolumn{3}{|c|}{ Uncultivated soils } & \multirow{2}{*}{$\begin{array}{l}\text { Gar- } \\
\text { den } \\
\text { soils, } \\
\text { plow } \\
\text { zone }\end{array}$} & \multirow{2}{*}{$\begin{array}{c}\text { Soils, } \\
\text { compo- } \\
\text { nents of } \\
\text { variance } \\
\text { study }\end{array}$} \\
\hline & $\begin{array}{l}\text { Black- } \\
\text { gum }\end{array}$ & Oak $^{2}$ & $\begin{array}{l}\text { Per- } \\
\text { sim- } \\
\text { mon }\end{array}$ & $\begin{array}{l}\text { Red } \\
\text { maple }\end{array}$ & $\begin{array}{l}\text { Sassa- } \\
\text { fras }\end{array}$ & $\begin{array}{l}\text { Smooth } \\
\text { sumac }\end{array}$ & $\begin{array}{l}\text { Sweet } \\
\text { gum }\end{array}$ & $\begin{array}{l}\text { Black } \\
\text { cherry }\end{array}$ & $\begin{array}{l}\text { Black- } \\
\text { eyed } \\
\text { peas }\end{array}$ & $\begin{array}{c}\text { Cab- } \\
\text { bage }^{3}\end{array}$ & Corn & $\begin{array}{l}\text { Green } \\
\text { beans }\end{array}$ & $\begin{array}{l}\text { Lima } \\
\text { beans }\end{array}$ & $\begin{array}{c}\text { Toma- } \\
\text { toes }\end{array}$ & $\begin{array}{c}\text { A } \\
\text { hori- } \\
\text { zon }\end{array}$ & $\begin{array}{c}\mathrm{B} \\
\text { hori- } \\
\text { zon }\end{array}$ & $\begin{array}{l}\text { C } \\
\text { hori- } \\
\text { zon }\end{array}$ & & \\
\hline
\end{tabular}

\begin{tabular}{|c|c|c|c|c|c|c|c|c|c|c|c|c|c|c|c|c|c|c|c|}
\hline \multicolumn{20}{|c|}{ High-death-rate area } \\
\hline Bacon & 3 & 3 & 3 & 3 & 1 & 3 & 2 & 3 & 3 & 2 & 3 & 3 & 3 & 3 & 3 & 3 & 3 & 3 & \\
\hline Bleckley..... & 3 & 3 & 3 & 3 & 3 & 3 & 3 & $\begin{array}{l}0 \\
3\end{array}$ & 3 & 3 & $\begin{array}{l}3 \\
3\end{array}$ & 3 & 3 & 3 & 3 & 3 & 3 & $\mathbf{3}$ & 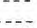 \\
\hline Burke & 4 & 4 & 4 & 4 & 4 & 4 & 4 & 4 & 4 & 4 & 4 & 4 & 4 & 4 & 4 & 4 & 4 & 4 & 12 \\
\hline Dodge...... & 3 & 3 & 3 & 3 & 3 & 3 & $\frac{x}{2}$ & 3 & 3 & 3 & 3 & 3 & 3 & 3 & 3 & 3 & 3 & 3 & $\ldots$ \\
\hline Emanuel & 4 & 4 & 4 & 4 & 1 & 4 & 4 & 4 & 4 & 3 & 4 & 4 & 4 & 4 & 4 & 4 & 4 & 4 & ... \\
\hline Jeff Davis........ & 3 & 3 & 3 & 3 & 3 & 3 & 3 & 3 & 3 & 3 & 3 & 3 & 3 & 3 & 3 & 3 & 3 & 3 & - \\
\hline Jefferson & 4 & 4 & 4 & 4 & 1 & 4 & 4 & 4 & 4 & 4 & 4 & 4 & 4 & 4 & 4 & 4 & 4 & 4 & 6 \\
\hline Jenkins & 3 & 3 & 3 & 3 & 1 & 3 & 3 & 3 & 3 & 3 & $\begin{array}{l}4 \\
3\end{array}$ & 3 & $\begin{array}{l}7 \\
3\end{array}$ & 3 & 3 & 3 & 3 & 3 & 6 \\
\hline Warren & 3 & 3 & 3 & 3 & 1 & 3 & $\ddot{3}$ & 3 & 3 & 3 & 3 & 3 & 3 & 3 & 3 & 3 & 3 & 3 & 6 \\
\hline Subtotal.. & 30 & 30 & 30 & 30 & 18 & 30 & 28 & 30 & 30 & 28 & 30 & 30 & 30 & 30 & 30 & 30 & 30 & 30 & 30 \\
\hline
\end{tabular}

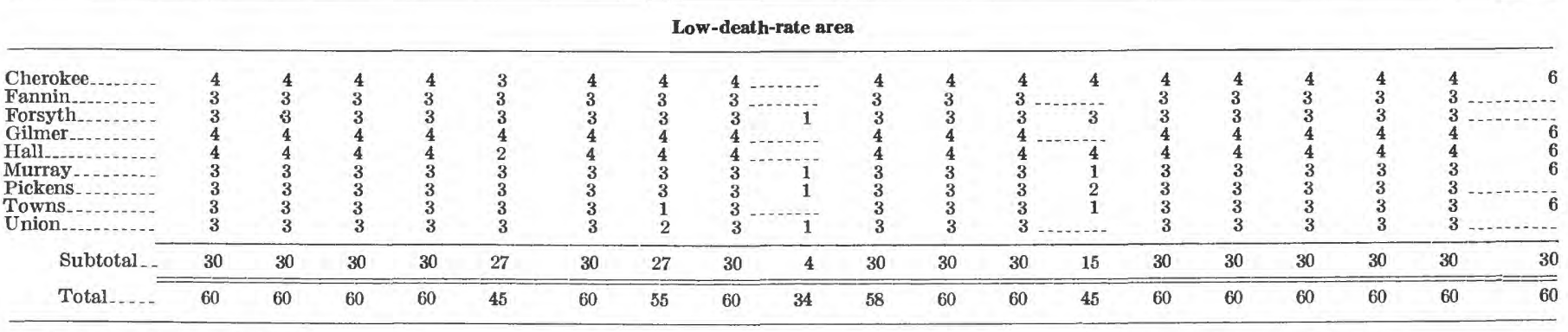

1 Tree samples were divided into stems and leaves, and these were analyzed separately; therefore the total number of tree samples is twice that shown.

2 Includes 44 samples of blackjack oak, 13 samples of post oak, and 3 samples of black oak.

3 Both cabbage and collards are included; they are botanically similar. 
in northern Georgia than in southern Georgia-however, a complete suite of samples could not be obtained in either area. Sweetgum was absent from only five sites.

Of the six kinds of vegetables that were studied, only corn, green beans, and tomatoes could be found in all gardens that were sampled, although cabbage (or collards) was absent from only two of the 60 gardens. Regional differences in preference for vegetables were most obvious with blackeyed peas. This vegetable was found in all 30 gardens that we sampled in the southern area, but in only four gardens in the northern area. Similarly, lima beans were found in all southern gardens, but in only half of the northern gardens. Of the vegetables that were observed but not sampled because of their immaturity at the time of the field study and their infrequent occurrence, Irish (white) potatoes were rarely seen in the southern gardens, and sweet potatoes (yams) were uncommon in the north. Other vegetables that were observed, but which occurred erratically, included squash, peppers, beets, peanuts, okra, cucumbers, eggplant, and melons. Com and tomatoes were found in almost all gardens that were examined and were by far the most common vegetables throughout the State.

\section{SAMPLING MEDIA}

\section{PLANTS}

The kinds of plants that were sampled, and their scientific names (Fernald, 1950), are listed below:

Blackgum, Nyssa sylvatica Marsh.

Blackjack oak, Quercus marilandica Muench.

Black oak, Quercus velutina Lam.

Post oak, Quercus stcllata Wang.

Persimmon, Diospyros virginiana L.

Red maple, Acer rubrum L.

Sassafras, Sassafras albidum (Nutt.) Nees

Sumac, Rhus glabra $\mathrm{L}$.

Sweet gum, Liquidambar styracifua $\mathrm{L}$.

Black cherry, Prunus serotina Ehrh.

Blackeyed peas, Vigna sinensis Endl. (samples included several cultivated varieties)

Cabbage, Brassica oleracea var. capitata $\mathrm{L}$.

Collards, Brassica oleracea var. acephala DC.

Corn, Zea mays L. (samples included both field corn and sweet corn)

Green beans, Phaseolus vulgaris $\mathrm{L}$. (samples included both green-pod and yellow-pod varieties )

Lima beans, Phaseolus limensis Macfad. (samples included both the bush form and the climbing form)

Tomato, Lycopcrsicum esculcntum Mill. (all samples were of the common red-fruited form)

The tree samples were stems (terminal parts of branches) about 12 inches long. The leaves were removed from the stems, and the leaves and the stems were analyzed separately. Both types of tree samples were analyzed, because it is known that some chemical elements are concentrated in stems, whereas others are concentrated in leaves. The samples were air dried, pulverized in a Wiley mill, weighed, and burned to ash in an electric oven in which the heat was increased $50^{\circ} \mathrm{C}$ per hour to a temperature of $550^{\circ} \mathrm{C}$ and held at this temperature for 14 hours. The ash was then weighed to determine the ash yield of the dry plant sample and was used in all subsequent analytical procedures.

The vegetable samples were prepared in the same manner as for table use; that is, the blackeyed peas were shelled and a few tender pods were left with the seeds, the cabbage and collards leaves were washed and cut, the corn grains were cut from the cobs, the pods of green beans were washed and broken into pieces, the lima beans were removed from the pods, and the tomatoes were washed and sliced. The prepared vegetables were packed in polyethylene bags as soon as possible after preparation and shipped by air to the Denver laboratories of the U.S. Geological Survey where they were oven dried to constant weight. Most vegetables, because of their content of sugar or colloids, or both, are difficult to air dry, in contrast to stem and leaf samples which air dry readily. The dried vegetable samples were pulverized and burned to ash in the same manner as the tree samples.

\section{sorrs}

In this report, soil-horizon terminology follows the traditional usage of the $\mathrm{A}$ and $\mathrm{B}$ horizons to designate divisions of the solum and of the $\mathrm{C}$ horizon to designate soil parent material (Baldwin and others, 1938). The uncultivated soils, at the tree-sample sites, were sampled from holes made by a clamshell digger to the depth necessary to include the $\mathrm{C}$ horizon of the soil. This depth ranged from less than 1 foot to 3 feet. The samples of the $\mathrm{A}$ and $\mathrm{B}$ horizons were taken from the sides of the holes by using a trowel, and the $\mathrm{C}$ horizon sample was taken from the bottom of the hole with the digger. Zonation ordinarily was well defined; some lithosols of the mountainous provinces and the regosols of the coastal plain, however, had indefinite horizons or no horizons and are termed azonal soils. Soils at two sites in the low-rate area were azonal lithosols, and soils at five sample sites in the high-rate area and two in the low-rate area were regosols. The lithosols were sampled by digging to bedrock or to a zone so stony that further digging was impractical, and the depth of the holes in the regosols was arbitrarily set at 2 feet. These two types of soil were sampled just below the surface, midway down the hole, and at the bottom of the hole; and the samples were, for convenience, desigated $\mathrm{A}, \mathrm{B}$, and $\mathrm{C}$ horizons, respectively. 
In order to obtain some measure of the homogeneity of soils at a site, two additional soil-sample holes were dug and the three soil horizons were sampled at each of five tree-sample sites in each of the different death rate areas. These additional sample holes were randomly located within a 30 -foot radius of the initial soil-sample hole. The 60 additional samples, when added to the 30 samples of the initial sample holes at the sites, provided 90 samples for the study of soil homogeneity. The results of this study are given in table 4 .

The garden soils were sampled by taking the required amount from soil that was 1-2 inches below the surface. These soils were well pulverized when sampled and had been thoroughly mixed by cultivation practices that had extended over many years, therefore only the "plow zone" was sampled. No attempt was made to record past or present fertilizing practices; questioning the owners from place to place about fertilizing soon revealed that such information was either unknown, uncertain, or of doubtful accuracy in regard to kinds of fertilizers used, rates and frequency of application, and the years when the alleged applications were made.

Widespread use of insecticides, principally lead arsenate and paris green (arsenic trioxide and copper acetate), is known to have been prevalent in past decades, therefore heavy metal residues were expected to be found in garden soils. Analyses of these soils, however, did not reveal unusual concentrations of these metals.

The soil samples were air dried, then sifted through a 200-mesh sieve and the -200 fraction used for chemical analysis. Some samples that had a large clay content were so hard when dry that it was necessary to grind them to powder in a ceramic mill before sieving.

\section{PROCEDURES USED IN CHEMICAL ANALYSIS}

The content of elements in plants that is reported was determined by analysis of the plant ash. The ash yield of the dry plant sample also is reported, therefore the element content of the dry plant can be computed. Contents of zinc and phosphorus were determined by colorimetric methods that were described by Ward, Lakin, Canney, and others (1963). Analyses for amounts of calcium were made by the EDTA titration method, and analyses for potassium by flame photometry. Quantities of the other elements were determined by semiquantitative spectrographic analysis (Myers, and others, 1961) after the ash of plant samples had been diluted with an equal weight of matrix composed of sodium silica ( 10 percent $\mathrm{Na}$ ). These values were reported in geometric brackets having the boundaries $1.2,0.83,0.56,0.38,0.26,0.18,0.12$, and so forth, percent; the brackets are identified by their respective geometric midpoints, such as $1.0,0.7,0.5,0.3$,
$0.2,0.15$. Thus, a reported value of 0.3 percent, for example, identifies the bracket from 0.26 to 0.38 percent as the analyst's best estimate of the concentration. The precision of a reported value is approximately plus or minus one bracket at the 68-percent level of confidence and plus or minus two brackets at the 95-percent level.

Soil samples were analyzed by the same methods that were used for plants, except the pulverized soil was not burned to ash (most samples had a very low organic content) and a matrix was not added to the sample for spectrographic analysis. The chemical composition of soil samples was reported as parts per million or percent of the air-drv weight of the soil.

The limits of detection of the analytical methods that were used follow (table 3).

TABLE 3.-Analytical limits of detection

[Values given are the lower limits, in percent, for the semiquantitative spectrographic method that was used, unless otherwise noted]

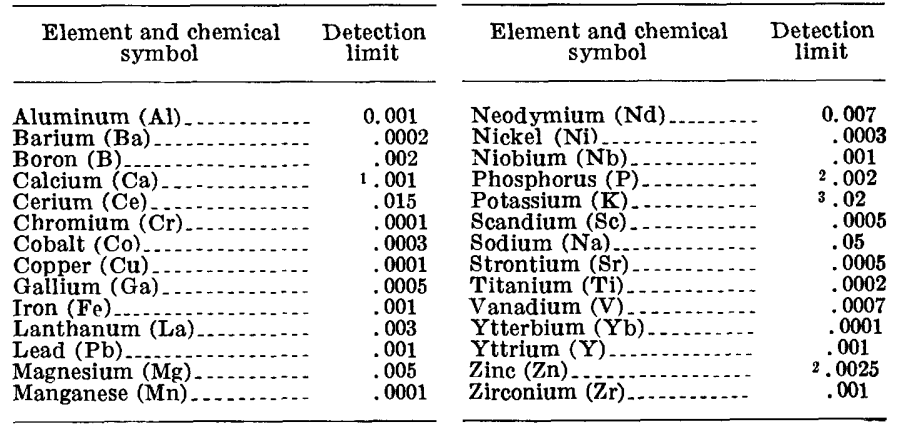

1 Analyzed by EDTA titration method.

3 Analyzed by flame photometry.

The values given in table 3 are approximate lower limits of determination. Some combinations of elements in a sample, however, affect these limits. Concentrations somewhat lower than these values may be detected in unusually favorable materials, whereas these limits of determination may not be attained in unfavorable materials. Upper limits in measuring the amounts of magnesium were exceeded by a few plant samples; these analyses were reported as $>10$ percent.

\section{METHODS OF STATISTICAL ANALYSIS}

The objective of the statistical analysis of the data has been to examine differences between plant and soil geochemistry in the high- and low-death-rate areas. The statistical significance of the differences between the two estimated means for each element concentration in each sample media was determined by analysis of variance methods. Analysis of variance was also used in the estimation of total sampling and analytical error associated with an individual site at which the A, B, and $\mathrm{C}$ horizons of uncultivated soils were collected. Cor- 
relation coefficients were computed to examine the covariation among the compositions of the various sampling media among the sampling sites in both the high- and low-death-rate areas.

Frequency distributions of most of the original chemical data, in units of weight percent, display high positive skewnesses and the variances of the distributions tend to be proportional to their respective means. Log transformation of the original data proved effective in correcting both these situations to a satisfactory degree. The frequency distributions of the logs of the original data tend to be normal; the distributions of the original data tend to be lognormal. Log transformation also overcomes some effects of the geometric brackets in which spectrographic analyses are reported (Miesch, 1967b, p. B5).

The geometric means were estimated by use of the antilog of the arithmetic mean of the logs. This is the appropriate measure of central tendency for a lognormal distribution and provides a "typical" or "characteristic" value for the element in the various sample media. A measure of variation is given by the geometric deviation, which is the antilog of the standard deviation of the logs. About two-thirds of the area under the lognormal distribution curve lies in the range $G M \div G D$ to $G M \times G D$, where $G M$ is the geometric mean and $G D$ is the geometric deviation. The confidence interval about the geometric mean, the geometric error $(G E)$, can be estimated from

$$
G E=10^{(t \log G D / \sqrt{N})}
$$

where $t$ is Student's $t$ and $N$ is the number of values on which the geometric mean is based. Where $t$ is selected at the 0.05 level of probability, the population geometric mean has the expected range $G M \div G E$ to $G M \times G E$, with 95-percent confidence.

Many of the elements studied were not detected in part of the samples from each media. The elements are presumably present in the media, but in concentrations below the sensitivities of the analytical methods used. Means and variances of the log concentrations, in these cases, were estimated by use of Cohen's (1961, p. 535) technique for type I censored distributions. The estimators are:

$$
\begin{gathered}
\hat{\mu}=\bar{x}-\lambda\left(\bar{x}-x_{0}\right) \text { and } \\
\hat{\sigma}^{2}=s^{2}+\lambda\left(\bar{x}-x_{0}\right)^{2},
\end{gathered}
$$

where $\hat{\mu}$ and $\hat{\sigma}^{2}$ are estimates of the population mean $\log$ and variance of the $\operatorname{logs}$, respectively, $\bar{x}$ and $s^{2}$ are the mean and variance of the logs of the concentration values above the analytical sensitivities, $x_{0}$ is the $\log$ of the sensitivity, and $\lambda$ is taken from table 2 of
Cohen (1961, p. 538). The estimated geometric mean is

$$
G M=10^{\hat{\mu}}
$$

and the geometric deviation is

$$
G D=10^{\hat{\sigma}} \text {. }
$$

Estimated geometric means and geometric deviations are given in tables 5-7. Where the element was not detected in some of the samples analyzed, as indicated on the tables, the estimates were derived by Cohen's technique.

The statistical significance of differences between mean concentrations of constituents in various media in the high- and low-death-rate areas was estimated by analysis of variance methods; results are given in tables 5-7. Differences between means estimated from highly censored data were not tested; the required statistical tests are not available. Where the censored part of the distribution was small, the unknown values were assigned to a semiquantitative spectrographic class immediately below the limit of sensitivity of the analytical method. The principal justification for replacing the unknown values is that the final answers are nearly independent of any reasonable values that may be used. The validity of analysis of variance results (tables 5-7) rests on three principal assumptions: (1) the sampling and analysis have been unbiased, or biases which may be present tend to be constant among sampling sites (Miesch, 1967a, p. A14), (2) the frequency distributions of the data are drawn from corresponding lognormal population distributions, and (3) the geometric deviations of the population frequency distributions are equal. The correctness of the first of these assumptions can only be inferred from the nature of the sampling techniques and methods of analysis, already described. The other two assumptions are only approximately correct, as inferred from tests for normality and variance homogeneity; but the observed departures of the respective properties from the ideal conditions are not sufficient to seriously invalidate the results.

It is doubtful that any two areas, even areas in proximity, contain exactly the same concentrations of any particular element or other constituent in any particular media. The analysis of variance, therefore, is an attempt to demonstrate the existence of differences we can be quite sure are present without the analysis, and failure of the tests to demonstrate a difference merely indicates that the test lacks sufficient power (the power could be increased by taking more samples). The purpose of the analysis of variance, therefore, is not to demonstrate the existence of differences in composition between the two areas, but to find those differences which appear 
to be large when compared with the variation within each of the two areas.

The computational procedures used in the analysis of variance followed those described by Anderson and Bancroft (1952, p. 327-330) for designs containing unqual numbers in subclasses.

Estimates of experimental error in the data pertaining to uncultivated soils were obtained from replicate sampling at 10 sites, five in the high-death-rate area and five in the low-death-rate area. Three sample holes, at random locations as much as 60 feet apart, were dug at each of the 10 sites, and samples were taken from each of the $\mathrm{A}, \mathrm{B}$, and $\mathrm{C}$ soil horizons. A total of 90 samples were used. The statistical model employed was

$$
X_{i j k}=\mu+\alpha_{i}+\beta_{i j}+\gamma_{i j k}
$$

where $X_{i j k}$ is the $\log$ concentration of an element in the $k$ th sample $(1 \leq k \leq 3)$ from the $j$ th site $(1 \leq j \leq 5)$ in the $i$ th area $(1 \leq i \leq 2)$, from either the $\mathbf{A}, \mathbf{B}$, or $\mathbf{C}$ horizon; $\mu$ is the grand mean log concentration of the element in the A, B, or C horizon at all sites, $\alpha_{i}$ is the deviation of the high- or low-death-rate area mean from the grand mean, $\beta_{i j}$ is the deviation of the site mean from the area mean, and $\gamma_{i j k}$ is the deviation of the $\log$ analytical value for a single hole from the mean for the site. The validity of the model depends on the absence of variable bias in sampling and analysis (Miesch, 1967a, p. A14). Estimates of the variance components for $\alpha, \beta$, and $\gamma$ were derived according to

\begin{tabular}{|c|c|c|}
\hline Source & $\begin{array}{l}\text { Degrees of } \\
\text { freedom }\end{array}$ & $\begin{array}{c}\text { Mean square is } \\
\text { estimate of }\end{array}$ \\
\hline Between areas._. & 1 & $\sigma_{\gamma}^{2}+3 \sigma_{\beta}^{2}+15 \sigma_{\alpha}^{2}$ \\
\hline Between sites & 8 & $\sigma_{\gamma}^{2}+3 \sigma_{\beta}^{2}$ \\
\hline Between holes_........ & 20 & $\sigma_{\gamma}^{2}$ \\
\hline
\end{tabular}

Estimates of the individual components, $\sigma_{\alpha}^{2}, \sigma_{\beta}^{2}$, and $\sigma_{\gamma}^{2}$ are given in table 4 . In general, the variance between the high- and low-death-rate areas $\left(\sigma_{\alpha}^{2}\right)$ is sufficiently large in comparison with variance components between sites and between samples that no difficulties are foreseen in identifying compositional differences between areas. With 30 sites per area and one sample per site, the within-area variance of the mean $\log$ for aluminum in the A horizon, for example is

$$
\frac{0.021+\frac{0.016}{1}}{30}=0.0012 .
$$

This value is a measure of the total error of the mean $\log$ aluminum content for an area and is satisfactorily low as compared with the variance between areas, 0.246 ( table 4).
TABLE 4.-Components of logarithmic variance between samples, sites, and areas where uncultivated soils were sampled in the highand low-death-rate areas

[Numbers in italic indicate that the variance is significant at the 95-percent level

\begin{tabular}{|c|c|c|c|c|c|c|c|c|c|}
\hline \multirow{4}{*}{ Element } & \multicolumn{9}{|c|}{ Component of logarithmic variance } \\
\hline & \multicolumn{3}{|c|}{ Between samples $\left(\sigma_{\gamma}{ }^{2}\right)$} & \multirow{2}{*}{\multicolumn{3}{|c|}{$\frac{\begin{array}{c}\text { Between sample sites } \\
\left(\sigma_{\beta}^{2}\right)\end{array}}{\text { Soil horizons }}$}} & \multicolumn{3}{|c|}{ Between areas $\left(\sigma_{\alpha}{ }^{2}\right)$} \\
\hline & & & & & & & & & \\
\hline & $\mathbf{A}$ & B & $\mathrm{C}$ & A & B & $\mathrm{C}$ & A & B & $\mathrm{C}$ \\
\hline 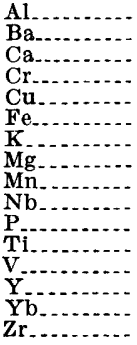 & $\begin{array}{r}0.016 \\
.021 \\
.023 \\
.018 \\
.020 \\
.021 \\
.018 \\
.030 \\
.028 \\
.020 \\
.044 \\
.015 \\
.022 \\
.036 \\
.041 \\
.037\end{array}$ & $\begin{array}{l}0.013 \\
.041 \\
.007 \\
.044 \\
.027 \\
.025 \\
.042 \\
.022 \\
.020 \\
.034 \\
.049 \\
.009 \\
.011 \\
.064 \\
.041 \\
.023\end{array}$ & $\begin{array}{l}0.031 \\
.014 \\
.017 \\
.028 \\
.042 \\
.020 \\
.014 \\
.062 \\
.022 \\
.034 \\
.047 \\
.010 \\
.033 \\
.020 \\
.025 \\
.042\end{array}$ & $\begin{array}{l}0.021 \\
.017 \\
.022 \\
.025 \\
.046 \\
.019 \\
.037 \\
.073 \\
.077 \\
.001 \\
.022 \\
.020 \\
.010 \\
.058 \\
.053 \\
.018\end{array}$ & $\begin{array}{l}0.038 \\
.025 \\
.019 \\
.027 \\
.031 \\
.035 \\
.117 \\
.078 \\
.063 \\
.001 \\
.033 \\
.017 \\
.022 \\
.014 \\
.016 \\
.029\end{array}$ & $\begin{array}{l}0.095 \\
.045 \\
.010 \\
.054 \\
.059 \\
.091 \\
.097 \\
.118 \\
.059 \\
0 \\
.047 \\
.017 \\
.048 \\
.114 \\
.095 \\
.024\end{array}$ & $\begin{array}{l}0.246 \\
.125 \\
.048 \\
.165 \\
.149 \\
.196 \\
.819 \\
.593 \\
.060 \\
.001 \\
.067 \\
0 \\
.252 \\
0 \\
0 \\
.022\end{array}$ & $\begin{array}{l}0.340 \\
.106 \\
.139 \\
.190 \\
.189 \\
.307 \\
.707 \\
.701 \\
.283 \\
.003 \\
.081 \\
.013 \\
.266 \\
0 \\
.013 \\
.009\end{array}$ & $\begin{array}{l}0.216 \\
.091 \\
.094 \\
.114 \\
.139 \\
.201 \\
.702 \\
.519 \\
.190 \\
.004 \\
.006 \\
.003 \\
.181 \\
0 \\
0 \\
.026\end{array}$ \\
\hline
\end{tabular}
of confidence]

The variance among sample sites within the high- and low-death-rate areas is generally similar to the variance within sites (table 4). This appears to be true for all chemical elements in all three soil horizons. Consequently, if further studies were undertaken with an objective that depended on distinguishing among the sites within either area, it would be necessary to collect considerably more than one sample at each site.

For example, in order to distinguish between two sites with respect to aluminum in the $A$ soil horizon (table 4 ), it would be necessary to collect a sufficient number of samples, $n$, within each site so that the observed $F$ ratio, estimated by

$$
\frac{(0.016)+n(0.021)}{(0.016)}
$$

would exceed the critical $F$ at a stated level of probability for 1 and $2(n-1)$ degrees of freedom. In this case, for the 0.05 level of probability, $n$ must equal or exceed 4; at least four samples from the $\mathrm{A}$ horizon at each sample site would be required.

Comparison of mean element concentrations (tables $5-7)$ for various plant and soil media in the high- and low-deatih-rate areas serves to identify covariation between plant and soil compositions on a broad scale. For example, the generally lower concentrations of many elements in both soils and trees of the high-death-rate area (tables 6,7$)$, compared with those of the low-deathrate area, points to a broad-scale covariation between tree and soil chemistry. Such covariation, however, may or may not be present on a smaller scale-within either of the two areas. Covariation between soil and plant compositions within both the high- and low-death-rate areas was examined by means of product-moment cor- 
relation coefficients (tables 8-11). Correlation coefficients were also used to examine covariation among soil horizons (table 12), and between the stems and leaves of trees (table 13) within each of the two areas.

The correlation coefficients are based on logarithms of the element concentrations. In cases where the element was not detected in either the plant or the soil (or the stem or the leaf) at a sampling site, that site was not represented in the data used. Therefore, the bivariate frequency distributions on which the correlation coefficients are based are censored at either or both the leftmost or the lowermost extremes. The degree of censoring is indicated by the number of sites in which the element was not detected in either or both sampling media (tables 8-13).

In cases where the element was detected in both sampling media at all sampling sites (that is, $N=0$ on tables 8-13), the bivariate frequency distributions of the logarithmic concentrations are uncensored and approximately normal. The statistical significance of the correlation coefficients, in these cases, may be determined from widely available tables of critical values of $r$. However, where the element was not detected in either or both sampling media at one or more sites (for example, $N \neq 0$ on tables 8-13), the statistical significance of the correlation coefficient is indeterminable, and the coefficient must be regarded only as a relative index of covariation.

\section{RESULTS OF ANALYSES}

COMPOSITIONS OF VEGETABLES AND GARDEN SOILS

The contents of certain elements in samples of vegetables and garden soils from the two death-rate areas, expressed as geometric means (in percent), and the variations in contents expressed by geometric deviations are given in table 5. The ash content of vegetables also is provided to permit converting the amounts of elements in vegetable ashes into amounts in the oven-dry vegetables. The weight of samples before dehydration (wet weight) was not recorded; therefore, the element content of "fresh" vegetables cannot be computed from these data.

\section{COMPOSITIONS OF TREES AND UNCULTIVATED SOILS}

The contents of certain elements in samples of tree stems and leaves from the two death-rate areas, expressed as geometric means (in percent), and the variations in contents expressed by geometric deviations are given in table 6 . The ash contents of stems and leaves are also provided to permit converting the amounts of elements in the ashes into amounts in the oven-dry stems and leaves.
Data in table 6 show that leaves, when burned, yield about twice as much ash as do stems. This difference in yield is believed not to result from contamination of leaves by dust, but to be caused by the difference in element content of primary and secondary growth products. Leaves have only primary growth (originating in primary meristem); stems have, in addition, secondary growth (originating in the cambium). Secondary growth produces an increase in "dry weight" as a result of the synthesis of organic compounds (lignin, among others) without a corresponding increase in amounts of the elements that constitute ash. Therefore, if equal weights of dried stems and leaves are burned the organic compounds are oxidized, and a greater weight of ash remains from the burned leaves.

An examination of the element content in the ash of tree stems and leaves reveals the following tendencies in element concentration :

Concentration greater in the stems-barium, calcium, copper (for several species), lead, and strontium.

Concentration greater in the leaves-aluminum, iron, magnesium, potassium. tit:mium, ytterbium, and zirconium.

Apparently equal or approximately equal concentrations in stems and leaves-boron, chromium, copper (for most species), manganese, nickel (variable with species), and phosphorus.

The element contents of uncultivated soils from the two death-rate areas are given in table 7. The contents (geometric means) of elements are printed in italic if the differences in content between the two areas are significant. If the differences in the content of an element are significant in one soil horizon, they are also significant in the other two horizons, except for ytterbium in which only the A horizon has this difference.

In garden soils (table 5) and in uncultivated soils (table 7) the same elements exist but in concentrations that are significantly different in the two death-rate areas. This fact suggests that cultivation practices over a period of years have not greatly altered the contents of many elements in garden soils.

\section{CORRESPONDENCE BETWEEN THE COMPOSITIONS OF PLANTS AND SOILS}

The correspondence between amounts of chemical elements in plants and those in soils in the areas studied can be examined, with the data available, on two scales. Correlation on a broad statewide scale may be examined by comparing the average plant and soil compositions for the high- and low-death-rate areas (tables 5-7). Correlation on a more detailed scale, between plant and 
TABLE 5.-Ash contents of vegetables and element contents of vegetable ashes and garden $[G M$, geometric mean (in percent); $G D$ geometric deviation; $N$, number of samples in which the element was not detected; ...., insufficient data; geometric means are in John B. McHugh, Harriet Neiman, A. L. Sutton, Jr.

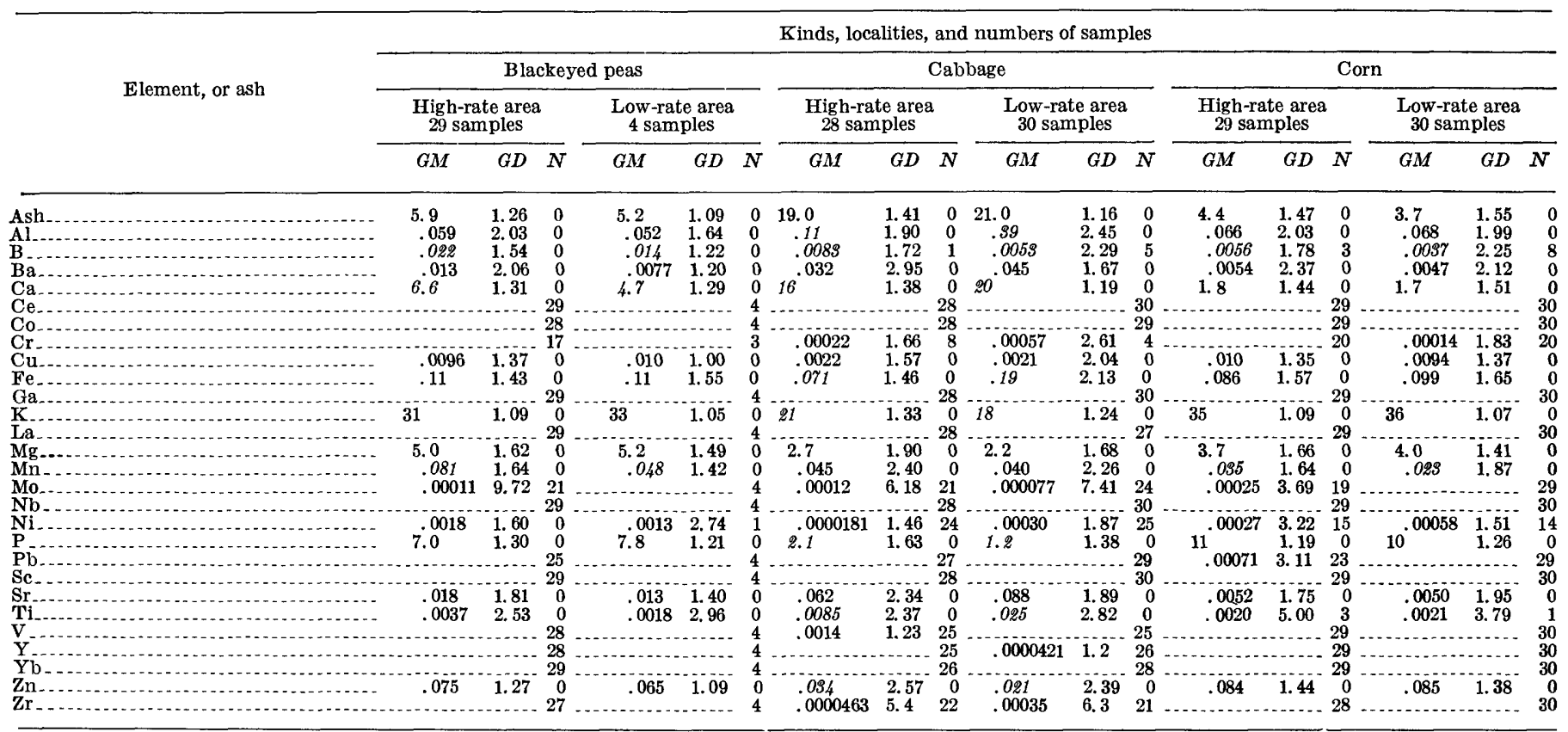

soil compositions within the high- and low-death-rate areas, has been examined by means of correlation coefficients (tables 8-11).

The concentration of some elements in soil (in an available form) is commonly assumed to determine the amount that the plant will absorb, unless the element is present in extremely large, or toxic, quantities or as toxic compounds. The major and minor essential elements obviously must be absorbed in quantities sufficient for metabolism of the plant, regardless of their relative 
soils from two areas in Georgia that have different cardiovascular mortality rates

italic where they are significantly different for the high- and low-death-rate areas at the 95-percent level of confidence. Analysts: John C. Hamilton, Thelma F. Harms, Barbara Tobin, and James $H$. Turner]

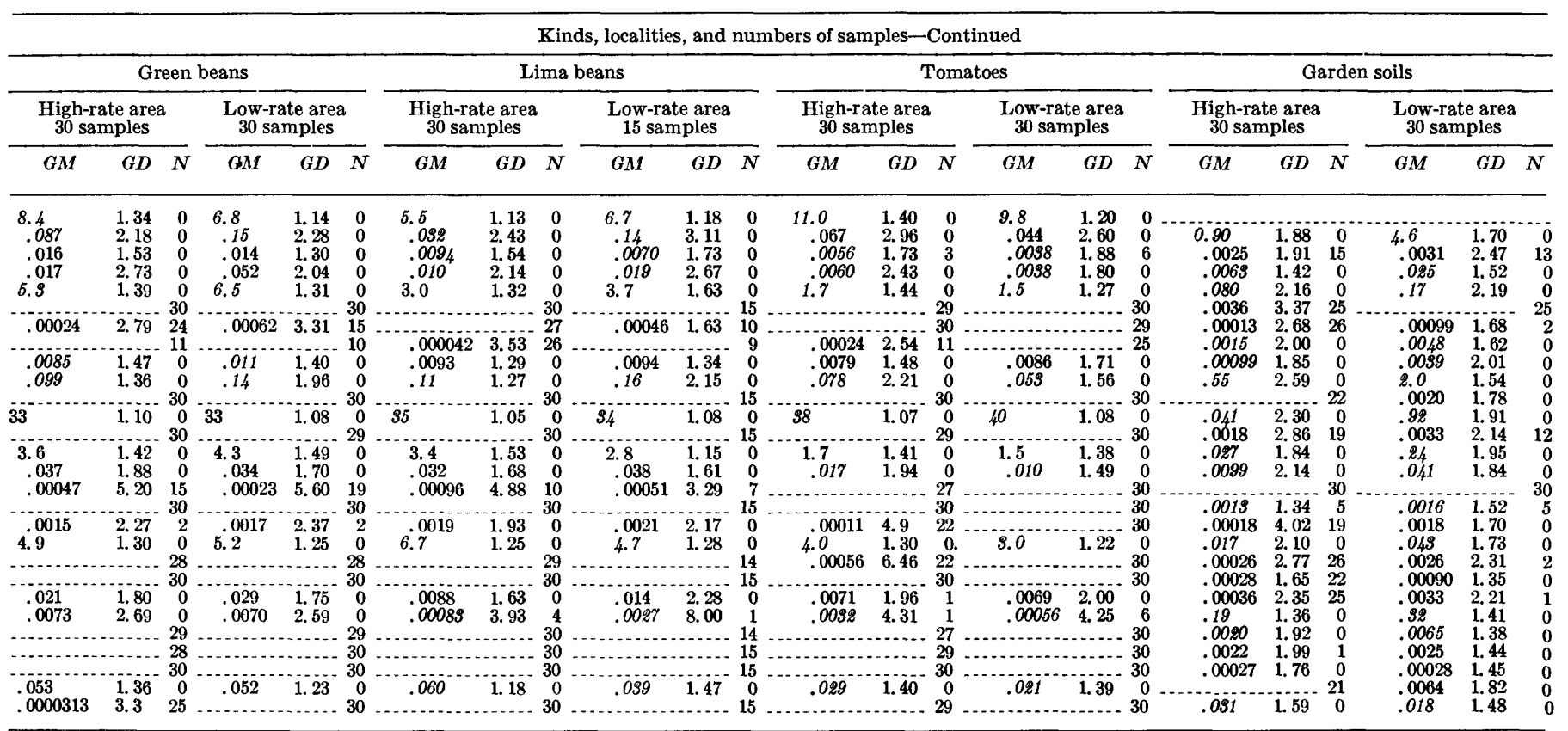

abundances in the soil, or the plant could not live. It is generally known, however, that many plants may absorb larger quantities of these elements than are required for metabolic processes, if large amounts are available in the soil-the so-called luxury consumption of elements by plants. Controlling factors in the absorption of the nonnutritive elements are poorly understood. A discussion of the complex chemical and physiological processes involved in the absorption of elements by plants is beyond the scope of this report. (See Sutcliffe, 1962.) 
TABLE 6.-Ash contents of trees and element contents of tree ashes from $G M$, geometric mean (in percent); $G D$, geometric deviation; $N$, number of samples in which the element was not detected; ..... insufficient data: geometric means are in

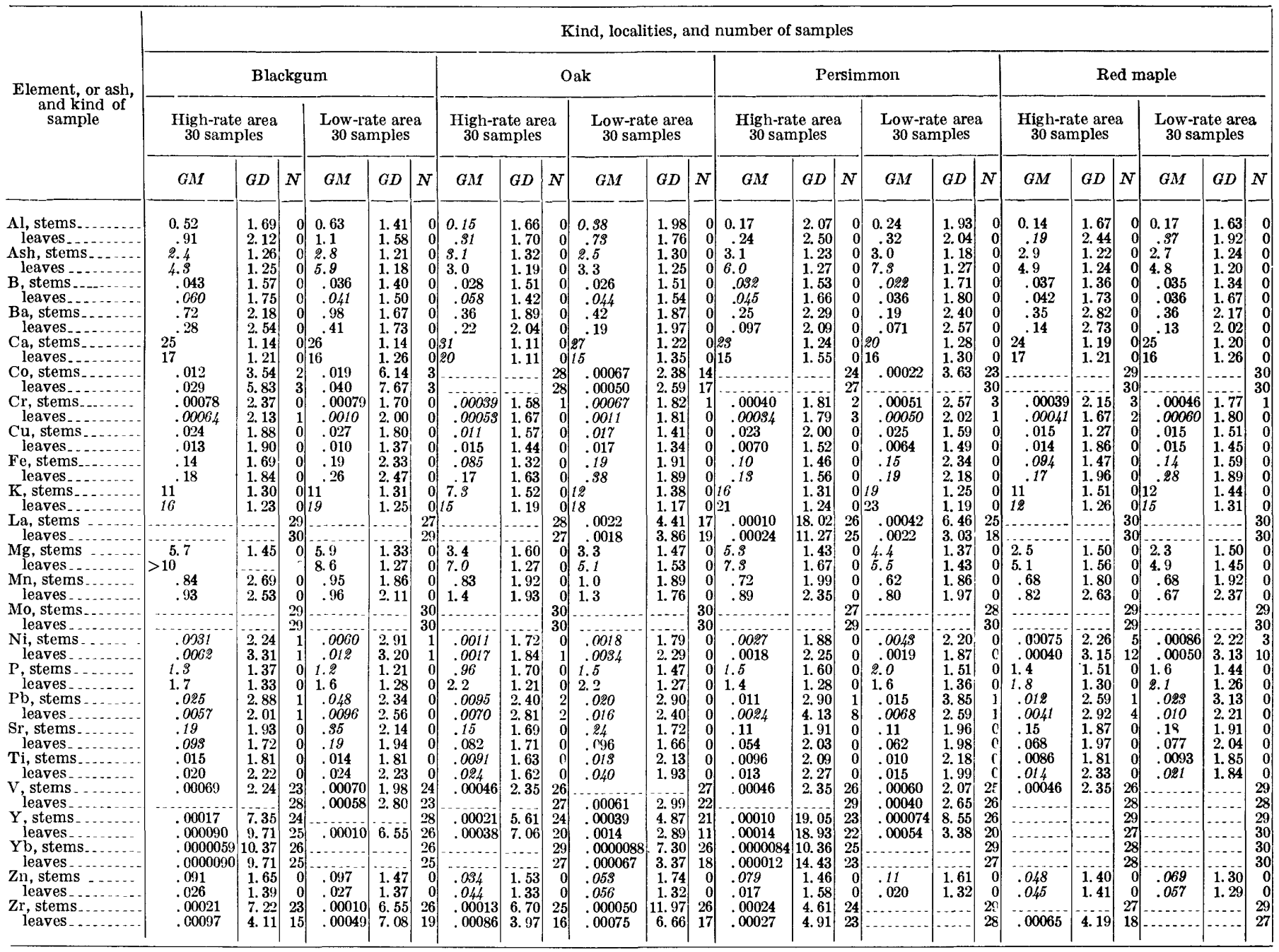


two areas in Georgia that have different cardiovascular mortality rates

italic where they are significantly different for the high- and low-death-rate areas at the 95-percent level of confidence. Analysts: John C. Hamilton, Thelma F. Harms, Barbara Tobin, and James H. Turner]

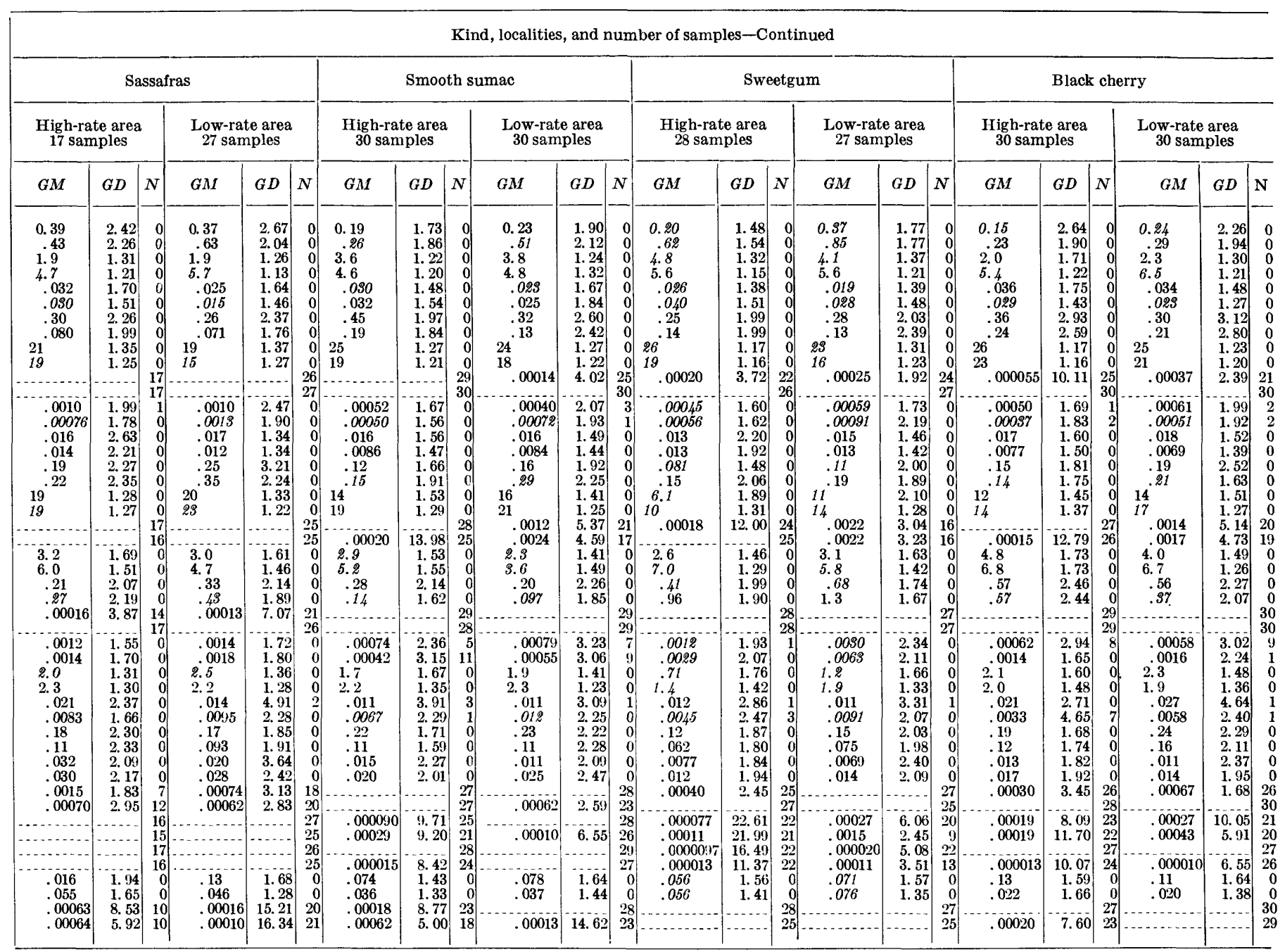


TABLE 7.-Element contents of uncultivated soils from two areas in Georgia that have different cardiovascular mortality rates

[ $G M$, geometric mean (in percent); $G D$, geometric deviation; $N$, number of samples in which the element was not detected; -..... insufficient data; geometric means are in italic where they are significantly different for the high- and low-death-rate areas at the 95 -percent level of confidence. Analysts: John C. Hamilton, Thelma F. Harms, John B. McHugh, Harriet Neiman, A. L. Sutton, Jr., Barbara Tobin, and James H. Turner

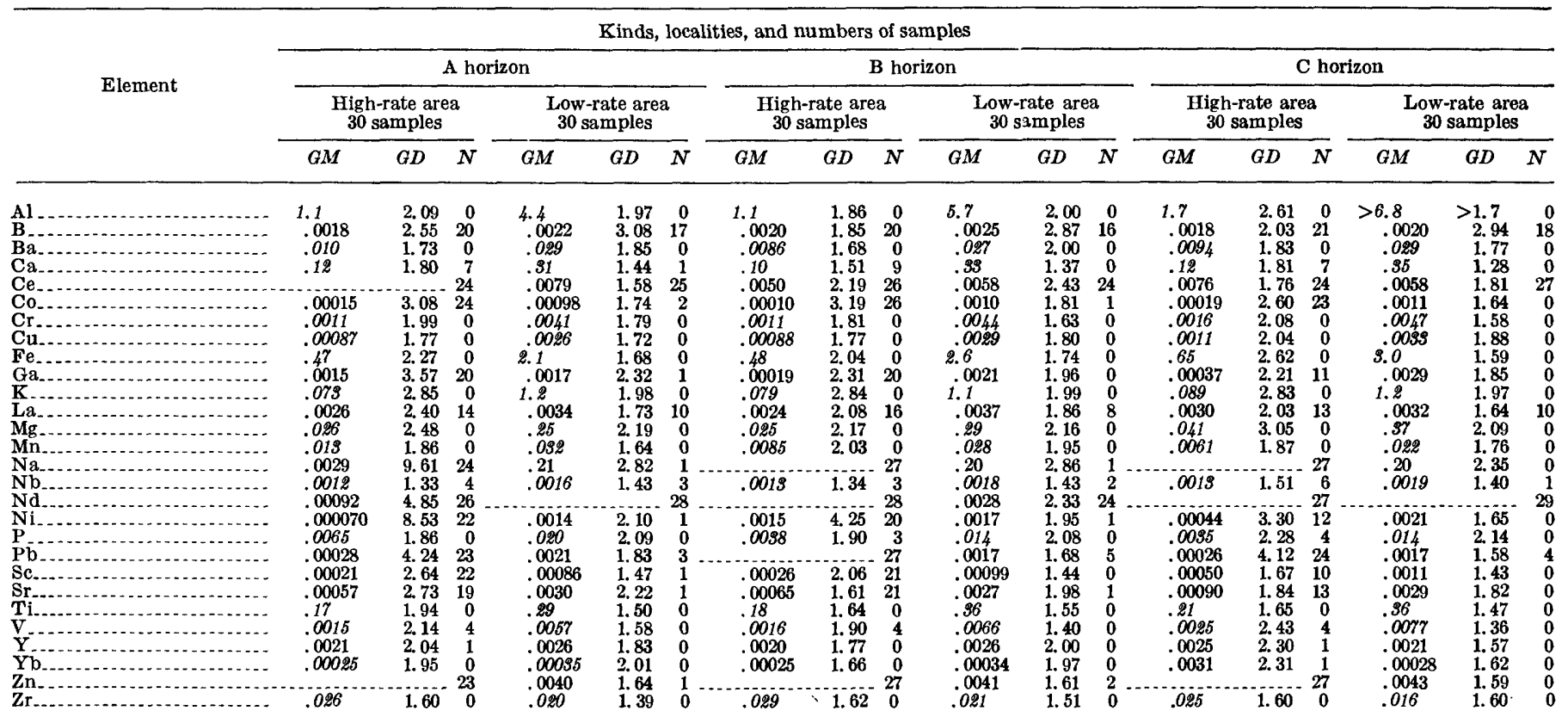

The diagrams in figures $3-6$ provide graphical summaries of the correlation coefficients in tables 8-11. All the diagrams are similarly constructed. The diagrsım in figure 3 , for example, summarizes the correlations between element contents in each of six vegetables and the soils of the gardens in which the vegetables grew. The garden soil is represented by the point at the center of the circular diagram. Each radius extending from this point represents a garden vegetable, as indicated. The distance of each point on the radius from the center of the circle is inversely proportional to the degree of positive correlation between the element content of the particular vegetable and the garden soil, among the sampling sites. Where the point lies near the center of the circle, the concentration of the element in the indicated vegetable shows a high degree of positive correlation with the concentration of the element in the soil.
Where the point lies near the inner circle, the concentration of the element in the vegetable is estimated to be nearly independent of the amount of the element in the soil. Where the point lies near the outer circumference of the circle, the concentration of the element in the vegetable displays a negative correlation with the concentration of the element in the soil; that is, vegetables containing higher concentrations of the element tend to occur in gardens where the concentration of the element in the soil is relatively low.

Figures 4, 5, and 6 contain similar diagrams summarizing the correlations of elements in the stems and leaves of trees with the amounts of the elements in the $\mathrm{C}, \mathrm{B}$, and A soil horizons, respectively. They also summarize the correlations of element concentrations among the three soil horizons. 
GEOCHEMICAL ENVIRONMENTS, CARDIOVASCULAR MORTALITY RATES, GEORGIA

TABLE 8.-Correlations between the amounts of elements in vegetables and garden soils in the high-and low-death-rate areas of Georgia $[r$, product-moment correlation coefficient between logarithms of concentrations; $N$, number of pairs ommitted because concentration of element in one or both kinds of samples (vegetable or soil) was beyond the range of measurement by the analytical methods that were used; ....., insufficient data]

\begin{tabular}{|c|c|c|c|c|c|c|c|c|c|c|c|c|c|c|c|c|c|c|c|c|c|c|c|c|}
\hline \multirow{3}{*}{ Element } & \multicolumn{4}{|c|}{ Blackeyed peas } & \multicolumn{4}{|c|}{ Cabbage } & \multicolumn{4}{|c|}{ Corn } & \multicolumn{4}{|c|}{ Green beans } & \multicolumn{4}{|c|}{ Lima beans } & \multicolumn{4}{|c|}{ Tomatoes } \\
\hline & \multicolumn{2}{|c|}{$\begin{array}{l}\text { High- } \\
\text { death-rate } \\
\text { area, 29 } \\
\text { pairs }\end{array}$} & \multicolumn{2}{|c|}{$\begin{array}{l}\text { Low- } \\
\text { death-rate } \\
\text { area, } 4 \\
\text { pairs }\end{array}$} & \multicolumn{2}{|c|}{$\begin{array}{c}\text { High- } \\
\text { death-rate } \\
\text { area, 28 } \\
\text { pairs }\end{array}$} & \multicolumn{2}{|c|}{$\begin{array}{l}\text { Low- } \\
\text { death-rate } \\
\text { area, } 30 \\
\text { pairs }\end{array}$} & \multicolumn{2}{|c|}{$\begin{array}{l}\text { High- } \\
\text { death-rate } \\
\text { area, 29 } \\
\text { pairs }\end{array}$} & \multicolumn{2}{|c|}{$\begin{array}{l}\text { Low- } \\
\text { death-rate } \\
\text { area, 30 } \\
\text { pairs }\end{array}$} & \multicolumn{2}{|c|}{$\begin{array}{l}\text { High- } \\
\text { death-rate } \\
\text { area, } 30 \\
\text { pairs }\end{array}$} & \multicolumn{2}{|c|}{$\begin{array}{l}\text { Low- } \\
\text { death-rate } \\
\text { area, } 30 \\
\text { pairs }\end{array}$} & \multicolumn{2}{|c|}{$\begin{array}{l}\text { High- } \\
\text { death-rate } \\
\text { area, } 30 \\
\text { pairs }\end{array}$} & \multicolumn{2}{|c|}{$\begin{array}{l}\text { Low- } \\
\text { death-rate } \\
\text { area, } 15 \\
\text { pairs }\end{array}$} & \multicolumn{2}{|c|}{$\begin{array}{l}\text { High- } \\
\text { death-rate } \\
\text { area, } 30 \\
\text { pairs }\end{array}$} & \multicolumn{2}{|c|}{$\begin{array}{l}\text { Low- } \\
\text { death-rate } \\
\text { area, 30 } \\
\text { pairs }\end{array}$} \\
\hline & $r$ & $N$ & $r$ & $N$ & $r$ & $N$ & $r$ & $N$ & $r$ & $N$ & $r$ & $N$ & $r$ & $N$ & $r$ & $N$ & $r$ & $N$ & $r$ & $N$ & $r$ & $N$ & T & $N$ \\
\hline $\begin{array}{l}\mathrm{Cr} \\
\mathrm{Cu} \\
\mathrm{Fe} \\
\mathrm{K} \\
\mathrm{Mg} \\
\mathrm{Mn} \\
\mathrm{Ni} \\
\mathrm{P} \\
\mathrm{Sr} \\
\mathrm{Ti} \\
\mathrm{V}\end{array}$ & $\begin{array}{r}0.38 \\
.05 \\
.14 \\
.06 \\
-.08 \\
-.05 \\
-.09 \\
-.39 \\
.23 \\
-.09 \\
.11 \\
.20 \\
-.72 \\
-.13 \\
. . .\end{array}$ & $\begin{array}{r}0 \\
14 \\
0 \\
0 \\
28 \\
17 \\
0 \\
0 \\
0 \\
0 \\
0 \\
18 \\
0 \\
24 \\
0 \\
28\end{array}$ & $\begin{array}{r}-0.68 \\
-.83 \\
-.75 \\
-.00 \\
-.04 \\
.76 \\
-.04 \\
. .65 \\
-.05 \\
-.89 \\
-.53\end{array}$ & $\begin{array}{l}1 \\
2 \\
0 \\
0 \\
4 \\
3 \\
0 \\
0 \\
0 \\
0 \\
0 \\
1 \\
0 \\
1 \\
0 \\
4\end{array}$ & $\begin{array}{r}0.45 \\
.36 \\
.53 \\
.06 \\
.10 \\
-.11 \\
.17 \\
-.06 \\
.40 \\
.17 \\
. .11 \\
-.77 \\
-.17\end{array}$ & $\begin{array}{r}0 \\
13 \\
0 \\
0 \\
28 \\
8 \\
0 \\
0 \\
0 \\
0 \\
0 \\
27 \\
0 \\
23 \\
0 \\
25\end{array}$ & $\begin{array}{r}0.19 \\
.18 \\
-.19 \\
.25 \\
-.11 \\
.50 \\
.22 \\
-.07 \\
.03 \\
.20 \\
.50 \\
-.06 \\
-.08 \\
-.09 \\
-.37\end{array}$ & $\begin{array}{r}4 \\
15 \\
0 \\
0 \\
29 \\
4 \\
0 \\
0 \\
0 \\
0 \\
0 \\
25 \\
0 \\
1 \\
0 \\
25\end{array}$ & $\begin{array}{r}0.13 \\
-.01 \\
.20 \\
.12 \\
.30 \\
-.10 \\
-.08 \\
-.41 \\
.28 \\
-.08 \\
-.92 \\
.07 \\
-.41 \\
.26 \\
-. .\end{array}$ & $\begin{array}{r}0 \\
16 \\
0 \\
0 \\
29 \\
20 \\
0 \\
0 \\
0 \\
0 \\
0 \\
26 \\
0 \\
24 \\
3 \\
29\end{array}$ & $\begin{array}{r}-0.16 \\
.17 \\
-.44 \\
.00 \\
.25 \\
.08 \\
.19 \\
.16 \\
.42 \\
-.10 \\
.45 \\
-.16 \\
-.34 \\
.01\end{array}$ & $\begin{array}{r}4 \\
18 \\
0 \\
0 \\
-30 \\
20 \\
0 \\
0 \\
0 \\
0 \\
0 \\
14 \\
0 \\
1 \\
1\end{array}$ & $\begin{array}{c}0.26 \\
-.37 \\
.14 \\
.00 \\
-.10 \\
-.39 \\
-.09 \\
-.28 \\
-.11 \\
-.27 \\
.44 \\
.11 \\
.25 \\
.07\end{array}$ & $\begin{array}{r}0 \\
15 \\
0 \\
0 \\
29 \\
11 \\
0 \\
0 \\
0 \\
0 \\
0 \\
20 \\
0 \\
25 \\
0 \\
29 .\end{array}$ & $\begin{array}{r}0.11 \\
.12 \\
.13 \\
-.03 \\
.50 \\
.14 \\
.49 \\
.05 \\
-.02 \\
.21 \\
.09 \\
.07 \\
-.02 \\
.02 \\
.01\end{array}$ & $\begin{array}{c}4 \\
13 \\
0 \\
0 \\
15 \\
10 \\
0 \\
0 \\
0 \\
0 \\
0 \\
2 \\
0 \\
1 \\
0\end{array}$ & $\begin{array}{r}0.13 \\
-.24 \\
-13 \\
-.11 \\
.00 \\
-.34 \\
-.31 \\
-.03 \\
-.03 \\
-.08 \\
.08 \\
-.10 \\
. .22 \\
-.01 \\
-.49\end{array}$ & $\begin{array}{r}0 \\
15 \\
0 \\
0 \\
28 \\
26 \\
0 \\
0 \\
0 \\
0 \\
0 \\
19 \\
0 \\
25 \\
4 \\
30\end{array}$ & $\begin{array}{r}0.29 \\
-.46 \\
-.19 \\
-.29 \\
-.94 \\
.16 \\
-.65 \\
.06 \\
.29 \\
-.22 \\
.44 \\
.15 \\
-.53 \\
.18 \\
.06\end{array}$ & $\begin{array}{c}1 \\
9 \\
0 \\
0 \\
10 \\
9 \\
0 \\
0 \\
0 \\
0 \\
0 \\
0 \\
0 \\
1 \\
1 \\
14\end{array}$ & $\begin{array}{r}-0.18 \\
.05 \\
-.30 \\
.01 \\
-.26 \\
.09 \\
-.26 \\
.01 \\
-.02 \\
-.29 \\
-.13 \\
-.33 \\
-.41 \\
-.50\end{array}$ & $\begin{array}{r}0 \\
6 \\
10 \\
0 \\
-30 \\
11 \\
0 \\
0 \\
0 \\
0 \\
0 \\
-28 \\
0 \\
26 \\
1 \\
27\end{array}$ & $\begin{array}{r}-0.10 \\
-.36 \\
-.58 \\
.34 \\
.42 \\
.65 \\
-.12 \\
.24 \\
-.01 \\
.01 \\
.07 \\
.01 \\
-.10 \\
\end{array}$ & $\begin{array}{r}4 \\
18 \\
0 \\
0 \\
29 \\
25 \\
0 \\
0 \\
0 \\
0 \\
0 \\
0 \\
30 \\
0 \\
1 \\
6 \\
30\end{array}$ \\
\hline
\end{tabular}

\section{VEGETABLES AND GARDEN SOILS}

Comparison of the compositions of garden soils in the high- and low-death-rate areas indicates that those in the high death-rate area tend to contain significantly lower concentrations of nearly all elements studied (table 5). This difference, which reflects the difference in the character of the bedrock geology in the two areas and the greater maturity of the soil in the high-deathrate area, is not apparent in the compositions of most of the vegetables, with the possible exceptions of cabbage and green beans. Cabbages from the high-deathrate area, like the garden soils, tend to contain lower concentrations of aluminum, chromium, iron, nickel, and titanum; other elements, except for boron and molybdenum, appear to be about equally concentrated in cabbages from the two areas in spite of their generally higher concentrations in soils of the low-death-rate area. The concentrations of several elements in green beans similarly appear to reflect the compositional differences in the soils between the two areas, but those in the other vegetables, in general, do not.
The correlations between the element contents of vegetables and of garden soils within each of the two areas, as indicated by the correlation coefficients (fig. 3 and table 8), also fail to indicate any general relationship between vegetable and soil compositions. About half of the correlation coefficients are positive and half are negative, and there seems to be little or no consistency of correlation within elements, vegetables, or areas. The indication is that the greater number of the coefficients are spurious, resulting largely from chance, and are not reproducible.

It is reasonable to conclude, therefore, that the compositions of garden vegetables within both the highand the low-death-rate areas are generally independent of the compositions of the soils in which they are grown. Some correspondence between the composition of cabbages and green beans and the compositions of the soils does appear to be present, on a broader scale, between the high- and low-death-rate areas; these two vegetables tend to exhibit some of the same compositional differences as do the soils from the two areas. 
HIGH-DEATH-RATE AREA

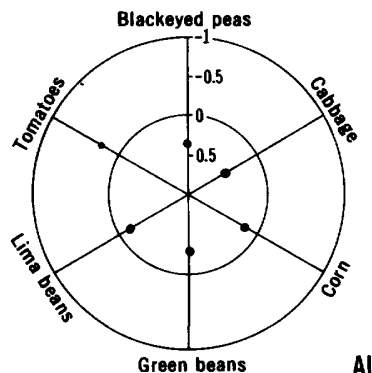

ALUMINUM

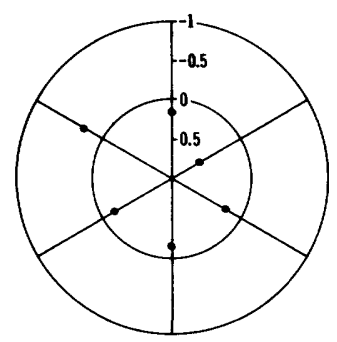

BARIUM

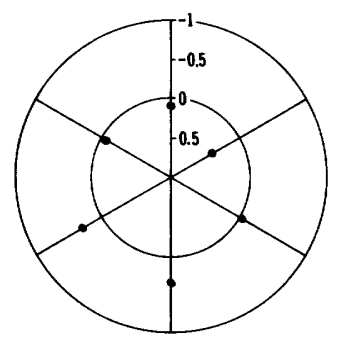

BORON

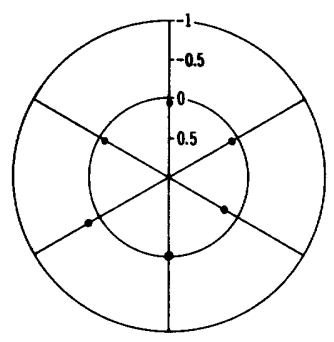

CALCIUM
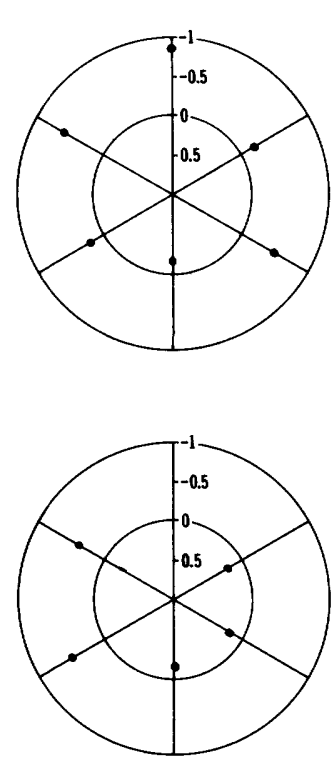

LOW-DEATH-RATE AREA
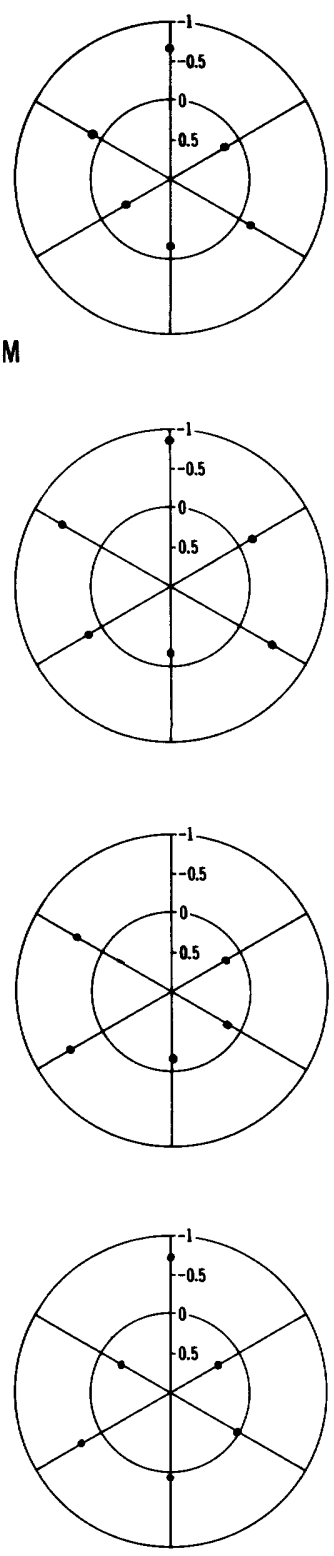

HIGH-DEATH-RATE AREA

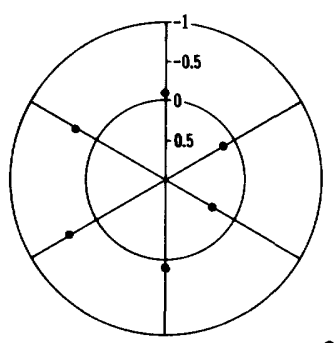

CHROMIUM

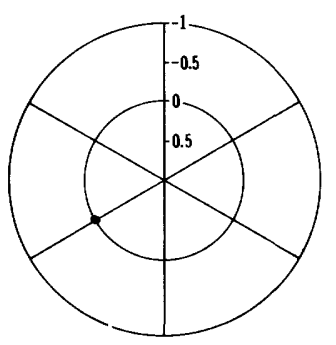

COBALT

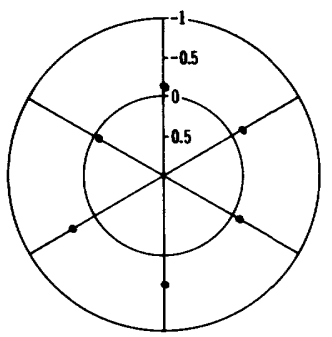

COPPER

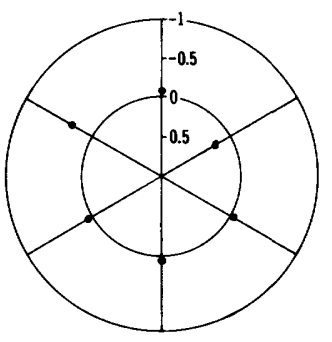

IRON
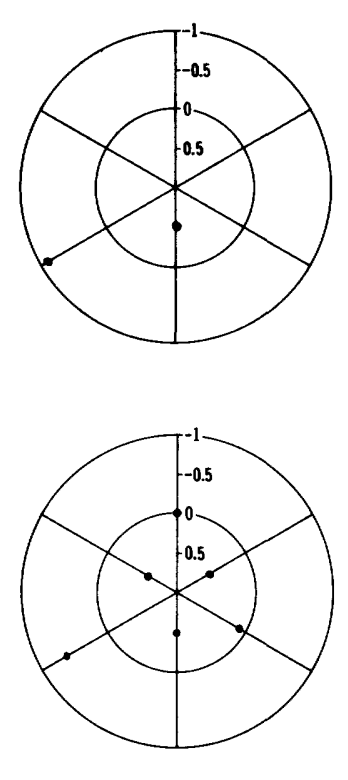

LOW-DEATH-RATE AREA
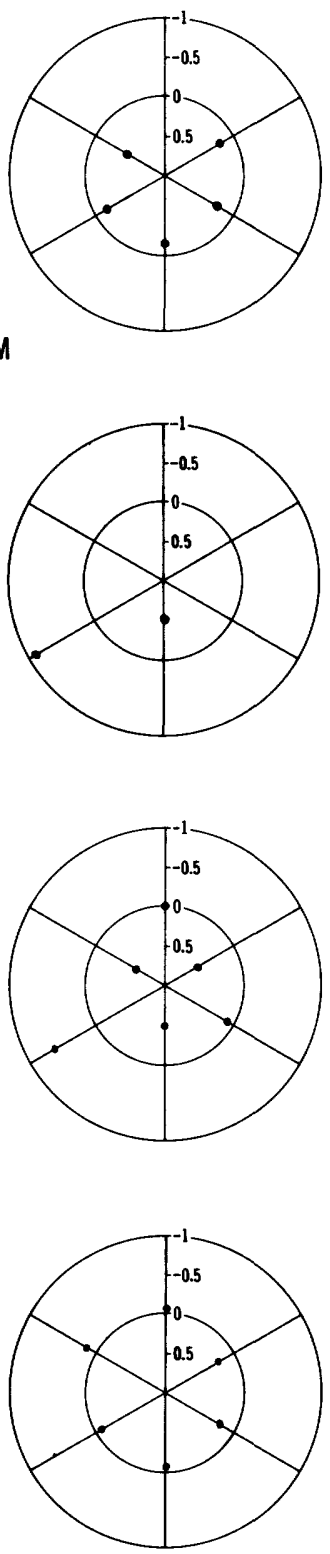

Figure 3.-Correlations between the amounts of elements in garden soils and the amounts in vegetables from the high and low cardiovascular death-rate areas of Georgia. Distance of the point on the radius from the center of the circle is inversely proportional to the correlation of the amount of the element in the vegetable and the amount in the garden soil. 
GEOCHEMICAL ENVIRONMENTS, CARDIOVASCULAR MORTALITY RATES, GEORGIA

HIGH-DEATH-RATE AREA

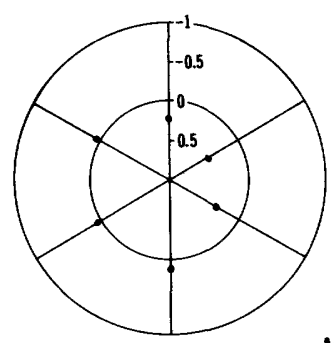

MAGNESIUM

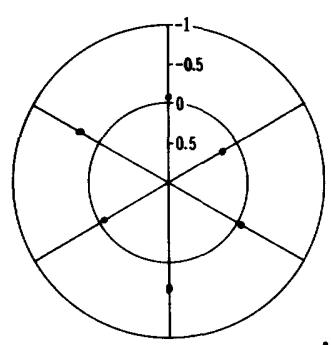

\section{MANGANESE}

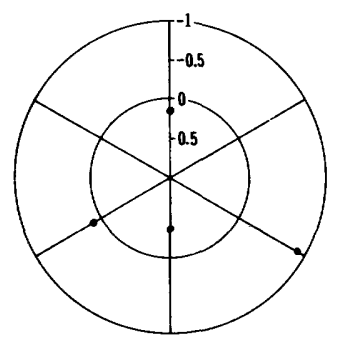

NICKEL

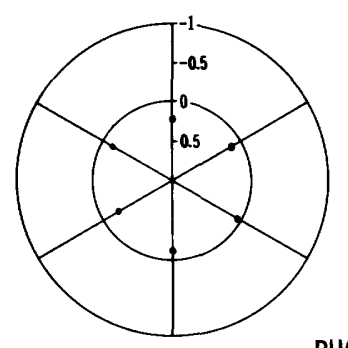

PHOSPHORUS



LOW-DEATH-RATE AREA
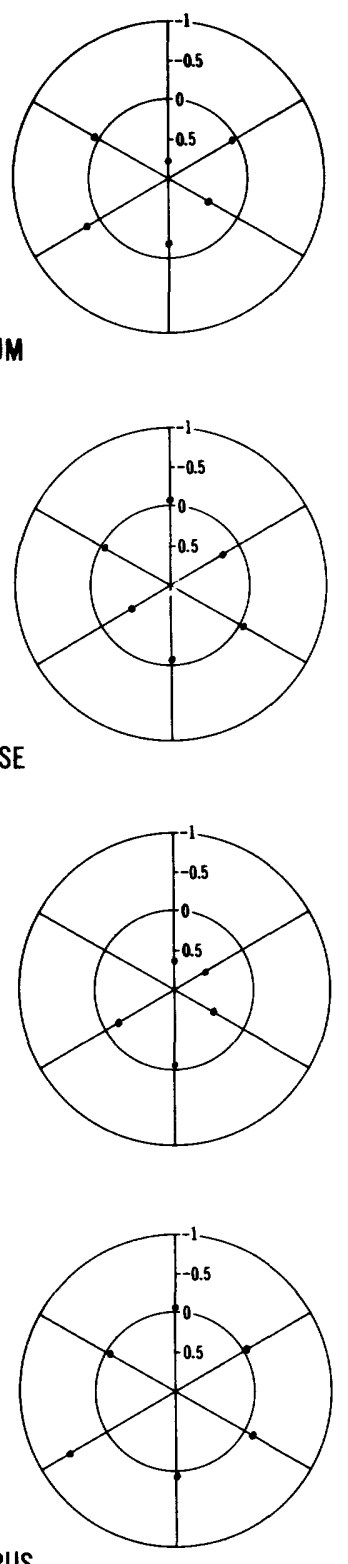

HIGH-DEATH-RATE AREA
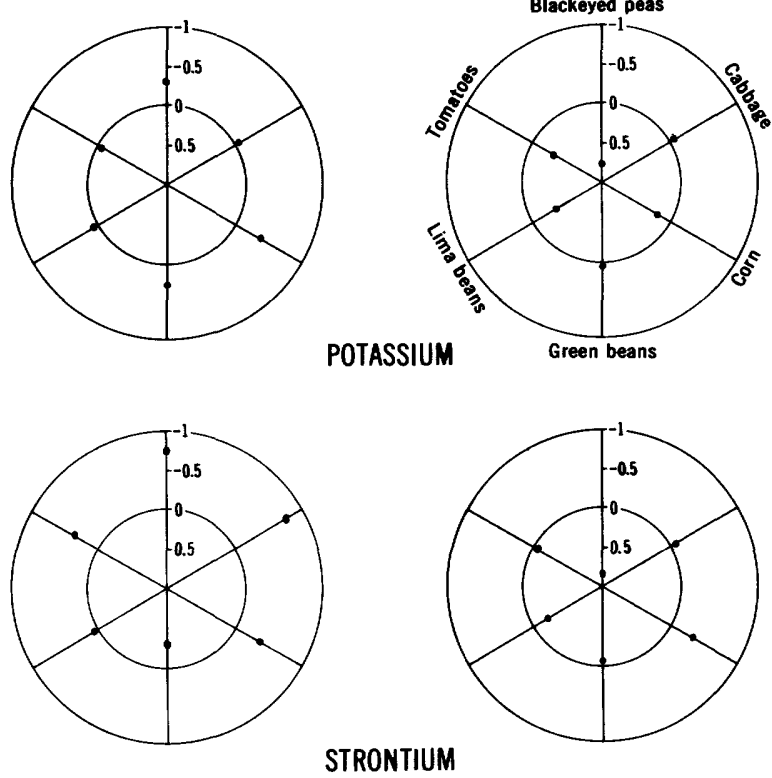

STRONTIUM

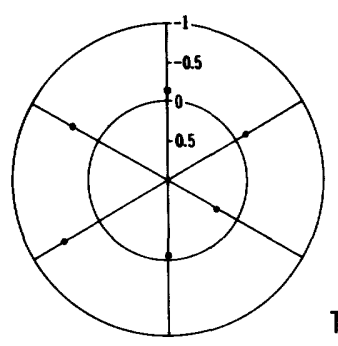

TITANIUM
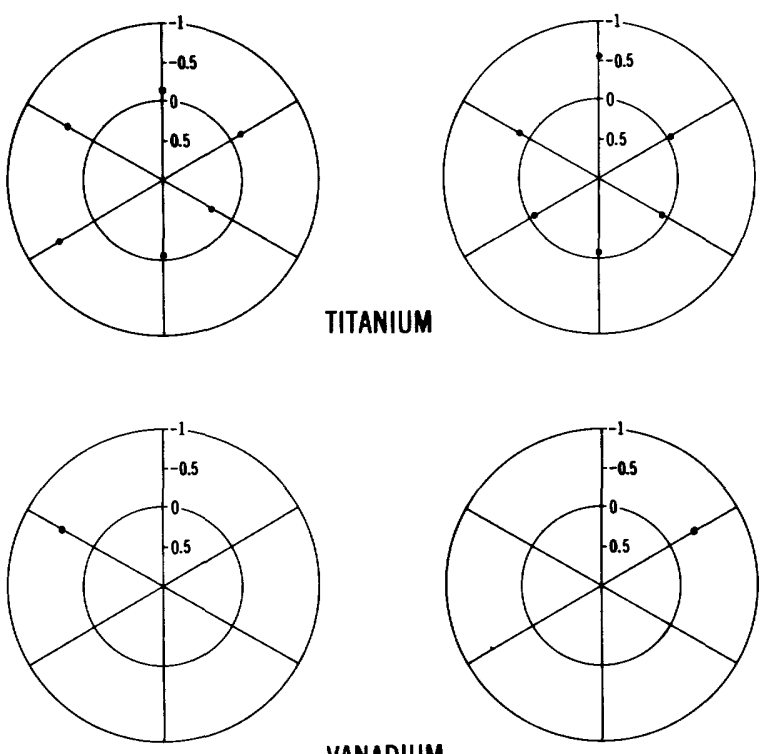

VANADIUM

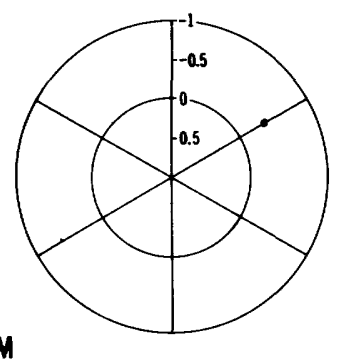

FIGURE 3.-Continued 


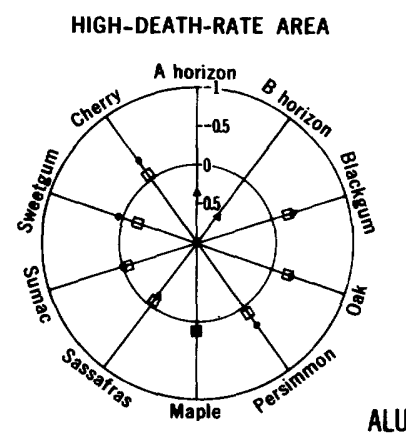

LOW-DEATH-RATE AREA



ALUMINUM

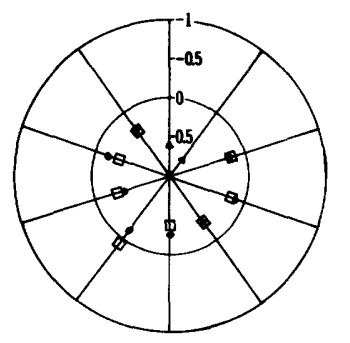

BARIUM
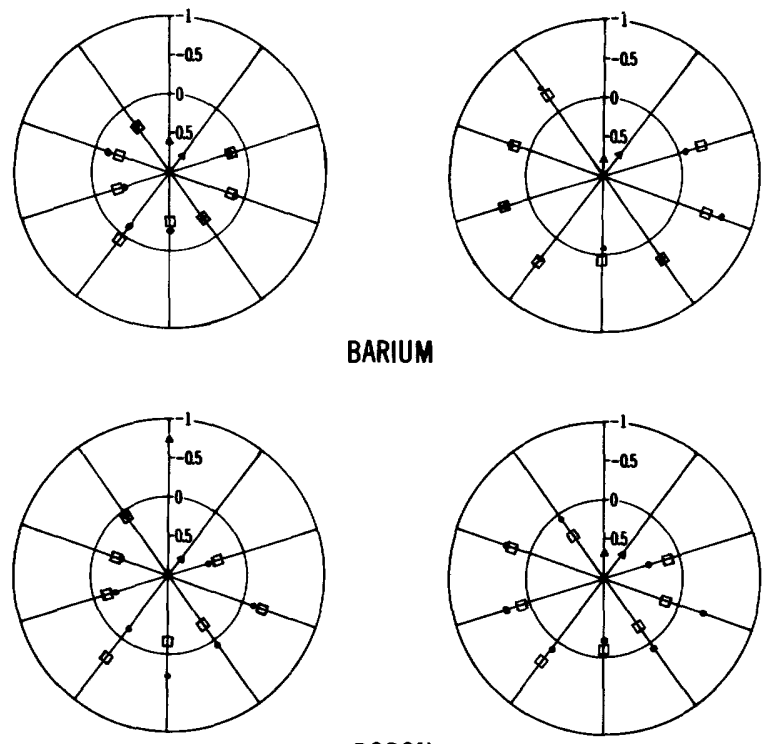

BORON
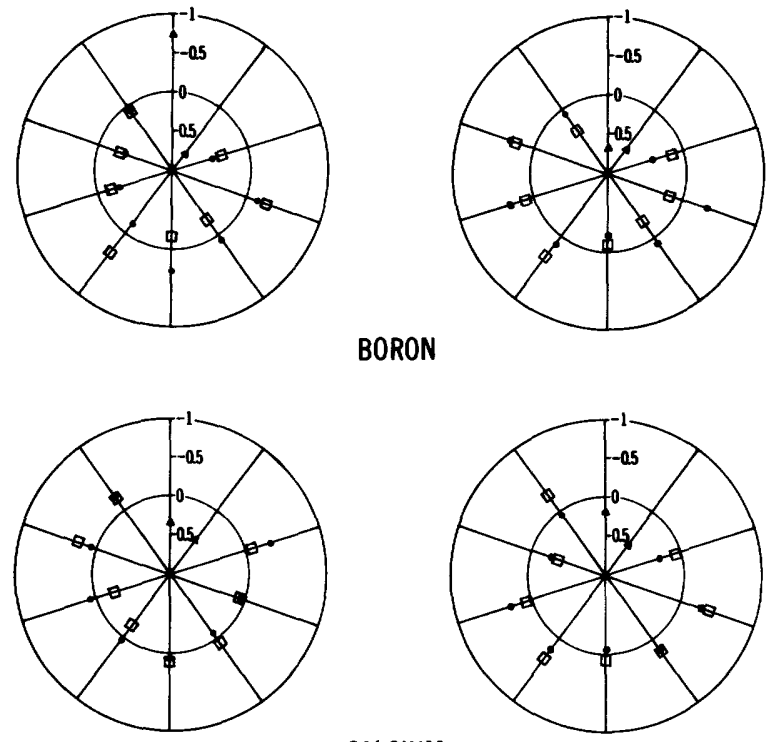

CALCIUM
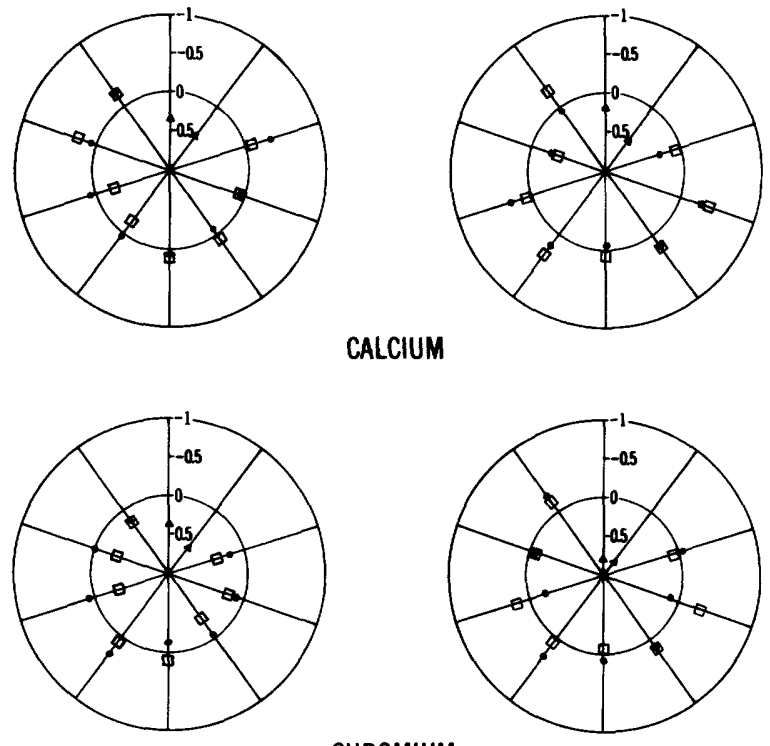

CHROMIUM
HIGH-DEATH-RATE AREA

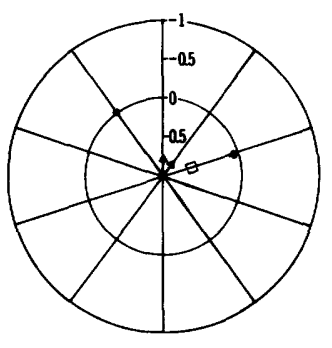

COBALT

LOW-DEATH-RATE AREA
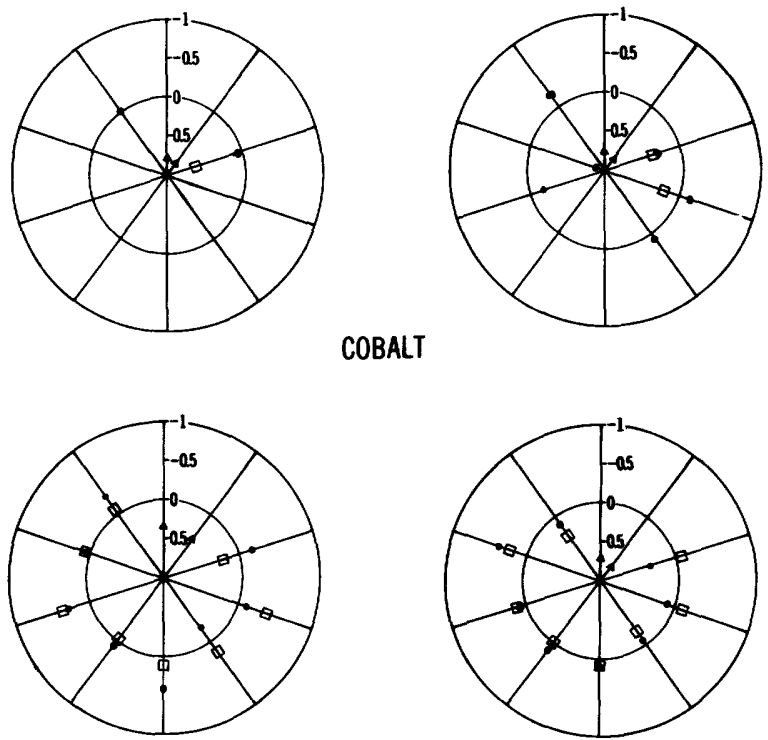

COPPER
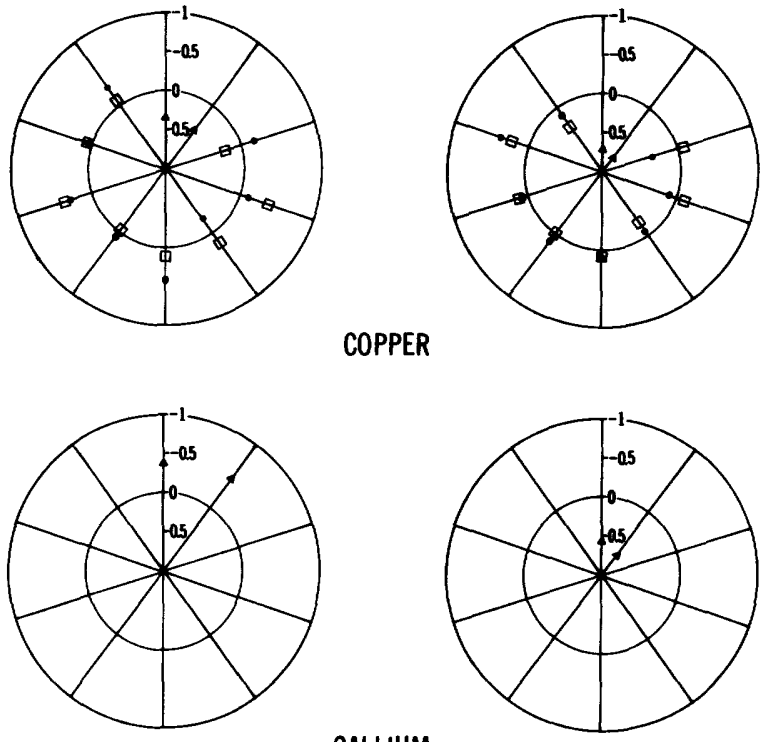

GALLIUM
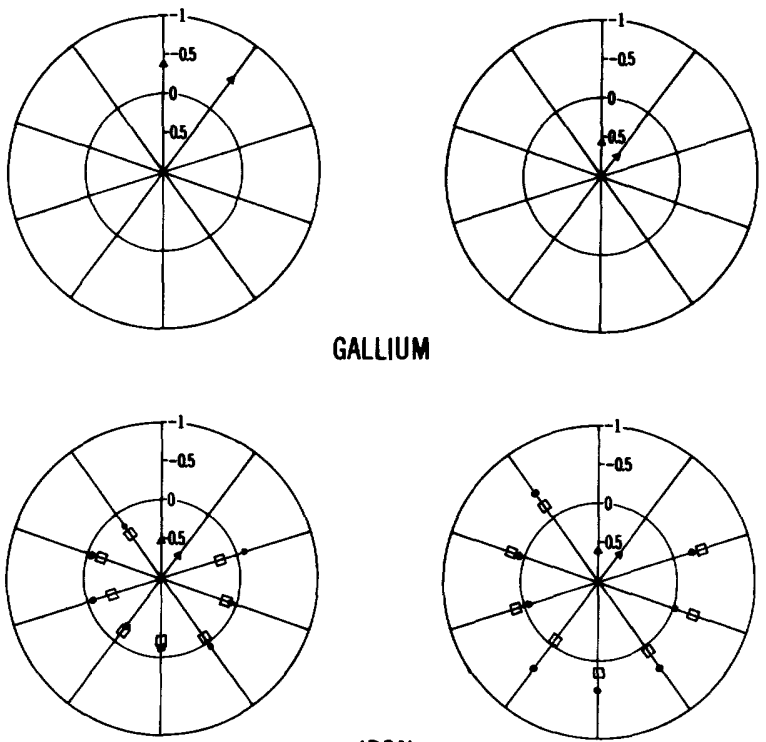

IRON
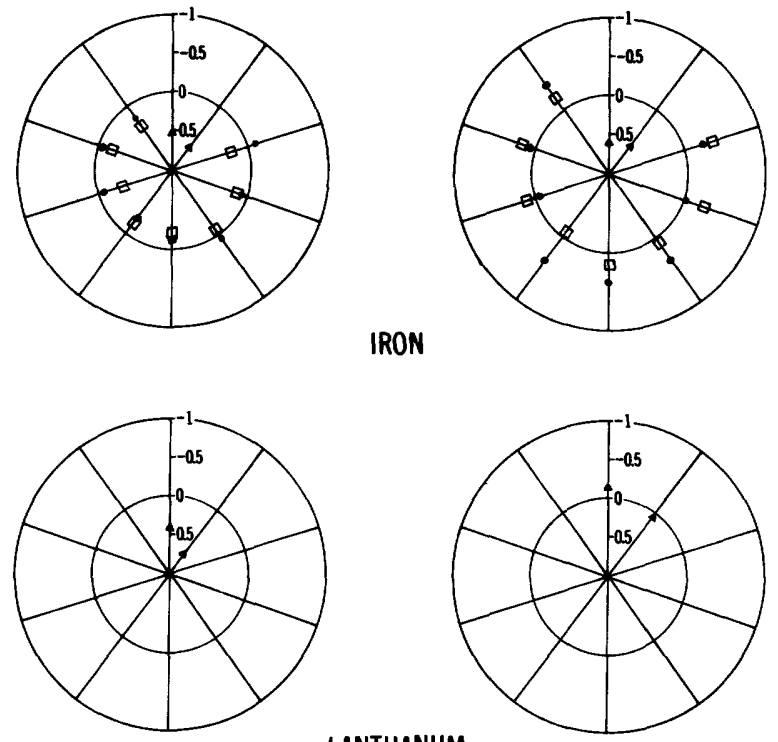

LANTHANUM

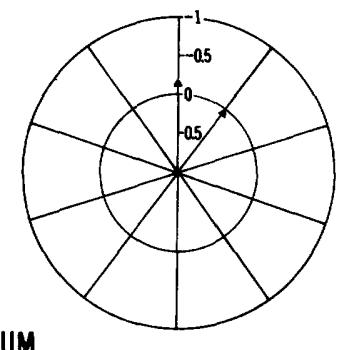

Figure 4.-Correlations between the amounts of elements in the $\mathrm{C}$ horizon of uncultivated soils (center of circles) and the amounts in the $A$ and $B$ soil horizons and in the stems and leaves of trees. Triangles represent soil correlations; dots represent stems, squares represent leaves, of trees. Distance of the symbols on the radii from the center of the circles is inversely proportional to the correlation of the amounts in the samples. 
GEOCHEMICAL ENVIRONMENTS, CARDIOVASCULAR MORTALITY RATES, GEORGIA

HIGH-DEATH-RATE AREA

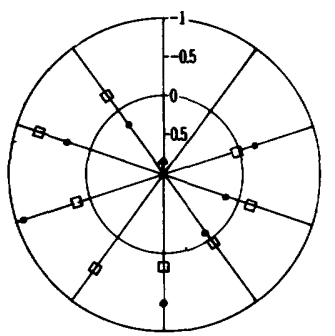

LEAD

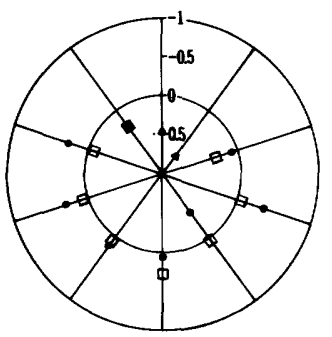

MAGNESIUM

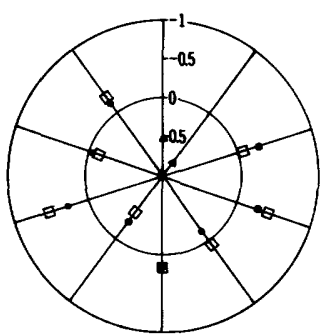

MANGANESE

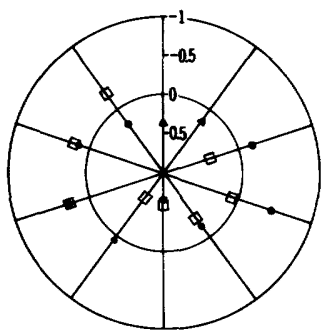

NICKEL
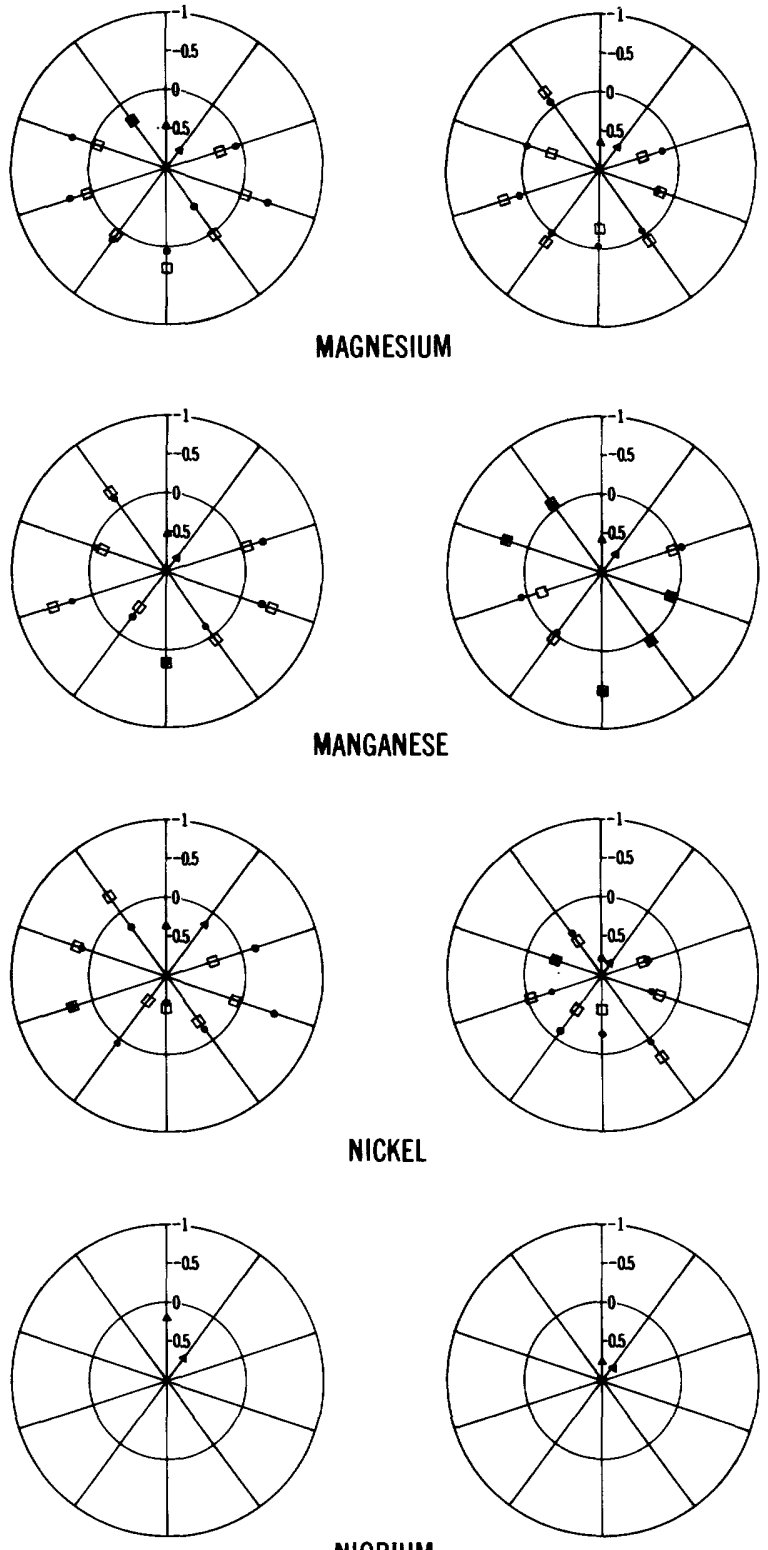

NIOBIUM

LOW-DEATH-RATE AREA

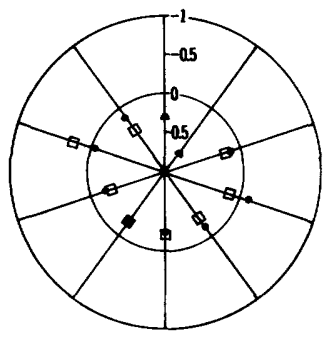



PHOSPHORUS

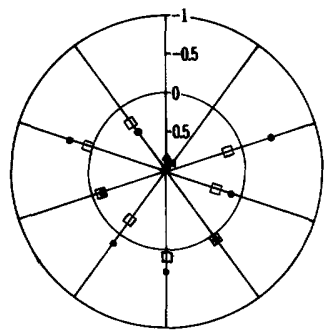

POTASSIUM
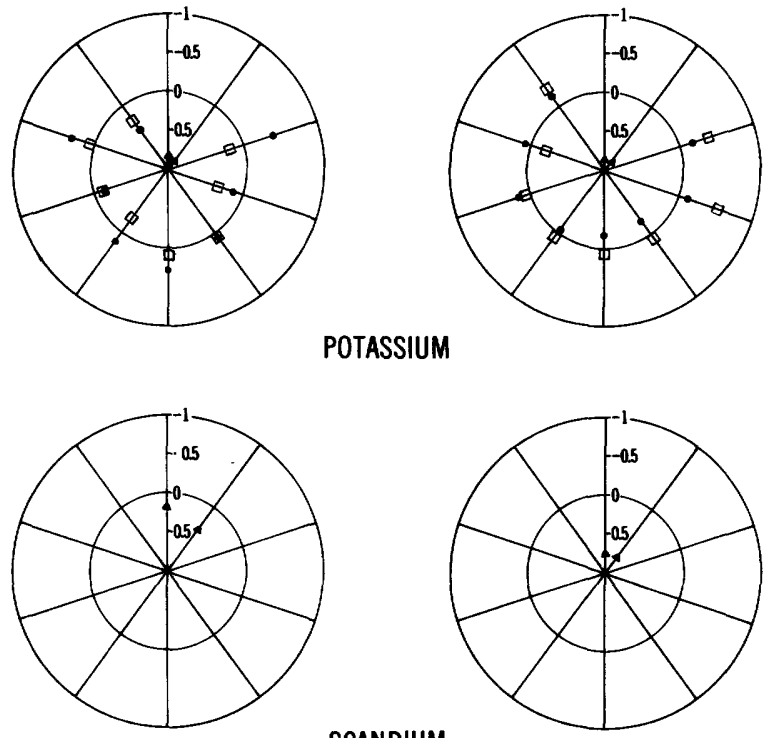

SCANDIUM
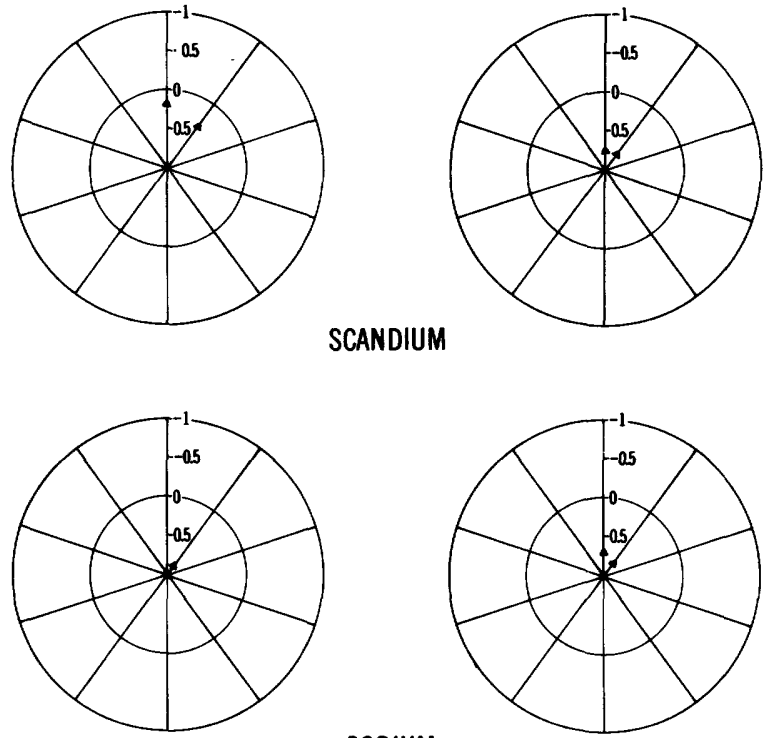

SODIUM
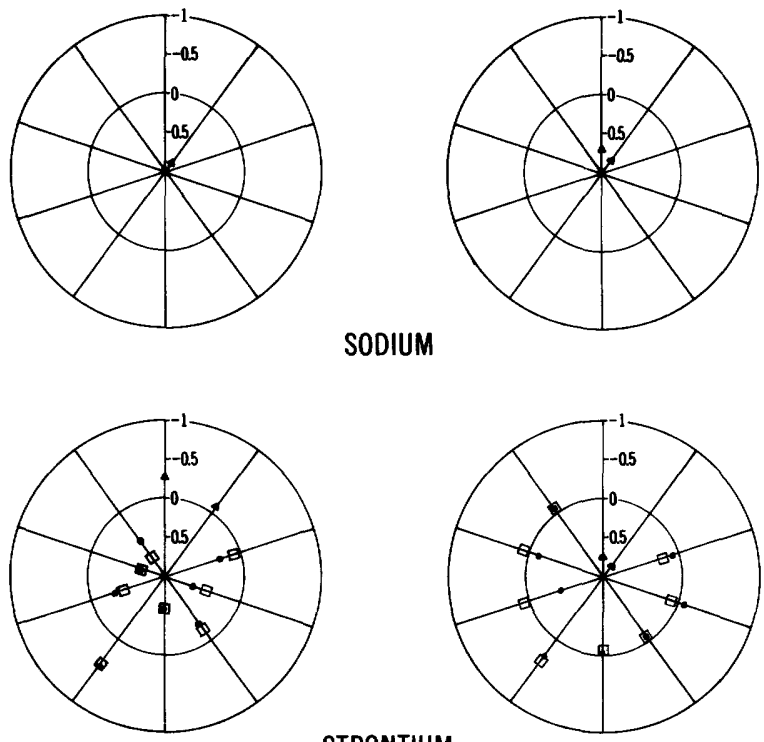

STRONTIUM

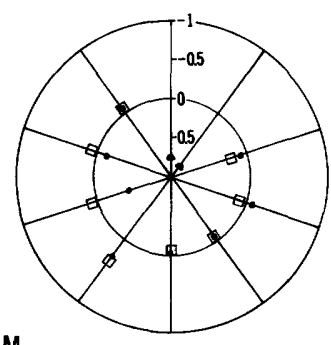

Figure $4 .-$ Continued 
C24

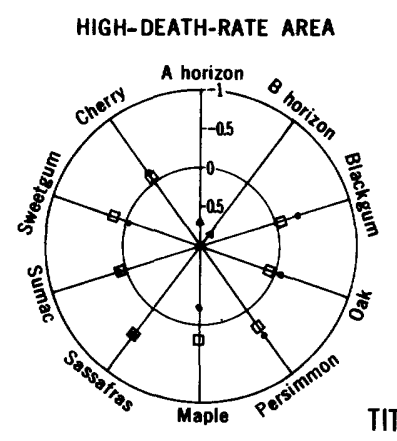

TITANIUM

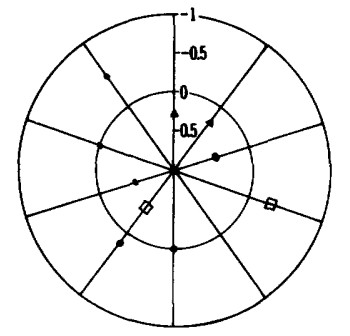

VANADIUM

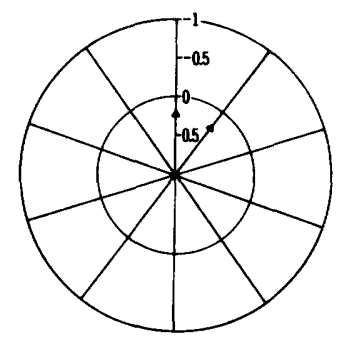

YTTERBIUM
STATISTICAL STUDIES IN FIELD GEOCHEMISTRY

LOW-DEATH-RATE AREA

HIGH-DEATH-RATE AREA

LOW-DEATH-RATE AREA

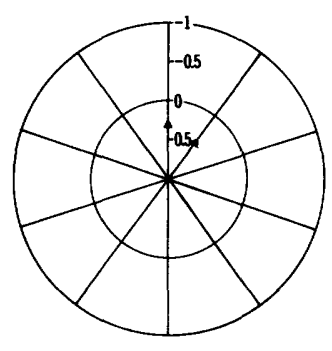

YTTRIUM
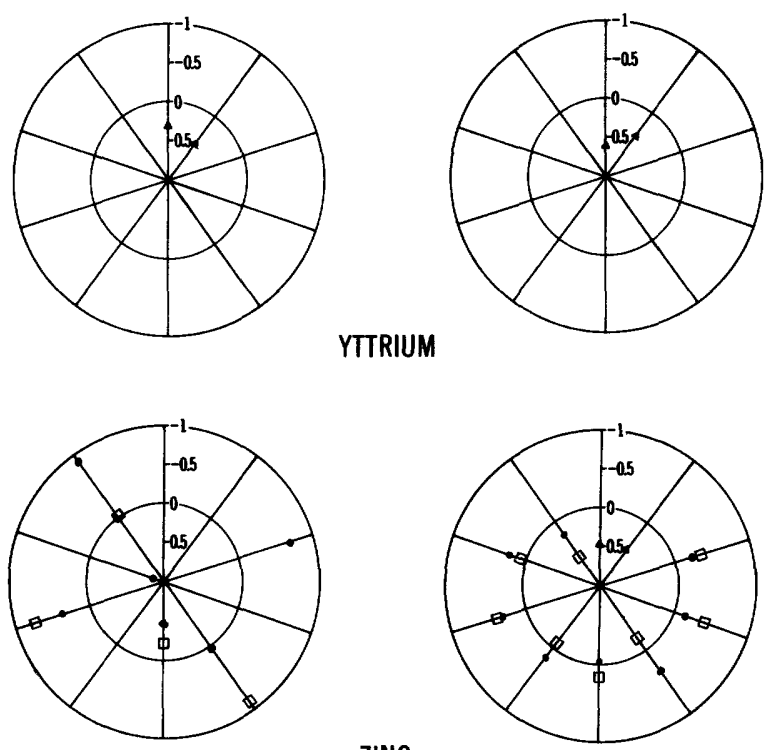

ZINC
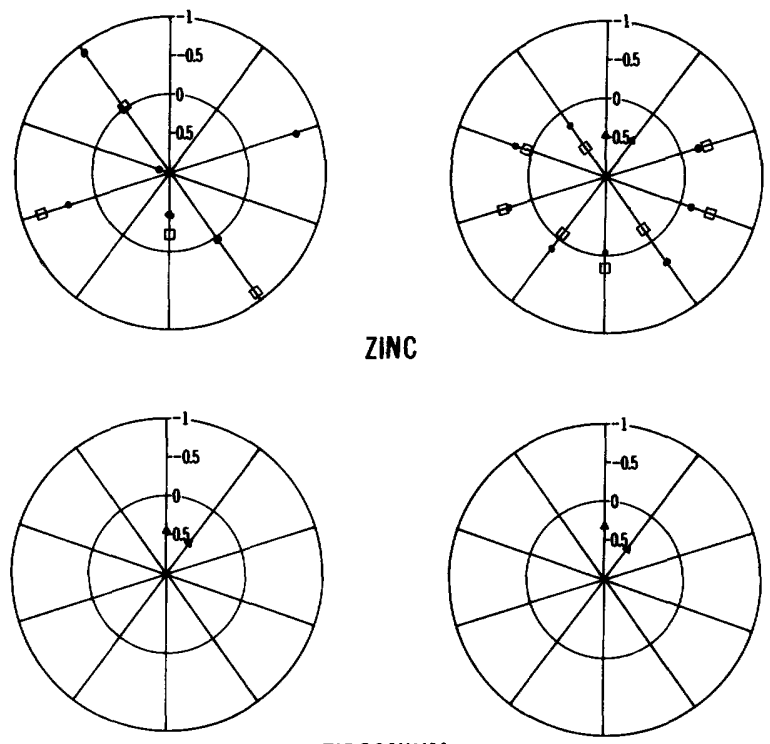

ZIRCONIUM

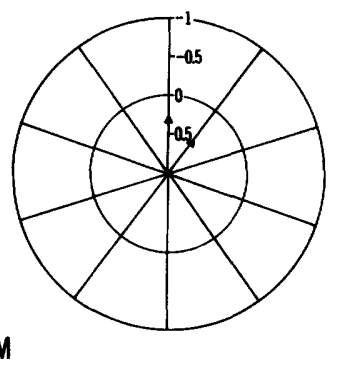

Frgure 4.-Continued 
TREES AND UNCULTIVATED SOILS

Comparisons of the element content of the three horizons of uncultivated soils (table 7) and of eight species of trees (table 6 ) from the two death-rate areas indicate that concentrations of most elements in both soils and trees tend to be higher in the low-death-rate area. Similar trends were shown earlier in this report for garden soils but the trends were not apparent, for the most part, in the garden vegetables. The ability to discriminate between the two areas on the basis of tree analyses as a whole contrasts with discriminations based on vegetable analyses, and the better discrimination using trees may be caused by their growth habit which also contrasts with that of vegetables. All vegetables that were sampled are annuals that grow only one season and are then harvested before they are mature. Thus they have only a short period of time available for absorbing elements from the soil, whereas trees may absorb elements for periods of many years. Vegetables have shallow root systems, in contrast to trees which have deep and widespread roots. Trees, therefore, may be more effective than vegetables in reflecting the chemical nature of the soil on which they grow.

Of the eight species of trees, oak appears to be the most sensitive to the variation in element content of soils from the two death-rate areas. This relationship of oak to uncultivated soils resembles that of cabbage to garden soils. Sweetgum trees follow oak in sensitivity to soil composition, and sassafras and smooth sumac seem to be the least sensitive species (table 6).

Stems and leaves appear to vary independently in containing amounts of elements that are significantly different in the two areas. Only some elements (for example, nickel and lead) in some trees (for example, blackgum and oak) show significant differences in contents in stems and leaves simultaneously.

Caution should be used in making generalizations of tree-soil relationships based on data presented in this report. The concentrations of the elements that were studied in Georgia soils are all believed to be within the "normal" range. The fact is well known that some trees, if growing on soils that contain highly anomalous amounts of certain elements (for example, soils overlying mineral deposits), contain anomalous amounts of the elements in which the soil is enriched.

Correlations of the amounts of elements in tree stems and in leaves and the three horizons of uncultivated soils are given in tables 9-11 and are illustrated in figures 4-6. These correlations fail to indicate any general relationships between tree and soil compositions. As with the correlations of vegetables and garden soils, about half of the correlation coefficients given in these tables are positive and half are negative, and little or no consistency is apparent within elements, trees, or death-rate areas. These results indicate that the greater number of coefficients result largely from chance and are not reproducible. 
TABLE 9.-Correlations between the amounts of elements in trees and in the $[r$, product-moment correlation coefficient between logarithms of concentrations; $N$, number of pairs omitted because concentration of element in

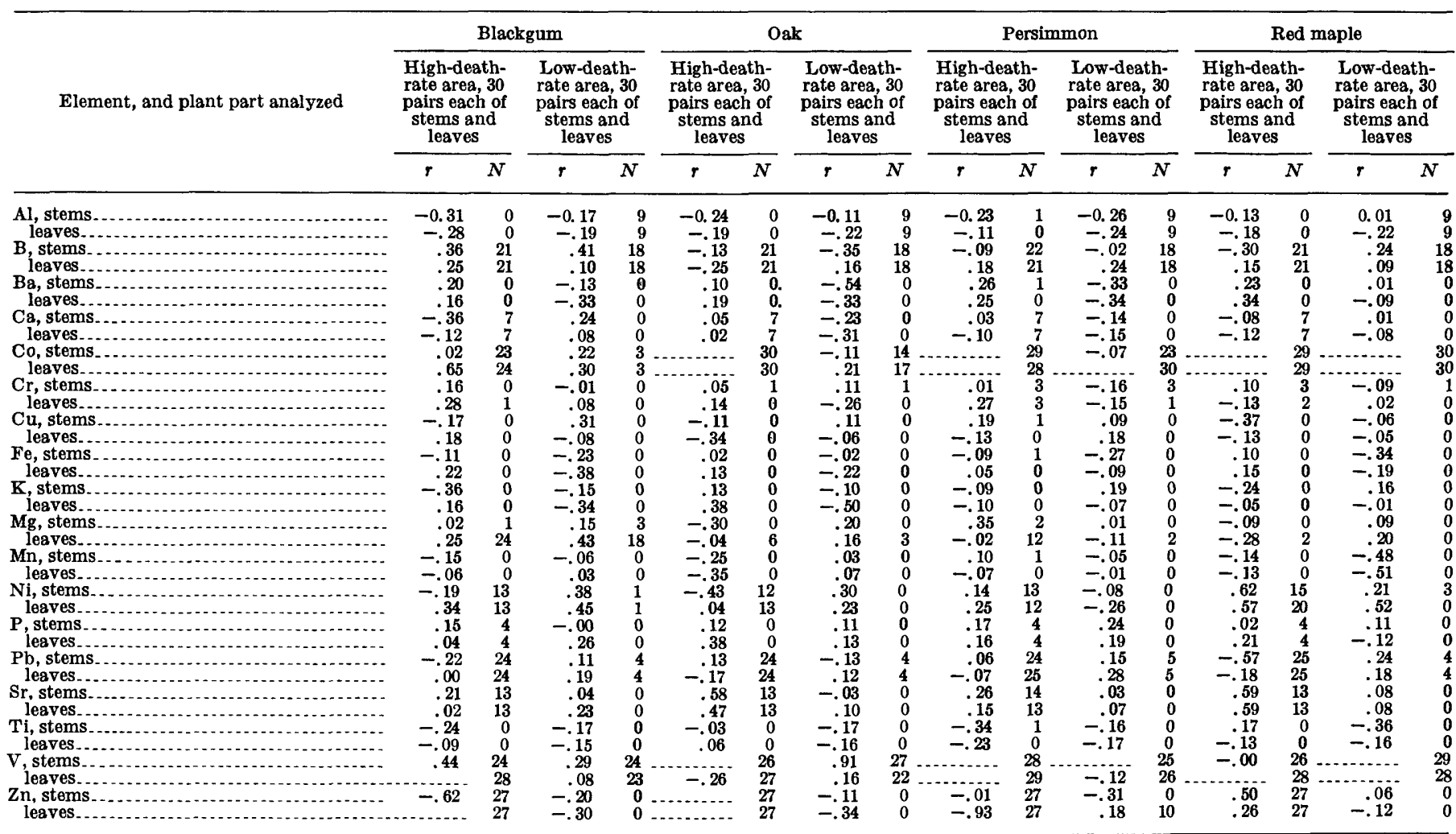

TABLE 10.-Correlations between the amounts of elements in trees and in the $[r$, product-moment correlation coefficient between logarithms of concentrations; $N$, number of pairs omitted because concentration of element in

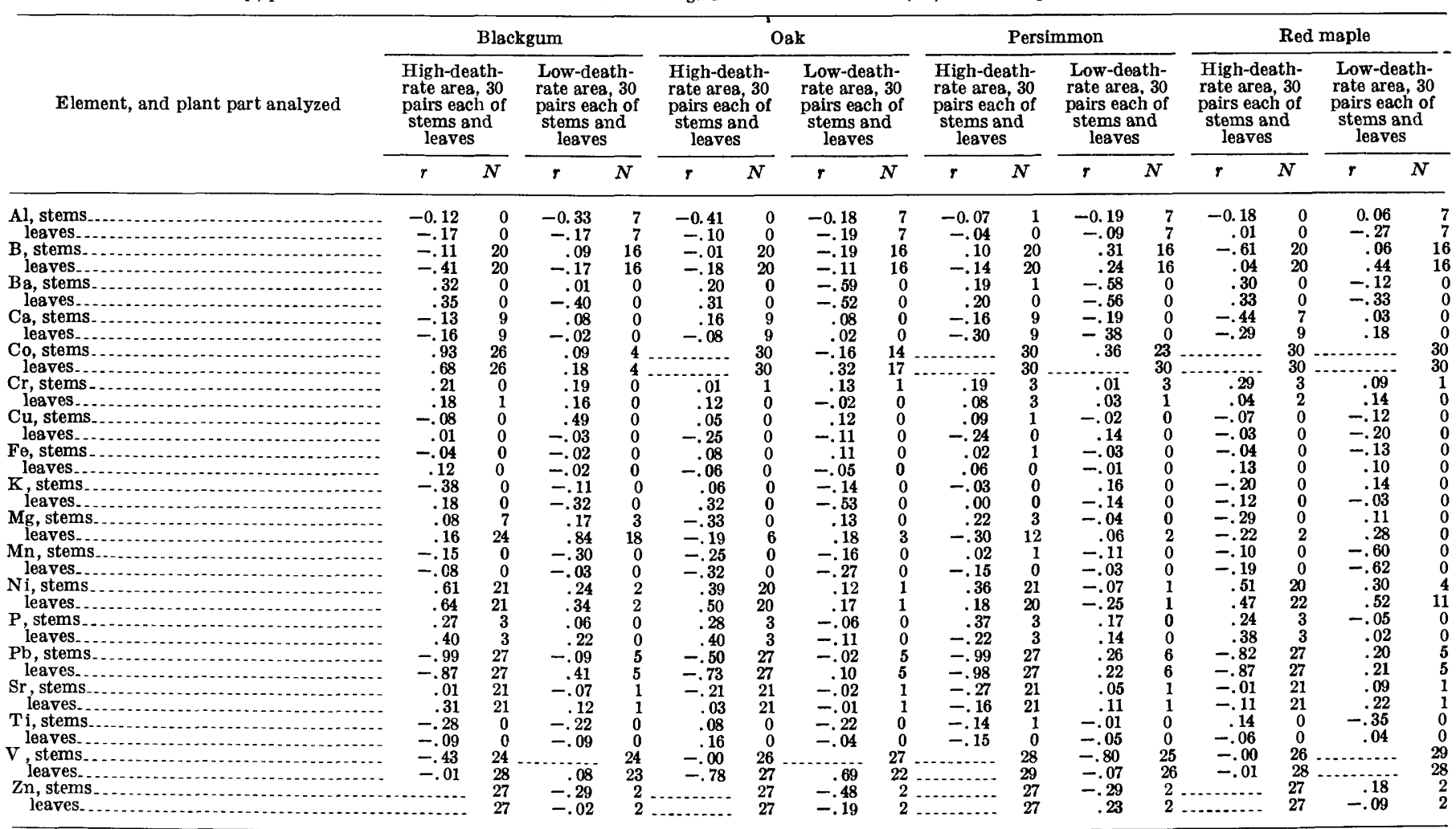


$C$ horizon of uncultivated soils in the high-and low-death-rate areas of Georgia

one or both kinds of samples (tree or soil) was beyond the range of measurement by the analytical methods that were used; ....., insufficient data]

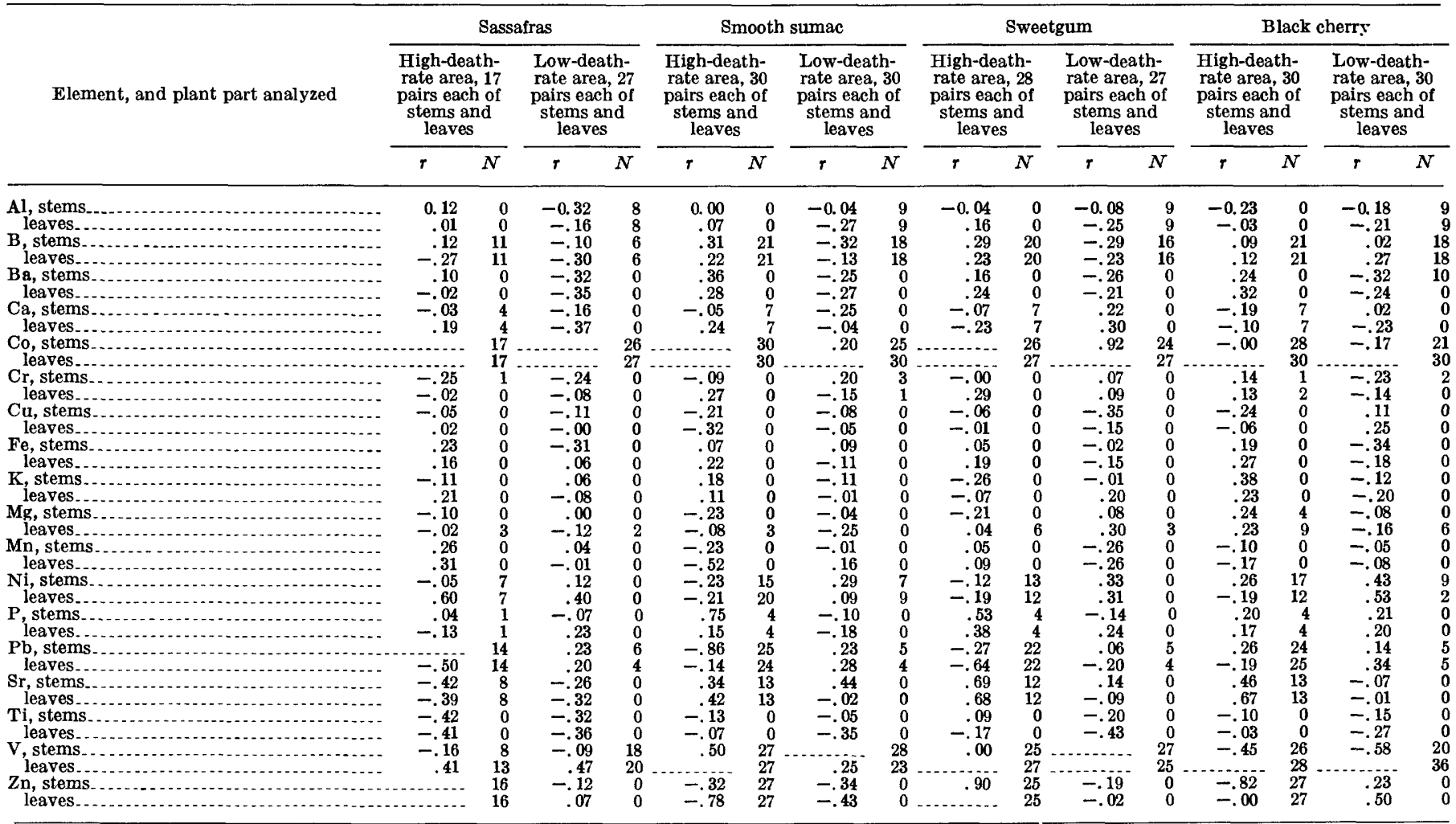

$B$ horizon of uncultivated soils in the high-and low-death-rate areas of Georgia

one or both kinds of samples (tree or soil) was beyond the range of measurement by the analytical methods that were used; ....., insufficient data]

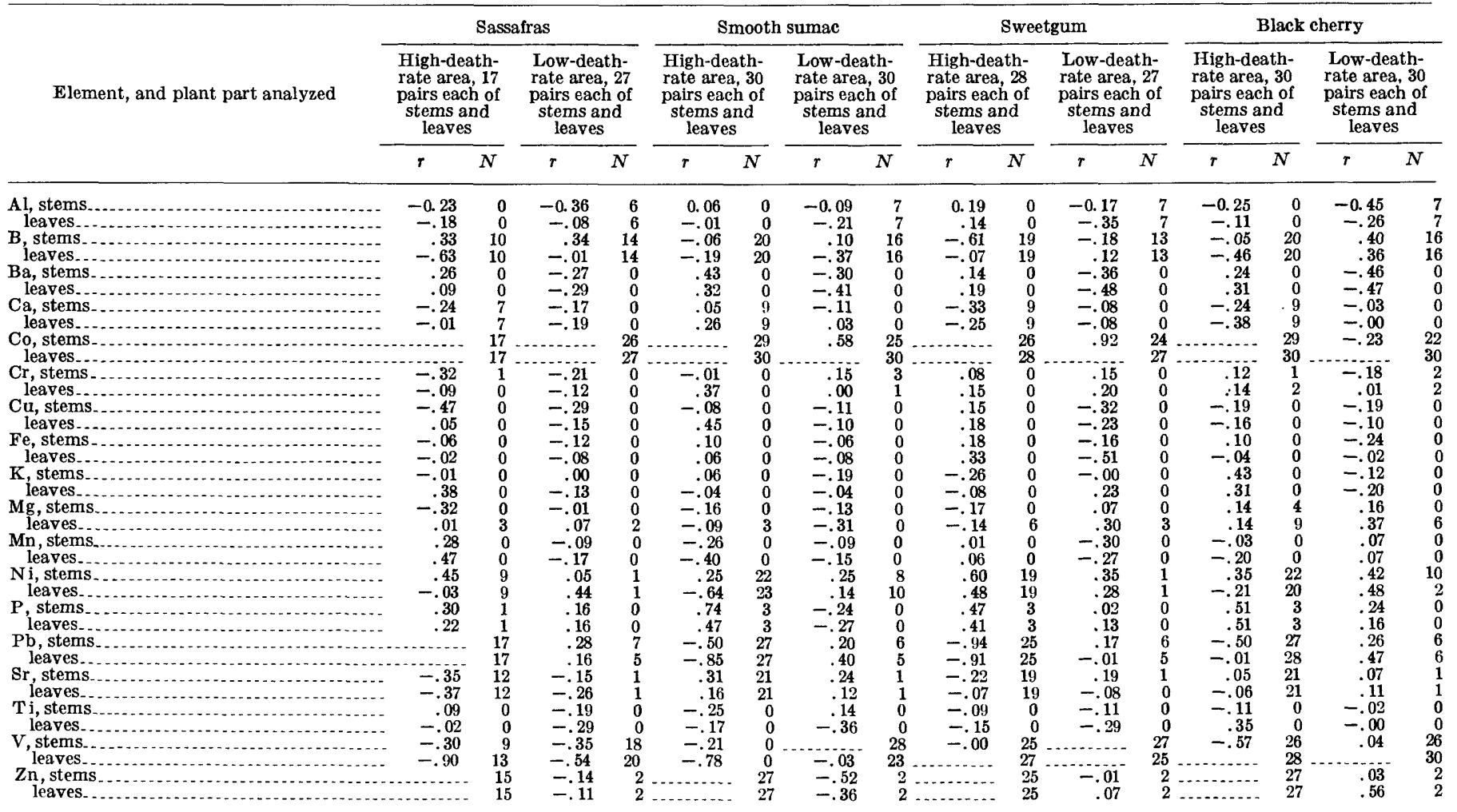


HIGH-DEATH-RATE AREA

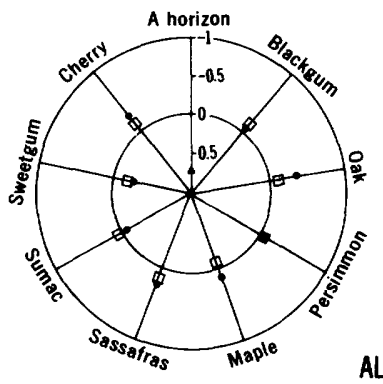

\section{ALUMINUM}

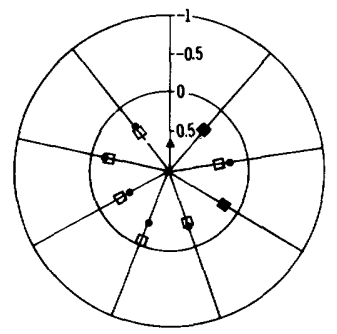

BARIUM
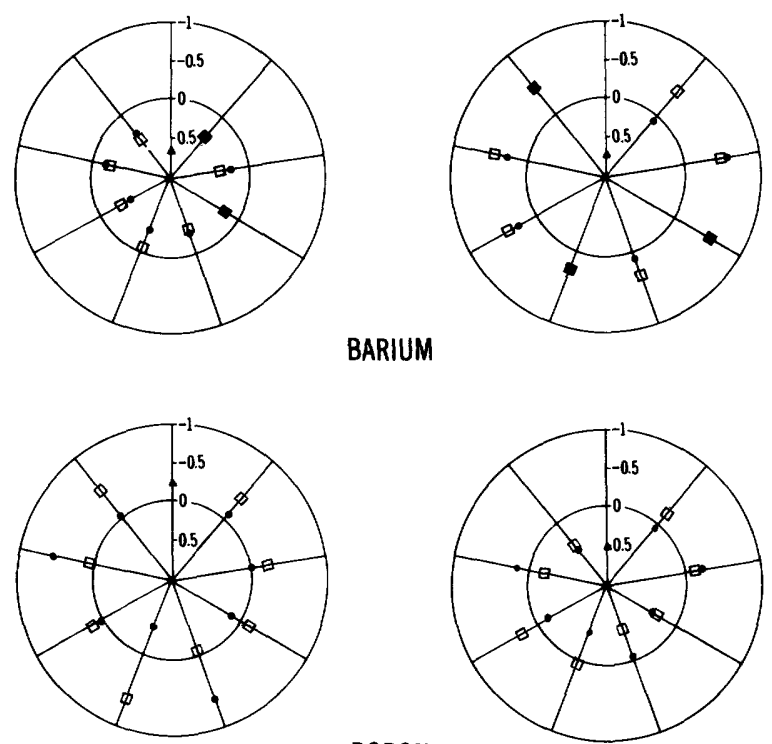

BORON
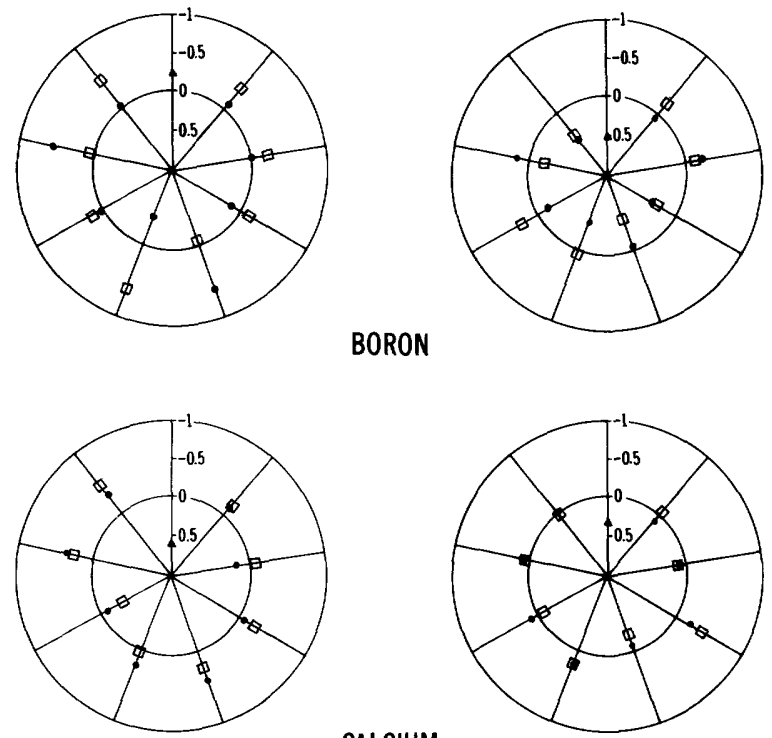

CALCIUM
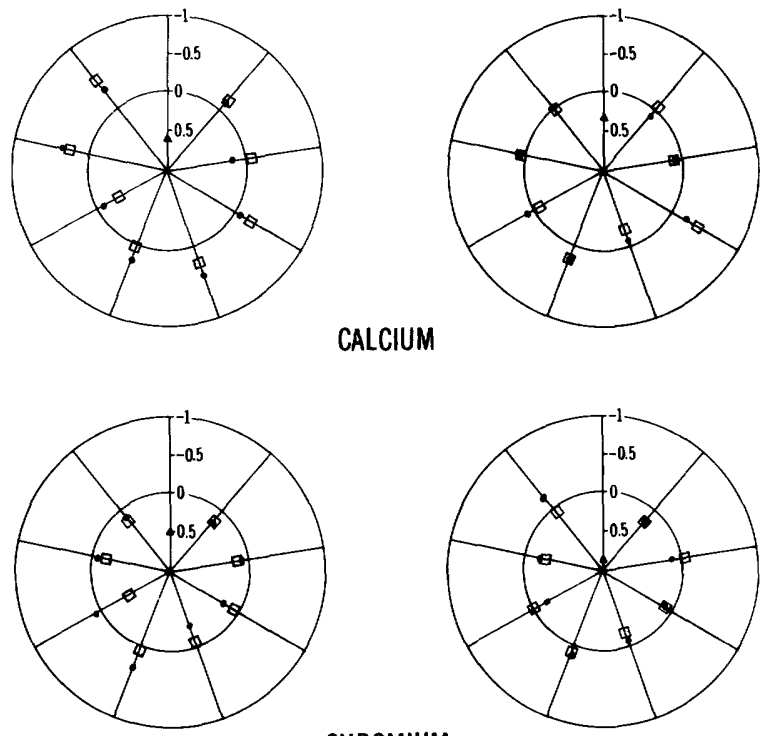

CHROMIUM

LOW-DEATH-RATE AREA

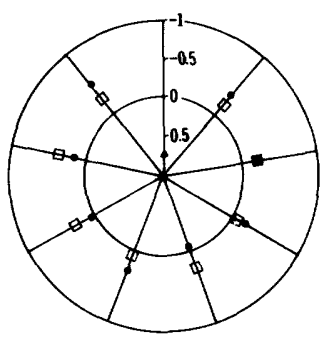

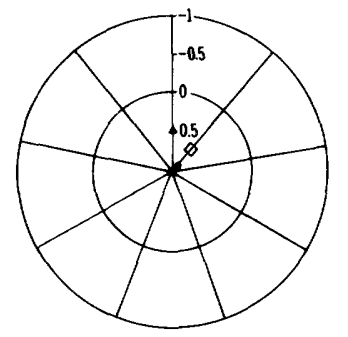

COBALT
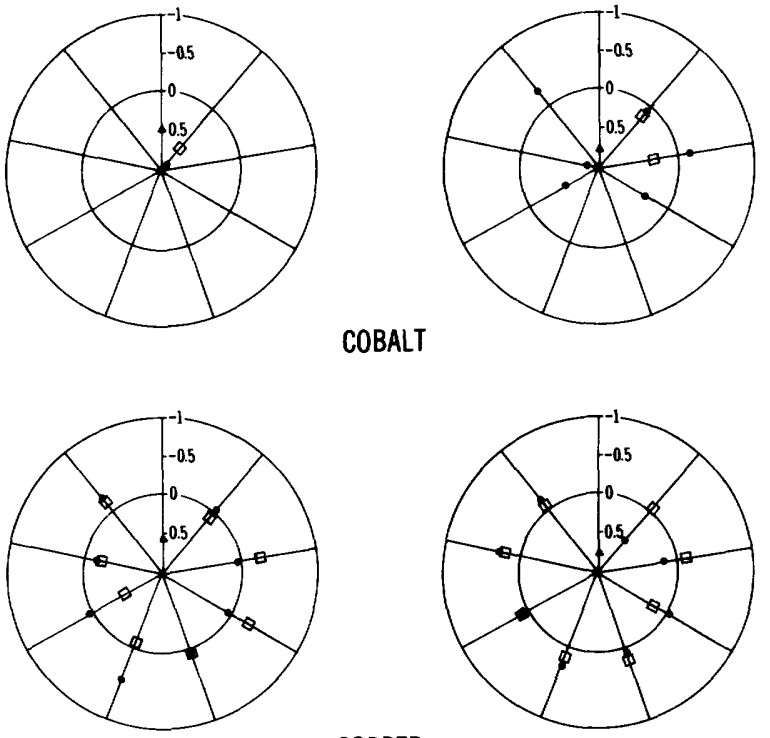

COPPER
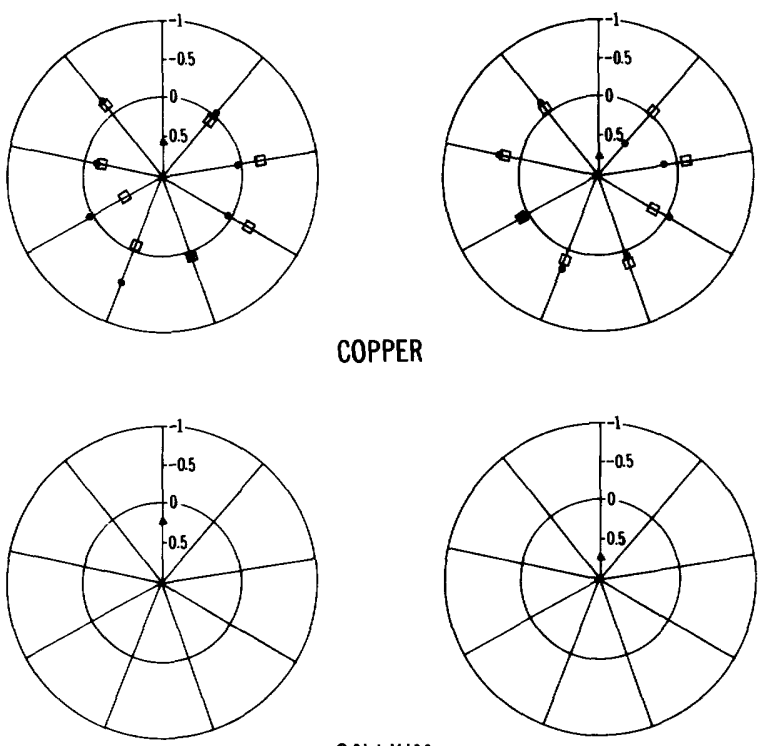

GALLIUM
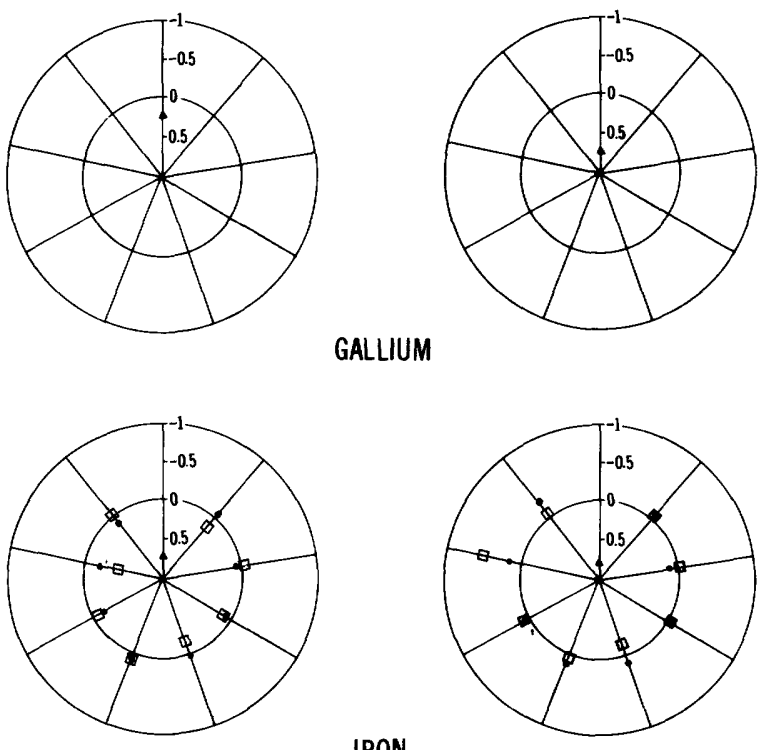

IRON
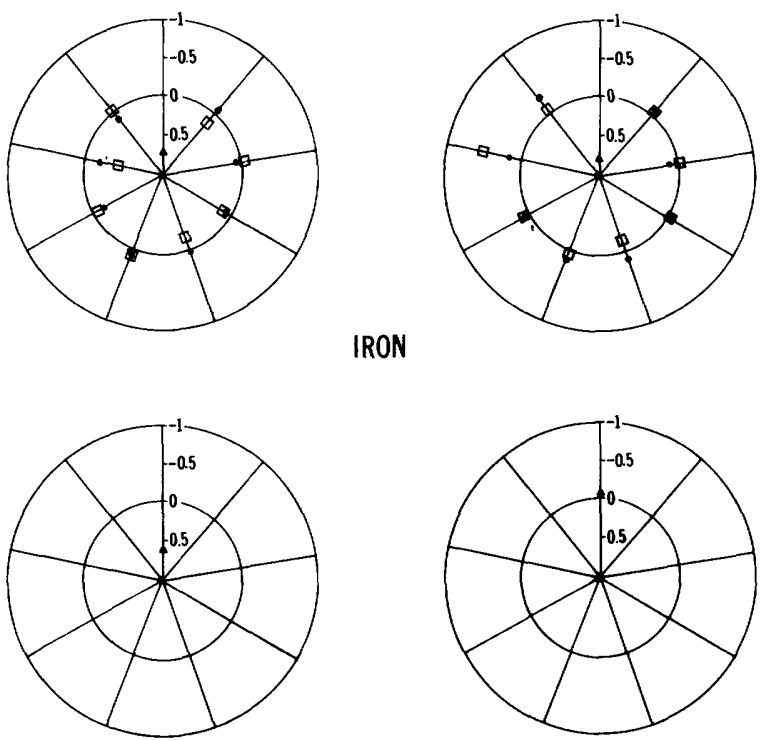

LANTHANUM

Figure 5.-Correlations between the amounts of elements in the $B$ horizon of uncultivated soils (center of circles) and the amounts in the A horizon of soils and in the stems and leaves of trees. Triangles represent soil correlations; idots represent stems, squares represent leaves, of trees. Distance of the symbols on the radii from the center of the circles is inversely proportional to the correlation of the amounts in the samples. 
HIGH-DEATH-RATE AREA

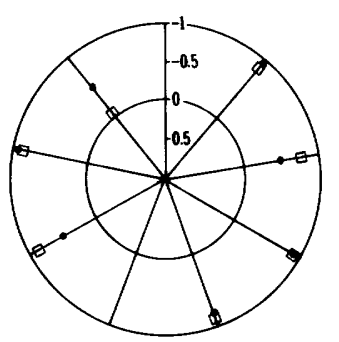

LEAD
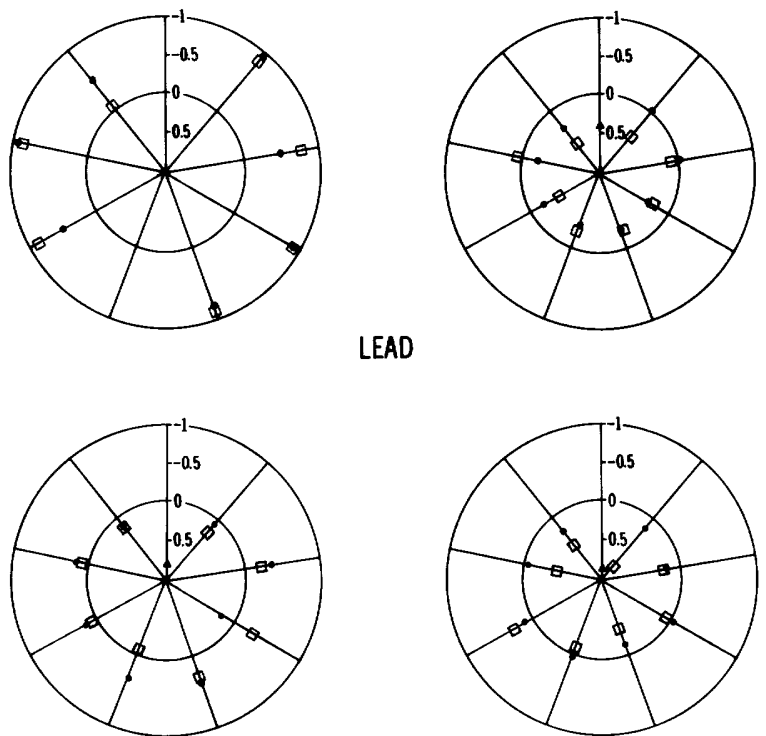

MAGNESIUM

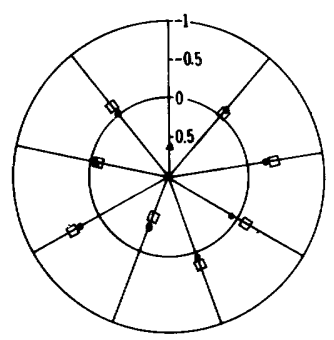

MANGANESE
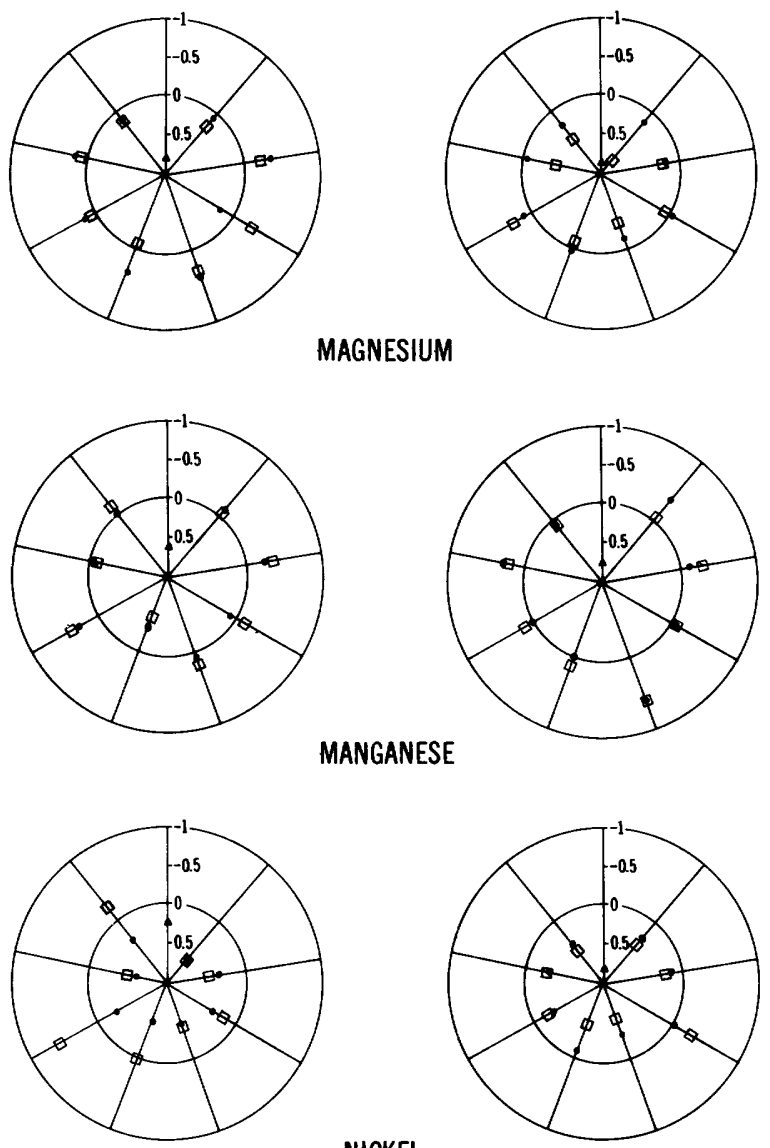

NICKEL
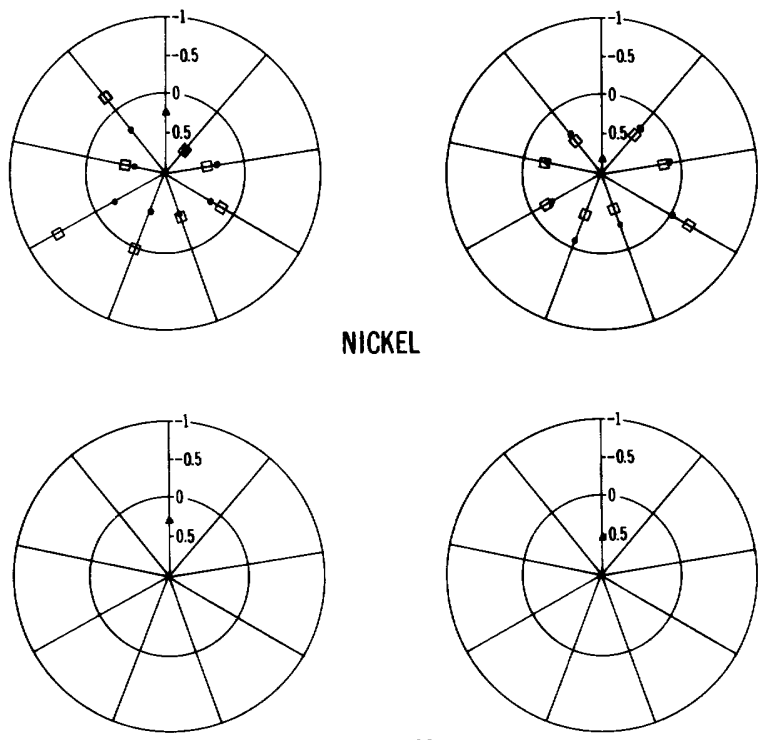

NIOBIUM
HIGH-DEATH-RATE AREA

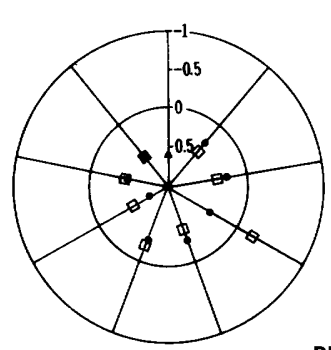

PHOSPHORUS
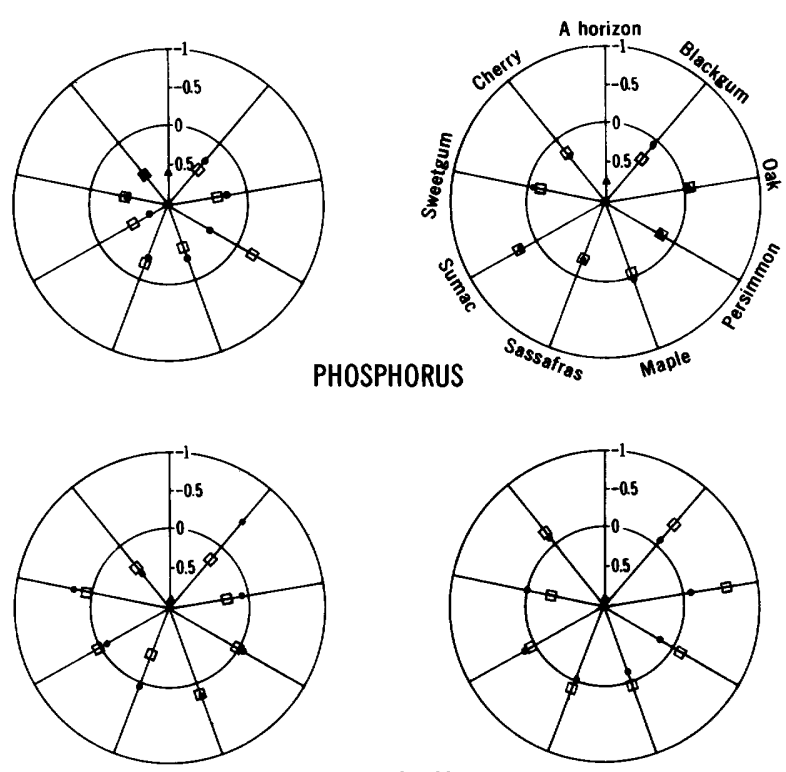

POTASSIUM
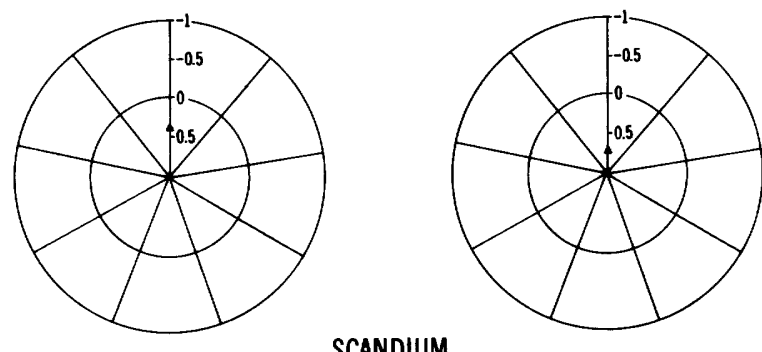

SCANDIUM



SODIUM
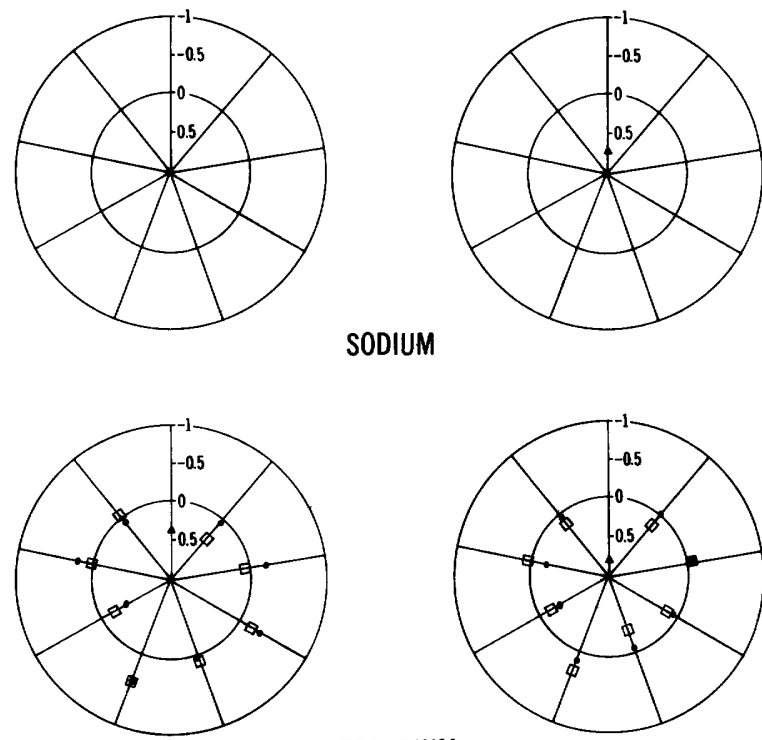

STRONTIUM

Figure 5.-Continued 
C30

STATISTICAL STUDIES IN FIELD GEOCHEMISTRY
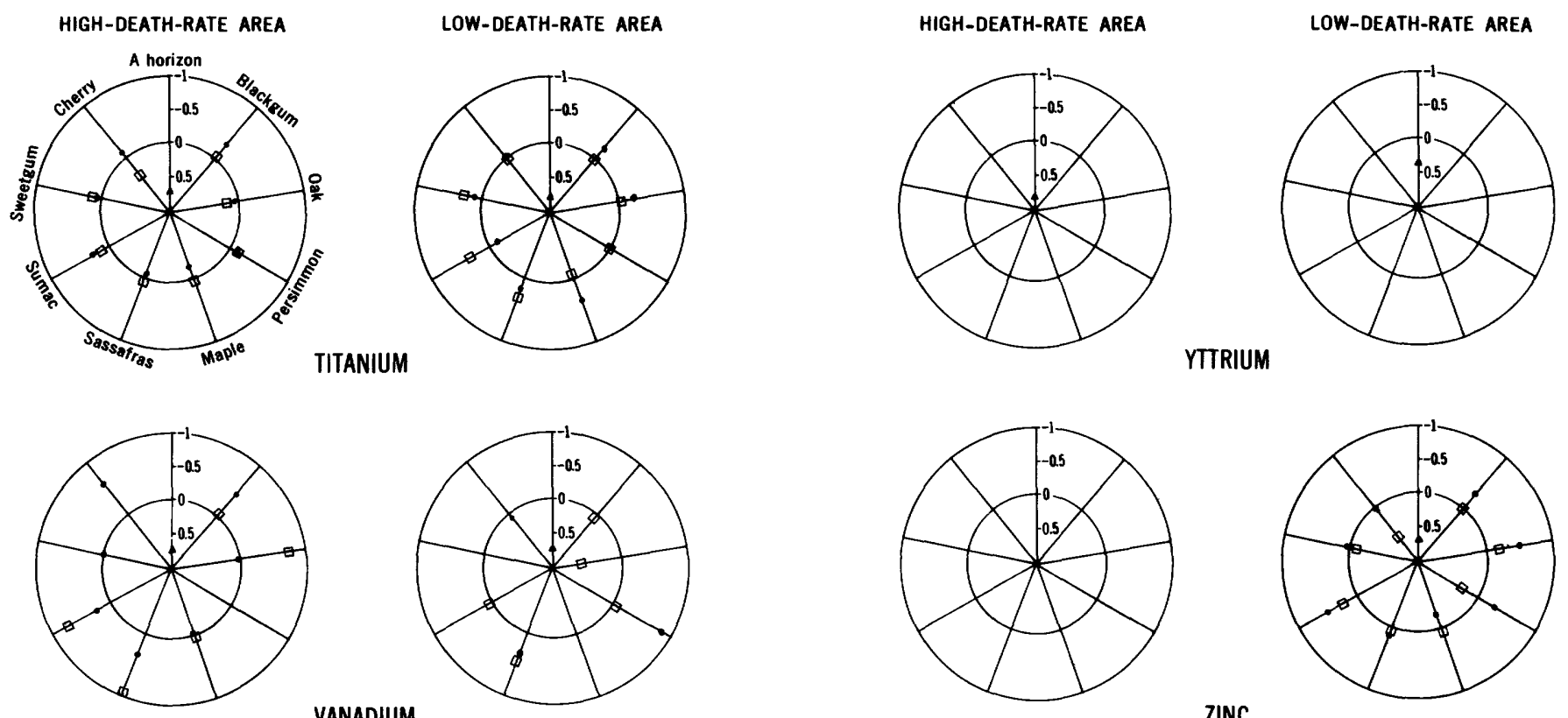

VANADIUM
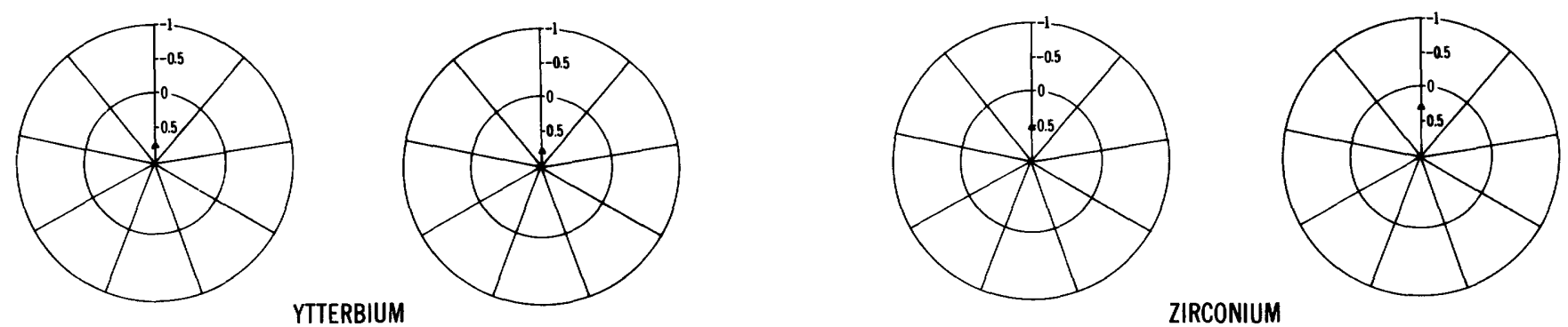

Figure 5.-Continued 
CORRESPONDENCE AMONG THE COMPOSITIONS OF SOIL HORIZONS

Correlations of the amounts of elements in samples of the three horizons of uncultivated soil are given in table 12 and illustrated in figures 4-6. The correlations of elements between the $\mathrm{A}$ and the $\mathrm{C}$ horizons (fig. 4 and table 12) are all positive except for boron, gallium, and strontium in the high-death-rate area and lanthanum in the low-death-rate area. The correlations of the amounts in the $\mathrm{B}$ and $\mathrm{C}$ horizons (fig. 4 and table 12) are all positive except for gallium and strontium in the highrate area. The correlations of the amounts in the $A$ and
B horizons (fig. 5 and table 12) are all positive except for lanthanum in the low-death-rate area.

These data indicate that the amounts of most elements in the three soil horizons are strongly interdependent. The elements that have negative correlations are nonnutritive, except boron which is a micronutrient; their differences in amounts in soil samples from the two death-rate areas are not significant at the 95-percent. level of confidence (table 7 ).

The results of this study also suggest that in searching for differences in amounts of most elements in the soils of the two death-rate areas, any one of the three soil horizons could be sampled alone. 
HIGH-DEATH-RATE AREA

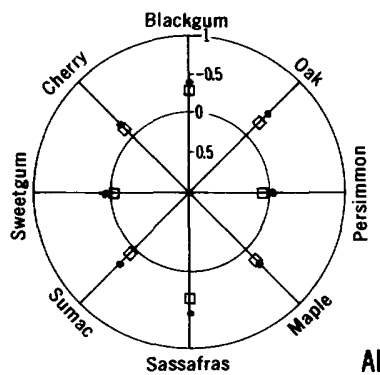

ALUMINUM

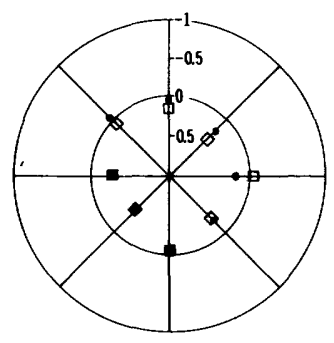

BARIUM

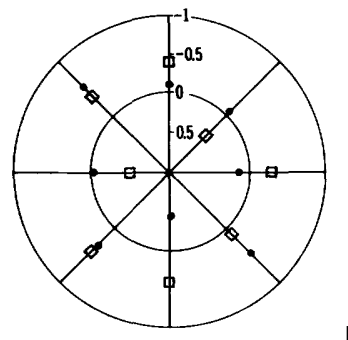

BORON



CALCIUM

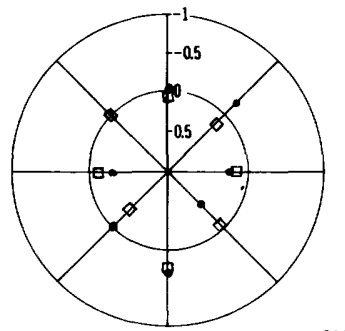

CHROMIUM
LOW-DEATH-RATE AREA
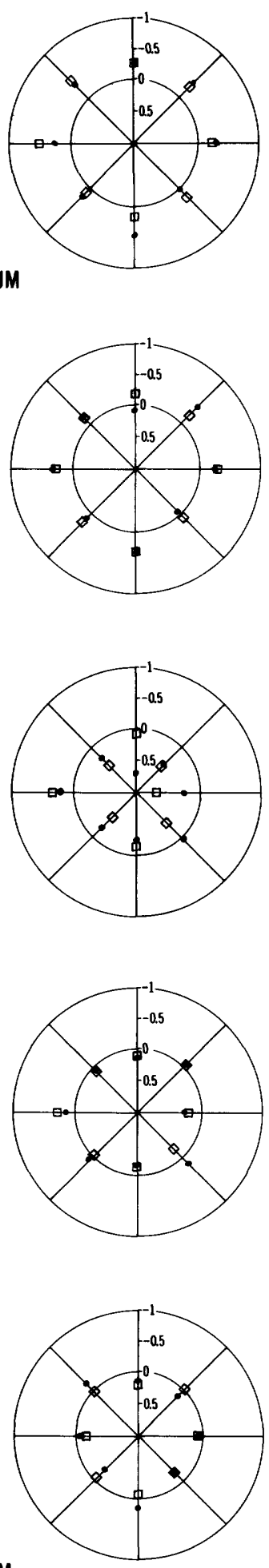

HIGH-DEATH-RATE AREA

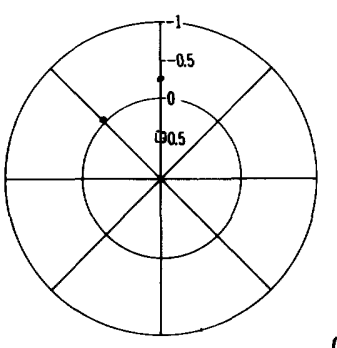

COBALT

LOW-DEATH-RATE AREA
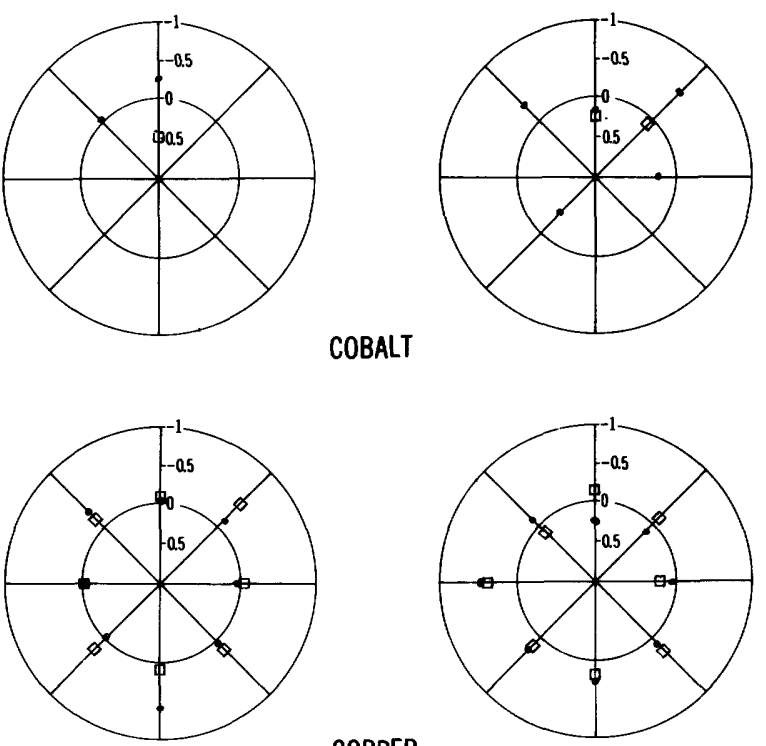

COPPER
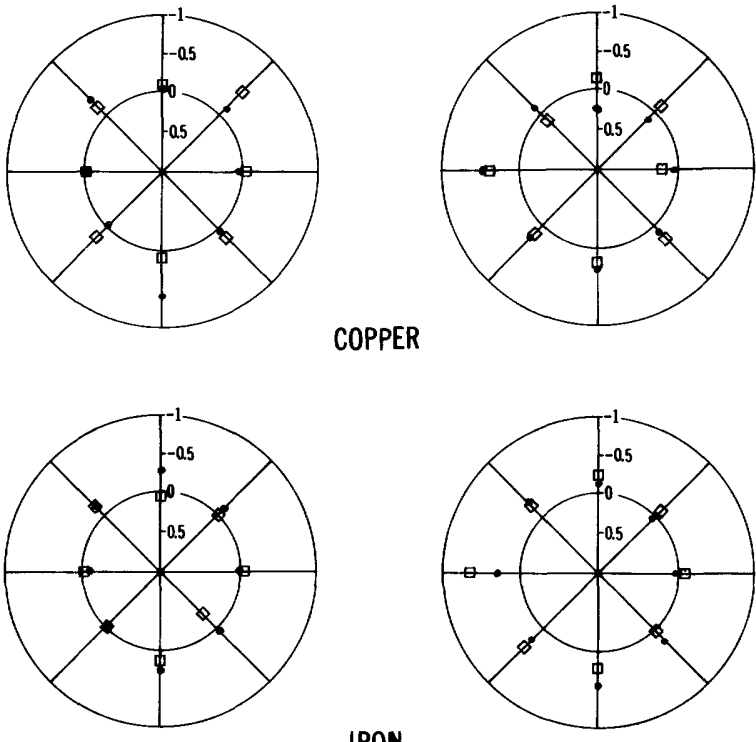

IRON
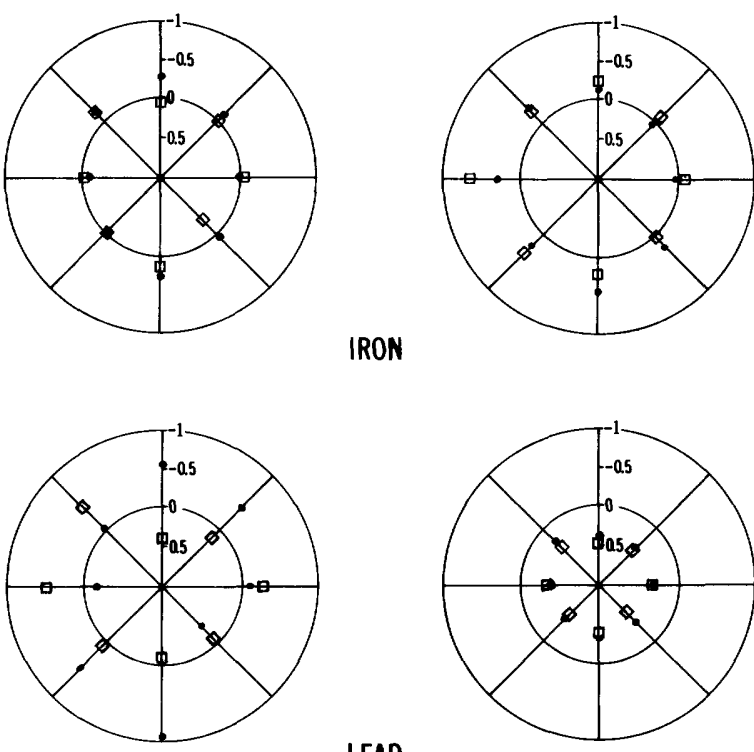

LEAD
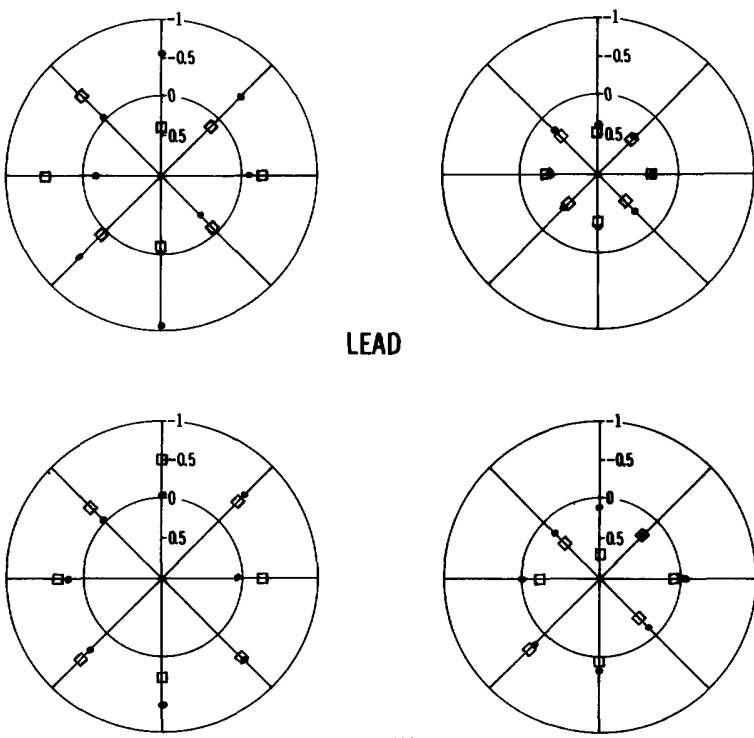

MAGNESIUM

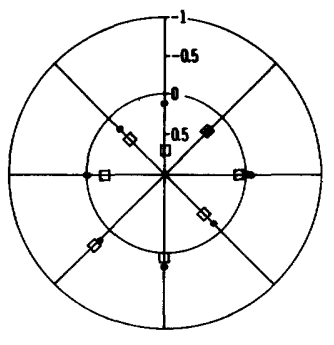

Fugure 6.-Correlations between the amounts of elements in the A horizon of uncultivated soils (center of circles) and the amounts in stems and leaves of trees. Dots represent stems, squares represent leaves. Distance of the symbols on the radii from the center of the circles is inversely proportional to the correlation of the amounts in the samples. 
GEOCHEMICAL ENVIRONMENTS, CARDIOVASCULAR MORTALITY RATES, GEORGIA

HIGH-DEATH-RATE AREA

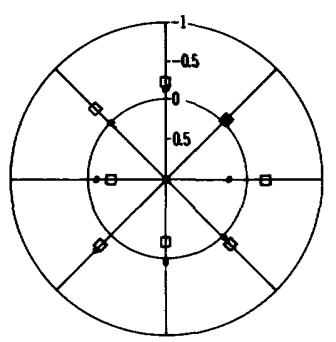

MANGANESE

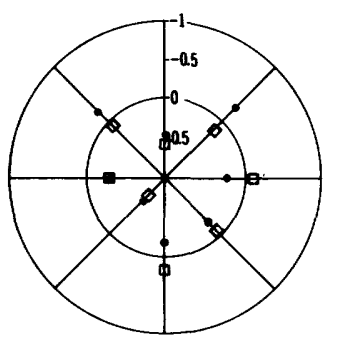

NICKEL
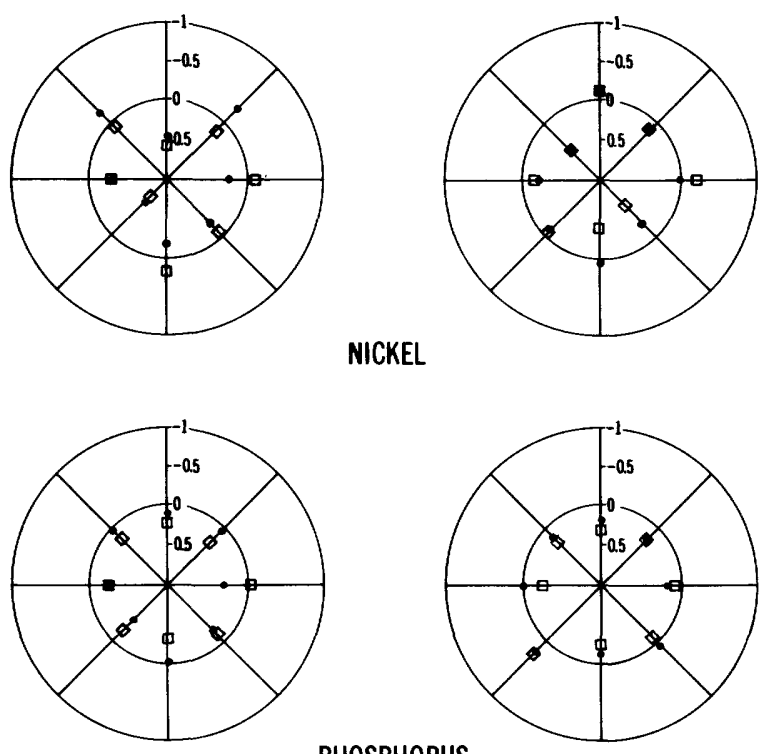

PHOSPHORUS

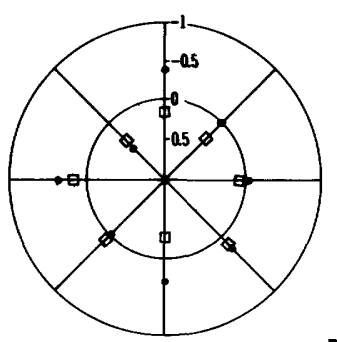

POTASSIUM

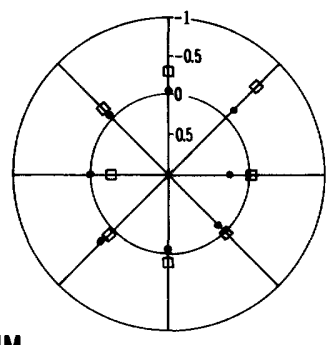

HIGH-DEATH-RATE AREA

LDW-DEATH-RATE AREA
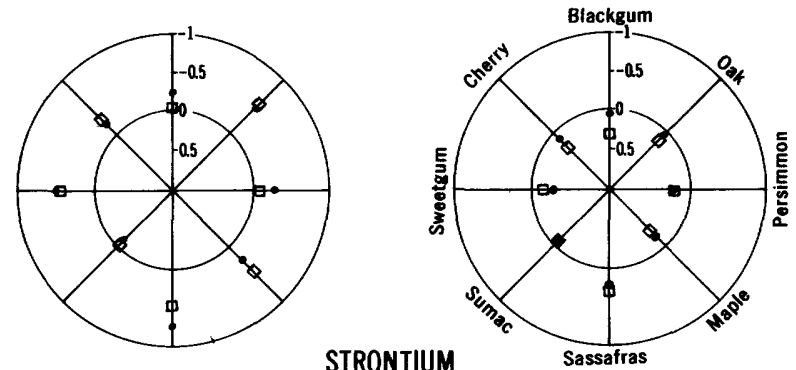

STRONTIUM

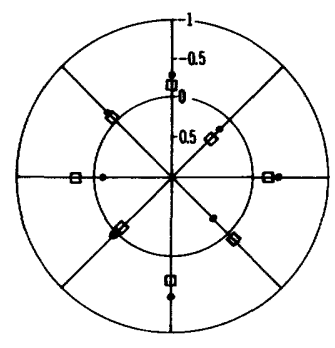

TITANIUM
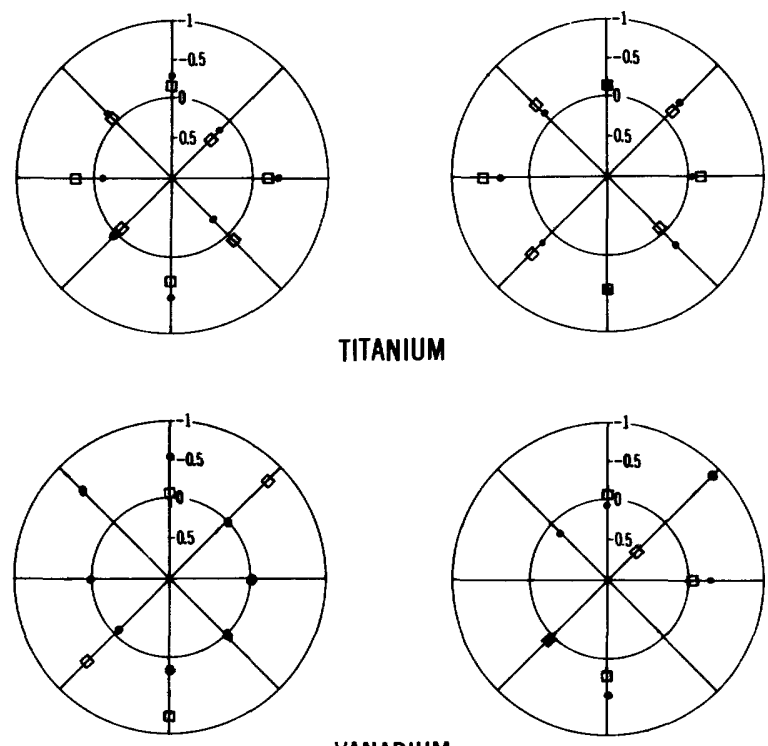

VANADIUM

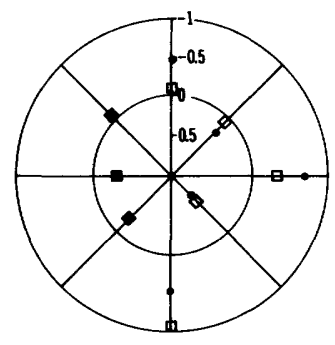

ZINC

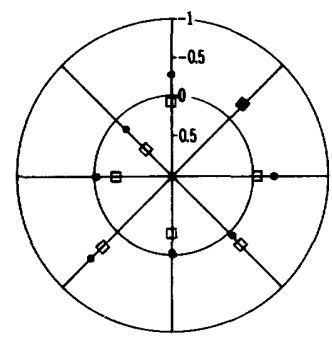

Figure 6.-Continued 
TABLE 11.-Correlations between the amounts of elements in trees and in the $A$ $[r$, product-moment correlation coefficient between logarithms of concentrations; $N$, number of pairs omitted because concentration of element in one

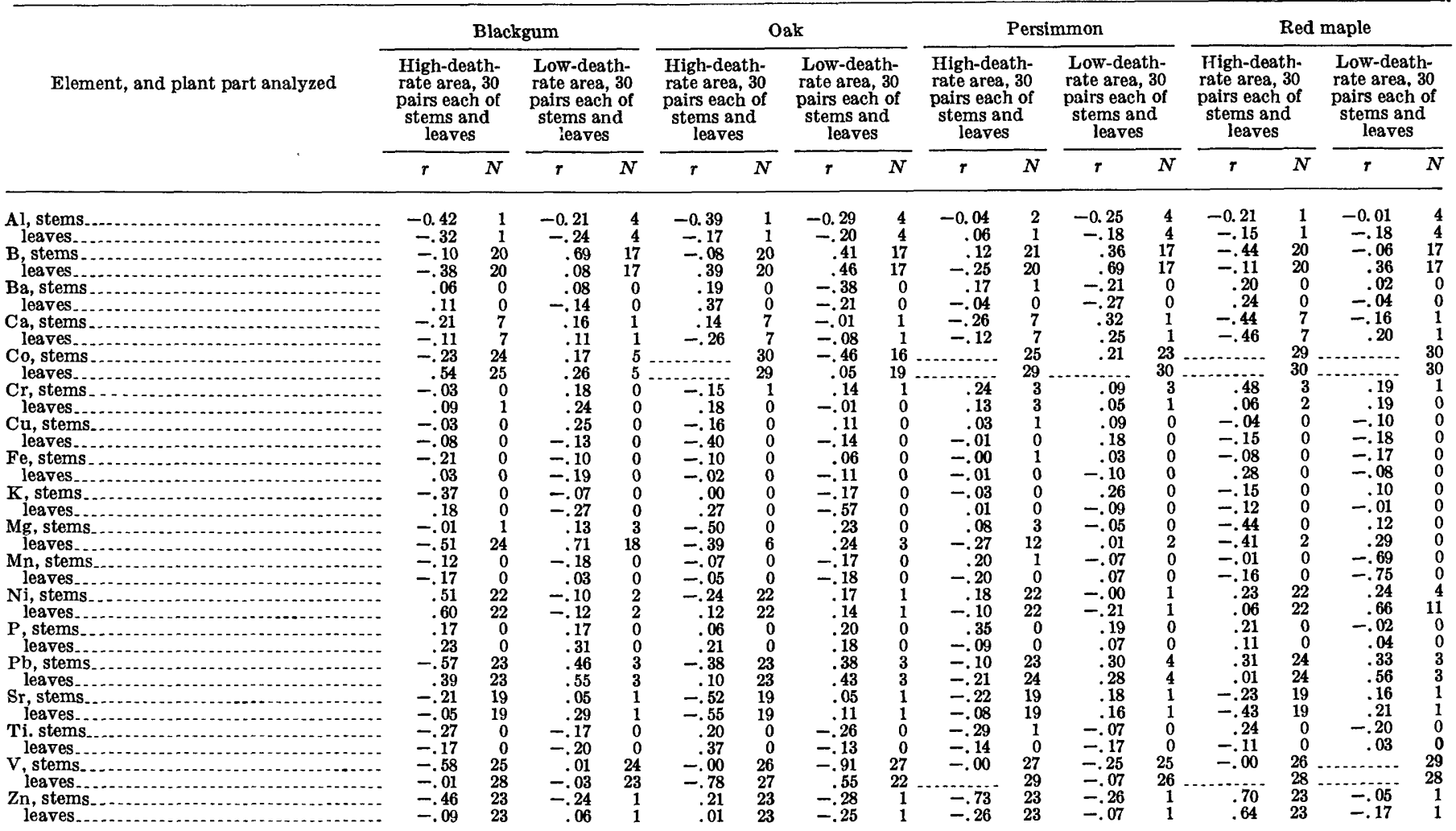

TABLE 12.-Correlations between the amounts of elements in horizons of uncultivated soils in the high-and low-death-rate areas of Georgia

$[r$, product-moment correlation coefficient between logarithms of concentrations; $N$, number of pairs omitted because concentration of element in the sample from one methods that were used; ....., no data available]

\begin{tabular}{|c|c|c|c|c|c|c|c|c|c|c|c|c|}
\hline \multirow{3}{*}{ Element } & \multicolumn{6}{|c|}{ High-death-rate area, 30 pairs } & \multicolumn{6}{|c|}{ Low-death-rate area, 30 pairs } \\
\hline & \multicolumn{2}{|c|}{$\begin{array}{l}\text { A and B } \\
\text { horizons }\end{array}$} & \multicolumn{2}{|c|}{$\begin{array}{l}\text { A and C } \\
\text { horizons }\end{array}$} & \multicolumn{2}{|c|}{$\begin{array}{l}\text { B and C } \\
\text { horizons }\end{array}$} & \multicolumn{2}{|c|}{$\begin{array}{l}\text { A and B } \\
\text { horizons }\end{array}$} & \multicolumn{2}{|c|}{$\begin{array}{l}\text { A and C } \\
\text { horizons }\end{array}$} & \multicolumn{2}{|c|}{$\begin{array}{l}\text { B and C } \\
\text { horizons }\end{array}$} \\
\hline & $r$ & $N$ & $r$ & $N$ & $r$ & $N$ & $r$ & $N$ & $r$ & $N$ & $r$ & $N$ \\
\hline 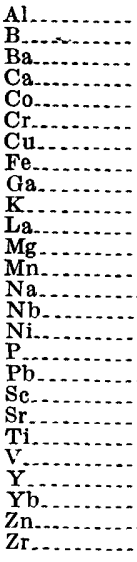 & $\begin{array}{r}0.74 \\
-.21 \\
.68 \\
.68 \\
.50 \\
.56 \\
.59 \\
.75 \\
.23 \\
.95 \\
.68 \\
.82 \\
.68 \\
.31 \\
.26 \\
.62 \\
.44 \\
.36 \\
.73 \\
.75 \\
.79 \\
.77 \\
.07 \\
.58\end{array}$ & $\begin{array}{r}1 \\
25 \\
0 \\
14 \\
27 \\
0 \\
0 \\
0 \\
21 \\
0 \\
19 \\
0 \\
0 \\
28 \\
6 \\
24 \\
3 \\
28 \\
22 \\
21 \\
0 \\
6 \\
1 \\
0 \\
29 \\
0\end{array}$ & $\begin{array}{r}0.39 \\
-.76 \\
.61 \\
.36 \\
.86 \\
.38 \\
.33 \\
.51 \\
-.38 \\
.81 \\
.46 \\
.46 \\
.51 \\
-.59 \\
.22 \\
.37 \\
.20 \\
.91 \\
.17 \\
-.31 \\
.76 \\
.30 \\
.34 \\
.27 \\
. .2 \\
.48\end{array}$ & $\begin{array}{r}1 \\
24 \\
0 \\
12 \\
27 \\
0 \\
0 \\
0 \\
21 \\
0 \\
17 \\
0 \\
0 \\
28 \\
8 \\
25 \\
4 \\
27 \\
28 \\
21 \\
0 \\
6 \\
1 \\
1 \\
29 \\
0\end{array}$ & $\begin{array}{r}0.57 \\
.89 \\
.87 \\
.45 \\
.86 \\
.56 \\
.35 \\
.63 \\
-.41 \\
.88 \\
.73 \\
.66 \\
.82 \\
.87 \\
.68 \\
.19 \\
.62 \\
. .25 \\
.33 \\
-.13 \\
.81 \\
.31 \\
.40 \\
.29 \\
. .25 \\
.54\end{array}$ & $\begin{array}{r}0 \\
26 \\
0 \\
13 \\
27 \\
0 \\
0 \\
0 \\
21 \\
0 \\
20 \\
0 \\
0 \\
27 \\
7 \\
22 \\
6 \\
29 \\
12 \\
23 \\
0 \\
6 \\
1 \\
1 \\
29 \\
0\end{array}$ & $\begin{array}{r}0.82 \\
.55 \\
.70 \\
.39 \\
.84 \\
.86 \\
.81 \\
.82 \\
.77 \\
.96 \\
-.06 \\
.91 \\
.78 \\
.78 \\
.55 \\
.87 \\
.79 \\
.38 \\
.74 \\
.86 \\
.79 \\
.77 \\
.39 \\
.76 \\
.71 \\
.34\end{array}$ & $\begin{array}{r}8 \\
18 \\
0 \\
1 \\
3 \\
0 \\
0 \\
0 \\
1 \\
0 \\
13 \\
0 \\
0 \\
1 \\
3 \\
1 \\
0 \\
5 \\
1 \\
2 \\
0 \\
0 \\
0 \\
0 \\
2 \\
0\end{array}$ & $\begin{array}{l}0.73 \\
.70 \\
.81 \\
.19 \\
.79 \\
.80 \\
.73 \\
.60 \\
.53 \\
.95 \\
-.15 \\
.67 \\
.62 \\
.74 \\
.78 \\
.83 \\
.82 \\
.30 \\
.79 \\
.83 \\
.75 \\
.50 \\
.60 \\
.49 \\
.52 \\
.34\end{array}$ & $\begin{array}{r}10 \\
19 \\
0 \\
1 \\
2 \\
0 \\
0 \\
0 \\
1 \\
0 \\
13 \\
0 \\
0 \\
1 \\
3 \\
1 \\
0 \\
4 \\
1 \\
1 \\
0 \\
0 \\
0 \\
0 \\
1 \\
0\end{array}$ & $\begin{array}{l}0.73 \\
.60 \\
.70 \\
.51 \\
.86 \\
.79 \\
.78 \\
.53 \\
.71 \\
.97 \\
.03 \\
.64 \\
.78 \\
.85 \\
.79 \\
.85 \\
.70 \\
.71 \\
.78 \\
.89 \\
.67 \\
.45 \\
.36 \\
.43 \\
.47 \\
.54\end{array}$ & $\begin{array}{r}1 \\
0 \\
0 \\
0 \\
0 \\
0 \\
0 \\
13 \\
0\end{array}$ \\
\hline
\end{tabular}

\section{CORRESPONDENCE BETWEEN THE COMPOSITIONS OF STEMS AND LEAVES OF TREES}

The correlations that indicate the correspondence of stem and leaf analyses are given in table 13 and illustrated in figure 7. The correlations are all positive except for ash, lead, and zinc in cherry, lead in sassafras, and magnesium in sweetgum, all in samples from the high-death-rate area. The correlations are most highly positive for aluminum, barium, calcium, manganese, and strontium.

These data indicate that the amounts of most elements in stems and leaves are strongly interdependent, and that in searching for differences in element content of trees from the two death-rate areas, either stems alone or leaves alone, could be used.

\section{SUMMARY}

1. Of the 159 counties in Georgia, the nine counties of northern Georgia that were chosen for geochemical studies because of their low rate of death due to cardiovascular diseases also are among the 20 counties having the lowest rate for all causes of death, as well as being 
horizon of uncultivated soils in the high-and low-death-rate areas of Georgia

or both kinds of samples (tree or soil) was beyond the range of measurement by the analytical methods that were used;...., insufficient data]

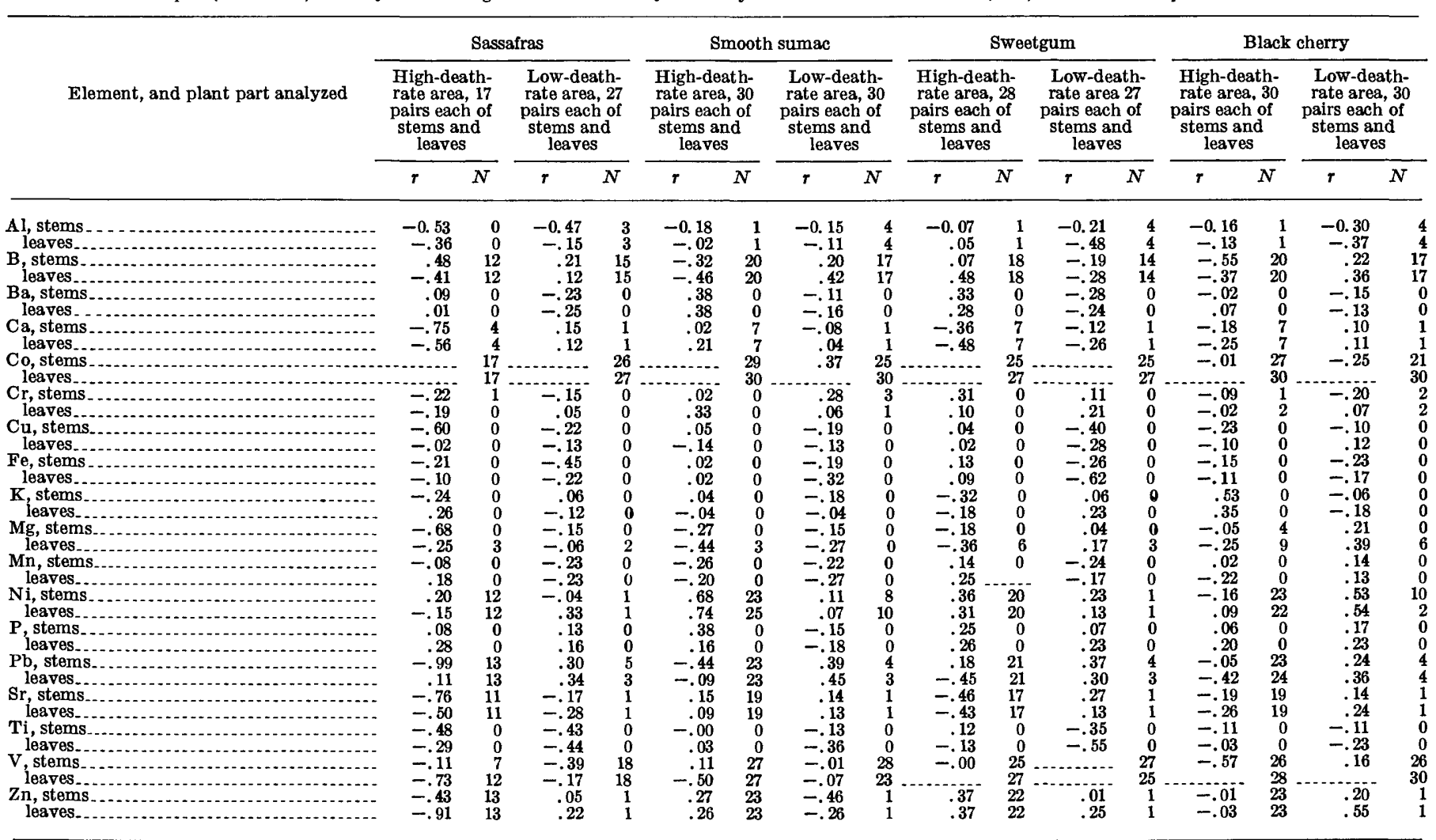

among those with the very lowest rate for the cardiovascular diseases generally, and coronary heart disease specifically. The counties chosen for study in central and south-central Georgia are all among the 20 counties having the highest rate for all causes of death, and have mortality rates for the cardiovascular diseases roughly twice as high as those for the low-rate counties that were studied. In this one State, contrasts in mortality rates for cardiovascular diseases are found which are almost as great as can be found between any two counties in the United States. These contrasts are not due to randon error, and almost certainly were not produced by the methods of data collection and classification.

2. The counties that have high cardiovascular death rates are located where Paleudult, Quartzipsamment, and Ochraquult soils predominate. These soils are derived from unconsolidated or slightly consolidated sands, sandy clays, and clays of the Atlantic Coastal Plain region. The counties with low death rates due to the same cause are located within the area of Hapludult soils that were derived from the weathering of rocks in the Appalachian Plateaus, Valley and Ridge, Blue Ridge, and Piedmont provinces.
3. The frequency of occurrence of the plants that were sampled differed in the two death-rate areas. The vegetables found most frequently in both areas were corn, green beans, tomatoes, and cabbage, and the most common trees were blackgum, persimmon, red maple, smooth sumac, and black cherry.

4. Estimates of experimental error in sampling soils indicated that in general the variation between the high- and low-death-rate areas is sufficiently large, in comparison with the variation between sites or between samples within sites, that compositional differences between soils from the two areas appear to be identifiable.

5 . The concentrations of the elements that were studied in both garden soils and uncultivated soils tend to be significantly different in the two death-rate areas and are generally higher in the low-death-rate area.

6. Because of the similarities in element content of the soil horizons at a sample site, the differences in concentrations of almost all elements in uncultivated soils from the two areas could have been determined by sampling any one of the three soil horizons.

7. The cultivation of garden soils apparently has not greatly altered their content of the elements that were 


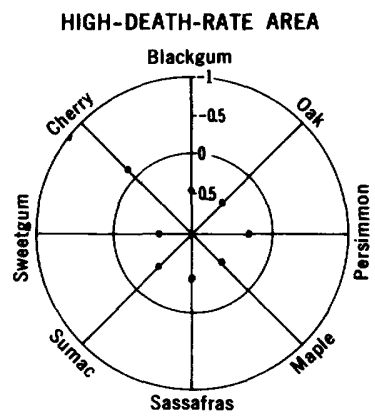

LOW-DEATH-RATE AREA

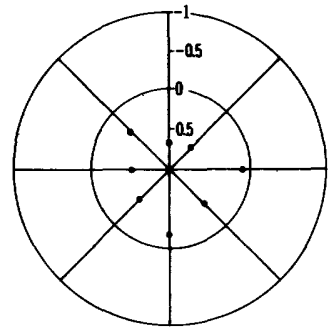

ASH

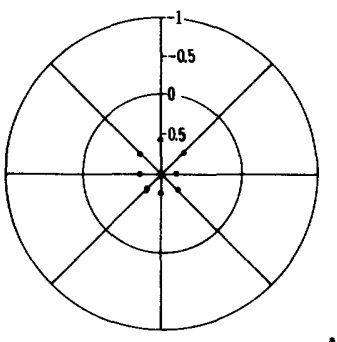

ALUMINUM

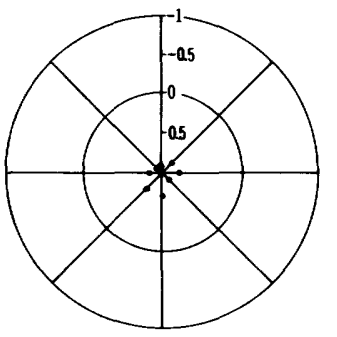

BARIUM
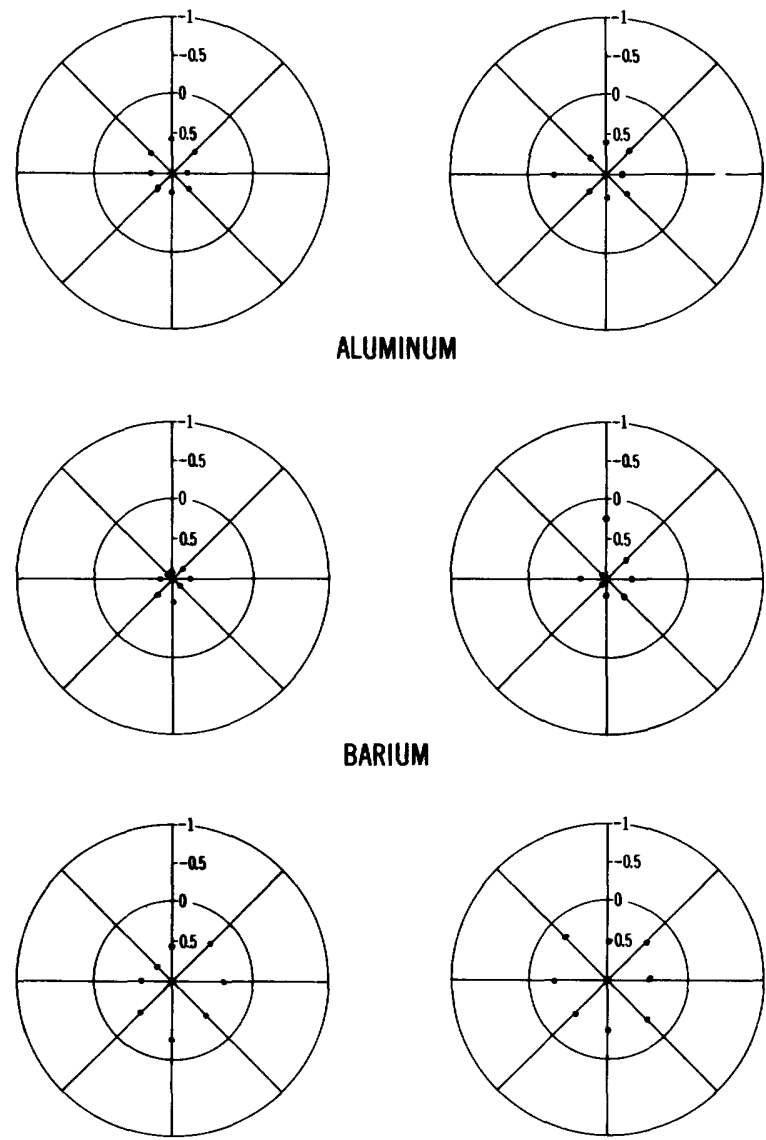

BORON
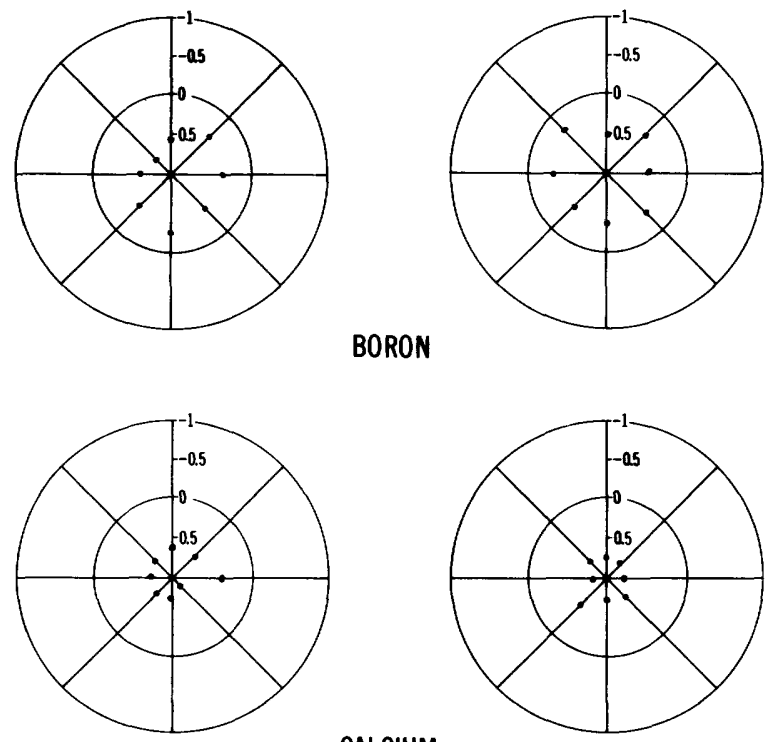

CALCIUM
HIGH-DEATH-RATE AREA

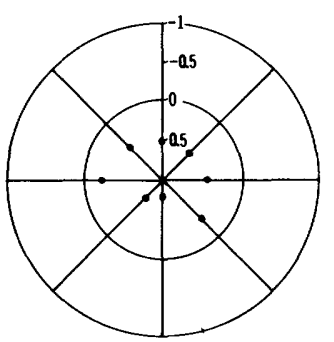

\section{CHROMIUM}

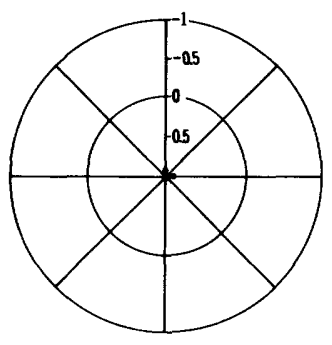

COBALT
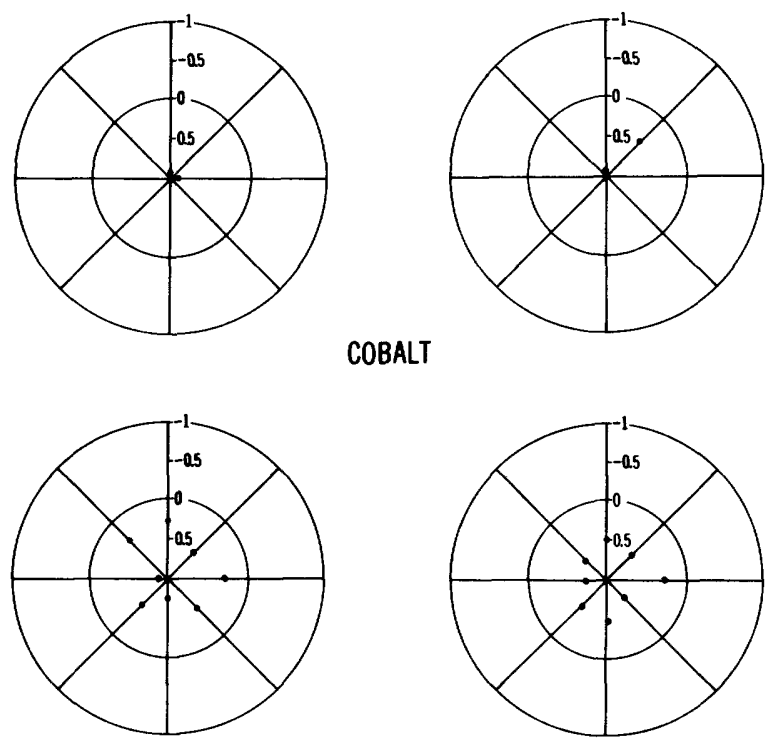

COPPER

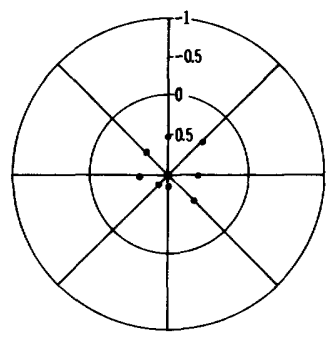

IRON
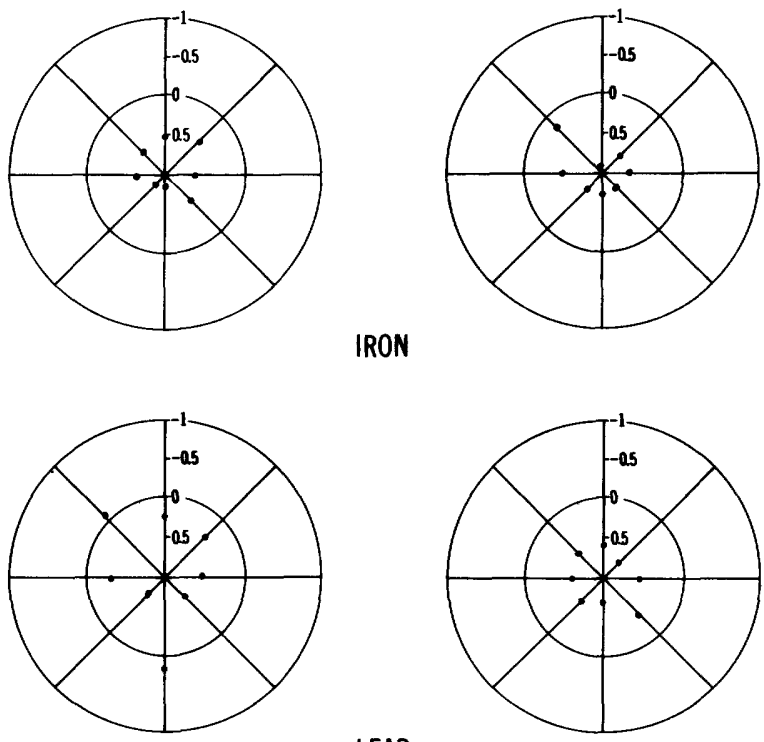

LEAD

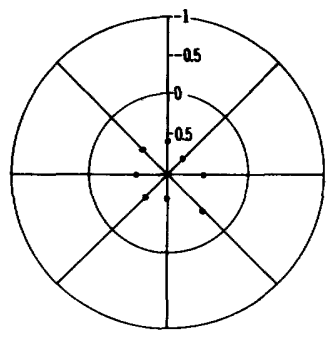

Figure 7.-Correlations between the amounts of elements in stems and in leaves of trees. The center of the circles represents stems, and the dots represent leaves. Distances of the dots on the radii from the center of the circles is inversely proportional to the correlation of the amounts in samples of stems and leaves. 
HIGH-DEATH-RATE AREA

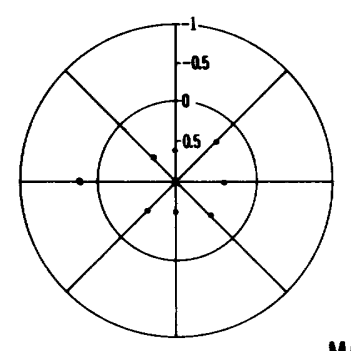

MAGNESIUM

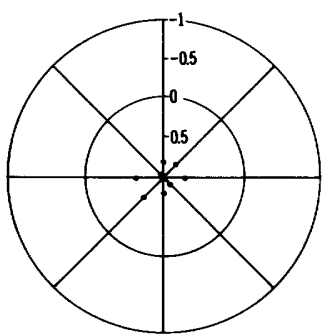

MANGANESE

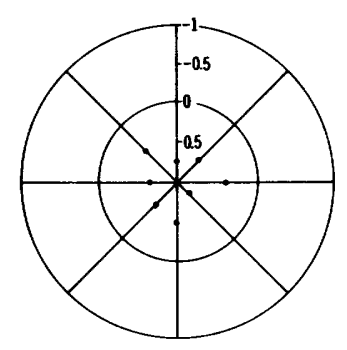

NICKEL

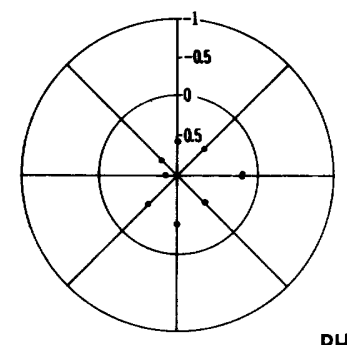

PHOSPHORUS

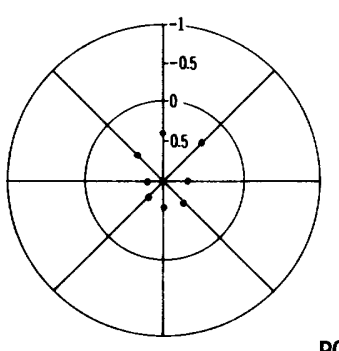

POTASSIUM


LOW-DEATH-RATE AREA
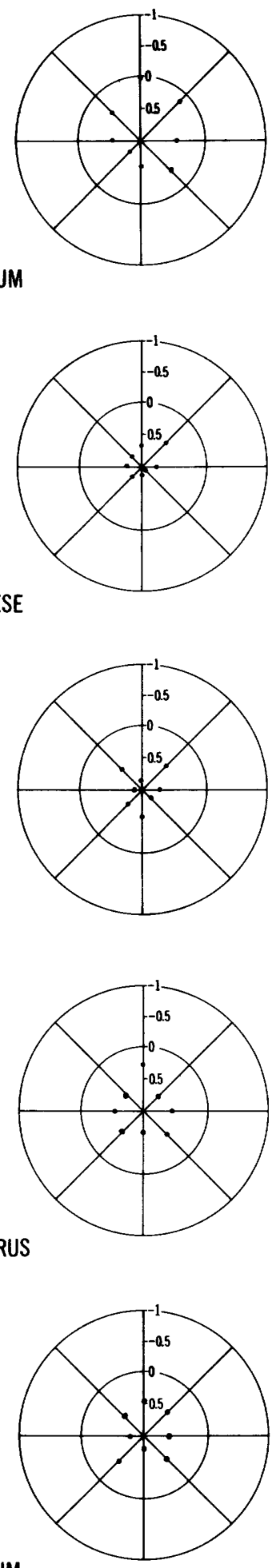

HIGH-DEATH-RATE AREA

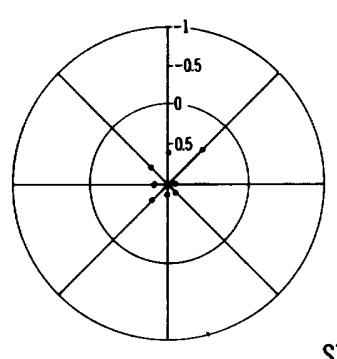

STRONTIUM

LOW-DEATH-RATE AREA
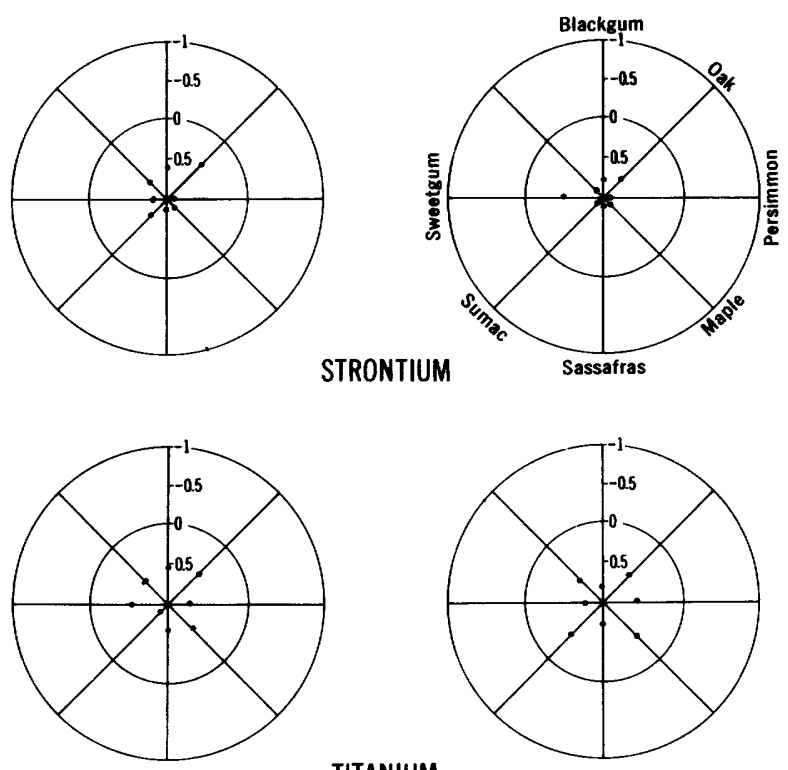

TITANIUM
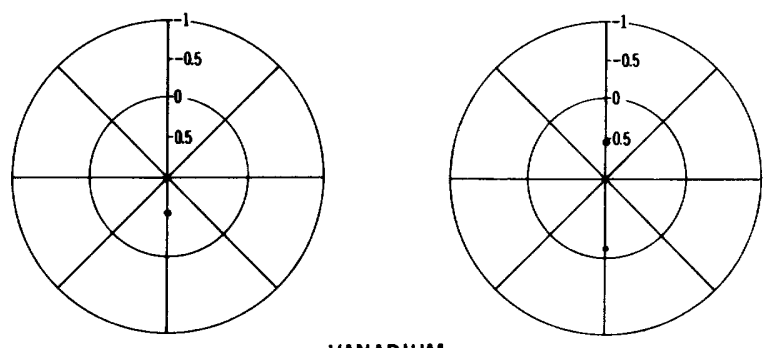

VANADIUM

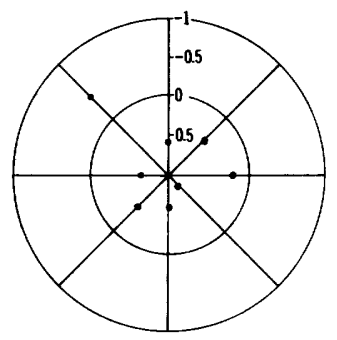

ZINC

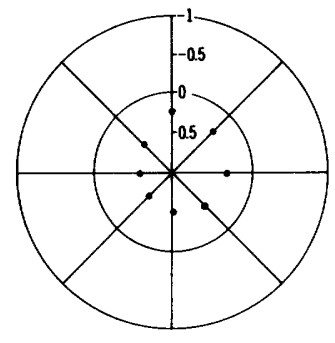

FIGURE 7 .-Continued 
TABLE 13.-Correlations between the amounts of elements in stems

$[r$, product-moment correlation coefficient between logarithms of concentrations; $N$, number of pairs omitted because concentration of element

\begin{tabular}{|c|c|c|c|c|c|c|c|c|c|c|c|c|c|c|c|c|}
\hline & \multicolumn{4}{|c|}{ Blackgum } & \multicolumn{4}{|c|}{ Oak } & \multicolumn{4}{|c|}{ Persimmon } & \multicolumn{4}{|c|}{ Red maple } \\
\hline Element or ash & \multicolumn{2}{|c|}{$\begin{array}{l}\text { High-death- } \\
\text { rate area, } \\
30 \text { pairs }\end{array}$} & \multicolumn{2}{|c|}{$\begin{array}{l}\text { Low-death- } \\
\text { rate area, } \\
30 \text { pairs }\end{array}$} & \multicolumn{2}{|c|}{$\begin{array}{l}\text { High-death- } \\
\text { rate area, } \\
\text { 30 pairs }\end{array}$} & \multicolumn{2}{|c|}{$\begin{array}{l}\text { Low-death- } \\
\text { rate area, } \\
\mathbf{3 0} \text { pairs }\end{array}$} & \multicolumn{2}{|c|}{$\begin{array}{l}\text { High-death- } \\
\text { rate area, } \\
30 \text { pairs }\end{array}$} & \multicolumn{2}{|c|}{$\begin{array}{l}\text { Low-death- } \\
\text { rate area, } \\
30 \text { pairs }\end{array}$} & \multicolumn{2}{|c|}{$\begin{array}{l}\text { High-death- } \\
\text { rate area, } \\
30 \text { pairs }\end{array}$} & \multicolumn{2}{|c|}{$\begin{array}{l}\text { Low-death- } \\
\text { rate area, } \\
30 \text { pairs }\end{array}$} \\
\hline 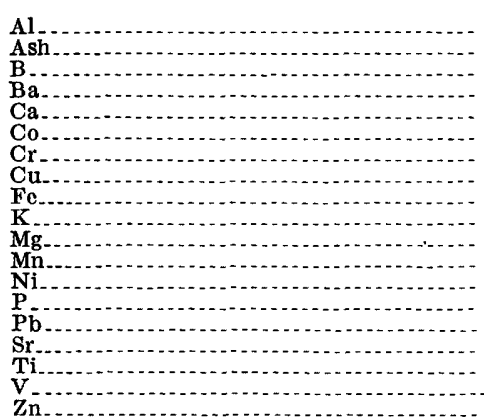 & $\begin{array}{l}0.65 \\
.49 \\
.61 \\
.91 \\
.67 \\
.93 \\
.53 \\
.32 \\
.54 \\
.44 \\
.67 \\
.85 \\
.77 \\
.62 \\
.30 \\
.65 \\
.58 \\
.6 .\end{array}$ & $\begin{array}{r}0 \\
0 \\
0 \\
0 \\
0 \\
3 \\
1 \\
0 \\
0 \\
0 \\
24 \\
0 \\
1 \\
0 \\
1 \\
0 \\
0 \\
28 \\
0\end{array}$ & $\begin{array}{l}0.65 \\
.73 \\
.54 \\
.26 \\
.76 \\
.94 \\
.72 \\
.54 \\
.92 \\
.50 \\
.02 \\
.72 \\
.87 \\
.31 \\
.62 \\
.83 \\
.83 \\
.57\end{array}$ & $\begin{array}{r}0 \\
0 \\
0 \\
0 \\
0 \\
3 \\
0 \\
0 \\
0 \\
0 \\
18 \\
0 \\
1 \\
0 \\
0 \\
0 \\
0 \\
26\end{array}$ & $\begin{array}{l}0.64 \\
.49 \\
.42 \\
.84 \\
.64 \\
.54 \\
.54 \\
.44 \\
.32 \\
.36 \\
.81 \\
.64 \\
.55 \\
.35 \\
.41 \\
.50 \\
.41\end{array}$ & $\begin{array}{r}0 \\
0 \\
0 \\
0 \\
0 \\
29 \\
1 \\
0 \\
0 \\
0 \\
6 \\
0 \\
1 \\
0 \\
3 \\
0 \\
0 \\
28 \\
0\end{array}$ & $\begin{array}{r}0.61 \\
.70 \\
.35 \\
.71 \\
.77 \\
.46 \\
.68 \\
.56 \\
.69 \\
.49 \\
.19 \\
.51 \\
.51 \\
.67 \\
.73 \\
.69 \\
.54 \\
. .33\end{array}$ & $\begin{array}{c}0 \\
0 \\
0 \\
0 \\
0 \\
18 \\
1 \\
0 \\
0 \\
0 \\
3 \\
0 \\
0 \\
0 \\
0 \\
0 \\
0 \\
28 \\
0\end{array}$ & \begin{tabular}{c}
0.85 \\
.41 \\
.41 \\
.79 \\
.40 \\
.95 \\
.45 \\
.28 \\
.62 \\
.72 \\
.43 \\
.73 \\
.39 \\
.18 \\
.56 \\
.93 \\
.77 \\
\hdashline .20
\end{tabular} & $\begin{array}{r}1 \\
0 \\
1 \\
1 \\
0 \\
27 \\
5 \\
1 \\
1 \\
0 \\
13 \\
1 \\
1 \\
0 \\
9 \\
1 \\
1 \\
30 \\
0\end{array}$ & $\begin{array}{c}0.80 \\
.12 \\
.52 \\
.74 \\
.78 \\
.48 \\
.31 \\
.64 \\
.60 \\
.46 \\
.80 \\
.75 \\
.54 \\
.54 \\
.89 \\
.58 \\
.31\end{array}$ & $\begin{array}{r}0 \\
0 \\
0 \\
0 \\
0 \\
30 \\
3 \\
0 \\
0 \\
0 \\
2 \\
0 \\
0 \\
0 \\
1 \\
0 \\
0 \\
28 \\
0\end{array}$ & \begin{tabular}{c}
0.72 \\
.53 \\
.40 \\
.88 \\
.86 \\
\hdashline .30 \\
.50 \\
.56 \\
.63 \\
.39 \\
.89 \\
.82 \\
.49 \\
.66 \\
.87 \\
.57 \\
. .80
\end{tabular} & $\begin{array}{r}0 \\
0 \\
0 \\
0 \\
0 \\
30 \\
4 \\
0 \\
0 \\
0 \\
2 \\
0 \\
13 \\
0 \\
5 \\
0 \\
0 \\
29 \\
0\end{array}$ & \begin{tabular}{c}
0.66 \\
.41 \\
.33 \\
.77 \\
.65 \\
\hdashline .64 \\
.64 \\
.73 \\
.50 \\
.33 \\
.91 \\
.82 \\
.45 \\
.36 \\
.87 \\
.40 \\
-.42
\end{tabular} & $\begin{array}{r}0 \\
0 \\
0 \\
0 \\
0 \\
30 \\
1 \\
0 \\
0 \\
0 \\
0 \\
0 \\
11 \\
0 \\
0 \\
0 \\
0 \\
29 \\
0\end{array}$ \\
\hline
\end{tabular}

studied, if judged by the concentrations of these elements in uncultivated soils.

8. The difference in element composition of soils from the two areas is not apparent in analyses of most vegetables from the two areas. Only cabbage and green beans tend to reflect, on a broad scale, the difference in amounts of certain elements in soils from the two areas.

9. Correlations between the element content of garden soils and of vegetables fail to indicate a general relationship between the composition of vegetables and the soils on which they grew.

10. Within each area, the results fail to demonstrate any consistent correlations between the element content of trees and the composition of any soil horizons at the sites where the trees grew.

11. The concentrations of elements in stems and in leaves of trees are strongly related. Where higher concentrations occur in the stems, higher concentrations are also found in the leaves.

12. Tendencies in the concentrations of certain eleinents indicate that stems concentrate barium, calcium, copper, lead, and strontium; leaves concentrate aluminum, iron, magnesium, potassium, titanium, ytterbium, and zirconium; and that stems and leaves are approximately equal in their concentrations of boron, chromium, manganese, nickel, and phosphorus.

13. In the low-death-rate area of northern Georgia the concentration of most elements in tree samples tends to be higher than in the high-death-rate areas of Georgia. Therefore, trees appear to be more sensitive than vegetables to the variation in element content of soils from the two areas.

\section{CONCLUSIONS}

1. The greater abundance of many chemical elements in soils from the low-death-rate area (northern Georgia), compared with their abundance in soils from the high-death-rate areas (south-central Georgia), is believed to reflect the differences in the character of the bedrock which provided the materials for soil formation. The sediments in the high-rate area probably had been extensively weathered and leached during their original deposition. Soils formed on these sediments, consequently, are relatively deficient in many elemental constituents. The present soils in the low-death-rate area, on the other hand, are being continously supplied with elements from the weathering of fresh igneous and metamorphic rocks.

2. The analyses of tree samples and some vegetable samples tend to reveal the geochemical differences in soils from the two areas only when examined on a broad scale.

3. The difference between the two areas in the levels of various chemical elements present in vegetables appears to be so slight as to be unlikely to contribute appreciably to the observed differences in death rates in middle-aged humans. These data show that garden vegetables do not clearly reflect the chemical compositions of the soils on which the vegetables grew. The chemicals in soils, however, may enter the human food chain in water, in food plants that were not sampled in this study, and in meat and milk from animals that have fed on cultivated forage plants and native vegetation.

4. If geochemical differences between the two areas do, in fact, have a causal relationship to death from 
and leaves of trees in the high-and low-death-rate areas of Georgia

in the sample (stems or leaves) was beyond the range of measurement by the analytical methods that were used; ...., insufficient data]

\begin{tabular}{|c|c|c|c|c|c|c|c|c|c|c|c|c|c|c|c|c|}
\hline \multirow[b]{2}{*}{ Element or ash } & \multicolumn{4}{|c|}{ Sassafras } & \multicolumn{4}{|c|}{ Smooth sumac } & \multicolumn{4}{|c|}{ Sweetgum } & \multicolumn{4}{|c|}{ Black cherry } \\
\hline & \multicolumn{2}{|c|}{$\begin{array}{l}\text { High-death- } \\
\text { rate area, } \\
17 \text { pairs }\end{array}$} & \multicolumn{2}{|c|}{$\begin{array}{l}\text { Low-death- } \\
\text { rate area, } \\
27 \text { pairs }\end{array}$} & \multicolumn{2}{|c|}{$\begin{array}{l}\text { High-death- } \\
\text { rate area, } \\
30 \text { pairs }\end{array}$} & \multicolumn{2}{|c|}{$\begin{array}{l}\text { Low-death- } \\
\text { rate area, } \\
30 \text { pairs }\end{array}$} & \multicolumn{2}{|c|}{$\begin{array}{l}\text { High-death- } \\
\text { rate area, } \\
28 \text { pairs }\end{array}$} & \multicolumn{2}{|c|}{$\begin{array}{l}\text { Low-death- } \\
\text { rate area, } \\
27 \text { pairs }\end{array}$} & \multicolumn{2}{|c|}{$\begin{array}{l}\text { High-death- } \\
\text { rate area, } \\
30 \text { pairs }\end{array}$} & \multicolumn{2}{|c|}{$\begin{array}{l}\text { Low-deatll- } \\
\text { rate area, } \\
30 \text { pairs }\end{array}$} \\
\hline $\begin{array}{l}\mathrm{Al} \\
\mathrm{A} \text { sh... } \\
\mathrm{B} \\
\mathrm{Ba} \\
\mathrm{Ca} \\
\mathrm{Ca}\end{array}$ & $\begin{array}{r}0.75 \\
.43 \\
.24 \\
.69 \\
.75\end{array}$ & $\begin{array}{l}0 \\
0 \\
0 \\
0 \\
0 \\
\end{array}$ & $\begin{array}{r}0.70 \\
.19 \\
.35 \\
.82 \\
.75\end{array}$ & $\begin{array}{l}0 \\
0 \\
0 \\
0 \\
0 \\
\end{array}$ & $\begin{array}{r}0.69 \\
.38 \\
.42 \\
.73 \\
.72\end{array}$ & $\begin{array}{l}0 \\
0 \\
0 \\
0 \\
0 \\
30\end{array}$ & $\begin{array}{r}0.69 \\
.51 \\
.40 \\
.89 \\
.56\end{array}$ & $\begin{array}{l}0 \\
0 \\
0 \\
0 \\
0\end{array}$ & $\begin{array}{r}0.68 \\
.60 \\
.59 \\
.83 \\
.75\end{array}$ & $\begin{array}{l}0 \\
0 \\
0 \\
0 \\
0\end{array}$ & $\begin{array}{r}0.32 \\
.56 \\
.33 \\
.66 \\
.87\end{array}$ & $\begin{array}{l}0 \\
0 \\
0 \\
0 \\
0 \\
27\end{array}$ & $\begin{array}{r}0.63 \\
-.17 \\
.78 \\
.89 \\
.69\end{array}$ & $\begin{array}{r}0 \\
0 \\
0 \\
0 \\
0 \\
\mathbf{3 0}\end{array}$ & $\begin{array}{r}0.73 \\
.43 \\
.25 \\
.94 \\
.69\end{array}$ & 0 \\
\hline
\end{tabular}

cardiovascular diseases, the cause would appear to be a deficiency, rather than an excess, of the elements that were studied.

\section{LITERATURE CITED}

Anderson, R. L., and Bancroft, T. A., 1952, Statistical theory in research : New York, McGraw-Hill Book Co., 399 p.

Baldwin, Mark, Kellogg, C. E., and Thorp, James, 1938, Soil classification, in Soils and men: U.S. Dept. Agriculture Yearbook 1938, p. 979-1001.

Carter, R. L., and Giddens, Joel, 1954, Soils of Georgia-Their formation, classification and management: Georgia Univ. College of Agriculture, Expt. Sta. Bull. 2, 68 p.

Cohen, A. C., Jr., 1961, Tables for maximum likelihood estimates-Singly truncated and singly censored samples: Technometrics, v. 3, no. 4, p. 535-541.

Cramer, H. W., 1967, Environmental science in early Georgia : Georgia Acad. Sci. Bull., v. 25, no. 4, p. 215-221.

Enterline, P. E., Rikli, A. E., Sauer, H. I., and Hyman, Merton, 1960 , Death rates for coronary heart disease in metropolitan and other areas: Public Health Repts., v. 75, no. 8, p. 759-766.

Fernald, M. L., 1950, Gray's manual of botany [8th ed.] : New York, American Book Co., $1632 \mathrm{p}$.

Georgia Division of Mines, Mining and Geology, 1939, Geologic map of Georgia : Georgia Div. Mines, Mining and Geology, 1 sheet.

Laurence, R. A., 1968, Ore deposits of the Southern Appalachians, p. 155-168, in Ridge, J. D., ed., Ore deposits of the United States, 1933-1967-The Graton-Sales volume: New York, Am. Inst. Mining, Metallurgical, and Petroleum Engineers, $991 \mathrm{p}$.

Lilienfeld, A. M., Pedersen, Einar, and Dowd, J. E., 1967, Cancer epidemiology-Methods of study: Baltimore, Johns Hopkins Press, $165 \mathrm{p}$.

Linder, F. E., and Grove, R. D., 1943, Vital statistics rates in the United States 1900-1940 : U.S. Dept. Health, Education, and Welfare, $1051 \mathrm{p}$.

Miesch, A. T. 1967a, Theory of error in geochemical data: U.S. Geol. Survey Prof. Paper 574-A, 17 p.
$1967 \mathrm{~b}$, Methods of computation for estimating geochemical abundance: U.S. Geol. Survey Prof. Paper 574-B, 15 p.

Myers, A. T., Havens, R. G., and Dunton, P. J., 1961, A spectrochemical method for the semiquantitative analysis of rocks, minerals and ores: U.S. Geol. Survey Bull. 1084-I, p. 207229.

Sauer, H. I., 1962, Epidemiology of cardiovascular mortalityGeographic and ethnic: Am. Jour. Public Health, v. 52, no. 1, p. 94-105.

Sauer, H. I., and Enterline, I. H., 1959, Are geographic variations in death rates for the cardiovascular diseases real?: Chronic Diseases Jour., v. 10, no. 6, p. 513-524.

Sauer, H. I., Payne, G. H., Council, C. R., and Terrell, J. C., 1966, Cardiovascular disease mortality patterns in Georgia and North Carolina: Public Health Rpts., v. 81, no. 5, p. 455465.

Shacklette, H. T., and Sauer, H. I., 1964, The association of cardiovascular mortality rates in Georgia with the abundance and distribution of certain elements in rocks, soils, and plants: U.S. Geol. Survey open-file report, $21 \mathrm{p}$.

Soil Survey Staff, 1960, Soil classification-A comprehensive system, 7th approximation: U.S. Dept. Agriculture, 265 p.

- 1967, Supplement to soil classification system (7th approximation) : U.S. Dept. Agriculture, 207 p.

Sutcliffe, J. F., 1962, Mineral salts absorption in plants: New York, Pergamon Press, 194 p.

U.S. Geological Survey, 1968, Landforms of the United States: U.S. Geol. Survey pamph., 15 p.

[U.S.] Soil Conservation Service, 1969, Distribution of principal kinds of soils-Orders, Suborders, and Great Groups, in National Atlas of the United States of America: U.S. Geol. Survey, sheet $86,2 \mathrm{p}$.

Ward, F. N., Lakin, H. W., Canney, F. C., and others, 1963, Analytical methods used in geochemical exploration by the U.S. Geological Survey : U.S. Geol. Survey Bull. 1152, 100 p.

World Health Organization, 1957, Manual of the international statistical classification of diseases, injuries and causes of death, 7th revision: Geneva, World Health Organization, v. 1, $393 \mathrm{p}$. 